\title{
Ionic liquids as a tool for lignocellulosic biomass fractionation
}

\author{
Andre M da Costa Lopes ${ }^{1}$, Karen G João ${ }^{1}$, Ana Rita C Morais', Ewa Bogel-Łukasik² and Rafał Bogel-Łukasik ${ }^{1 *}$
}

\begin{abstract}
Lignocellulosic biomass composes a diversity of feedstock raw materials representing an abundant and renewable carbon source. In majority lignocellulose is constituted by carbohydrate macromolecules, namely cellulose and hemicellulose, and by lignin, a polyphenilpropanoid macromolecule. Between these biomacromolecules, there are several covalent and non-covalent interactions defining an intricate, complex and rigid structure of lignocellulose. The deconstruction of the lignocellulosic biomass makes these fractions susceptible for easier transformation to large number of commodities including energy, chemicals and material within the concept of biorefinery. Generally, the biomass pre-treatment depends on the final goal in the biomass processing. The recalcitrance of lignocellulose materials is the main limitation of its processing once the inherent costs are excessively high for the conventional pre-treatments. Furthermore, none of the currently known processes is highly selective and efficient for the satisfactory and versatile use, thus, new methodologies are still studied broadly. The ionic liquid technology on biomass processing is relatively recent and first studies were focused on the lignocellulosic biomass dissolution in different ionic liquids (ILs). The dissolution in IL drives to the structural changes in the regenerated biomass by reduction of cellulose crystallinity and lignin content contrasting to the original biomass. These findings provided ILs as tools to perform biomass pre-treatment and the advantageous use of their specific properties over the conventional pre-treatment processes. This review shows the critical outlook on the study of biomass dissolution and changes occurred in the biomass during this process as well as on the influence of several crucial parameters that govern the dissolution and further pre-treatment process. The review of currently known methods of biomass fractionation in $\mathrm{IL}$ and aqueous-IL mixtures is also discussed here and perspectives regarding these topics are given as well.
\end{abstract}

Keywords: Ionic liquid, Lignocellulose, Biomass fractions, Pre-treatment, Cellulose, Lignin

\section{Introduction}

Lignocelluloses such as hardwood, softwood and agriculture residues are the main raw material from renewable feedstock representing an abundant carbon source [1]. The main components of lignocellulosic materials are cellulose, hemicellulose and lignin. Cellulose and hemicellulose constitute the carbohydrate fraction where cellulose is a linear semi-crystalline fibrous homopolysaccharide and hemicellulose is a branched amorphous heteropolysaccharide. Cellulose chains are embedded in the core of the lignocellulosic biomass with hydroxyl groups oriented to form strong intra- and intermolecular

\footnotetext{
*Correspondence: rafal.lukasik@lneg.pt

'Laboratório Nacional de Energia e Geologia, Unidade de Bioenergia, 1649-038 Lisbon, Portugal

Full list of author information is available at the end of the article
}

hydrogen bonds. This lattice network results in organised micro- and macrofibrils as well as interacts with the hemicellulose fraction. Lignin is characterised as an amorphous phenylpropanoid polymer that acts as a "glue" binding hemicellulose and cellulose by ester linkages and hydrogen bonds, respectively [2]. These molecular interactions define a complex and rigid structure forming a recalcitrant material against hydrolysis guiding to difficult, harsh and expensive separation processes [3].

Generally, the separation process of these compounds is performed by thermochemical and/or physical methods as a pre-treatment, exposing the carbohydrate fraction to facilitate further processing. Carbohydrates are subsequently hydrolysed to sugar monomers and then converted to bioalcohols (ethanol, butanol), carboxylic acids, biohydrogen or methane by fermentation
(C) Chemistry Central

(C) 2013 da Costa Lopes et al.; licensee Chemistry Central Ltd. This is an Open Access article distributed under the terms of the Creative Commons Attribution License (http://creativecommons.org/licenses/by/2.0), which permits unrestricted use,

distribution, and reproduction in any medium, provided the original work is properly cited. 
processes [4,5]. On the other hand, the extracted lignin can be used as a low-value heating fuel, binder, dispersant, emulsifier and sequestrant. Lignin can also act as a source of high-value molecules, such as biologically active polyphenols and tannins [6,7]. The conventional methodologies have technological limitations such as an insufficient selectivity and partial degeneration of products that compromise the efficiency of the separation processes. Hence, the current and envisaged investigations are focused on understanding the pathways to improve the selective separation of lignocellulose compounds to accomplish feasible and sustainable processes.

Ionic liquids (ILs) are recognised to facilitate more green applications in reactions and separations due to their unique beneficial properties, such as negligible vapour pressure $[8,9]$ and high thermal stability [10]. Their very low vapour pressure reduces the risk of exposure that is a clear advantage over the use of the classical volatile solvents. Although, studies of basic properties in the environmental risk assessment of ILs are still required [11], it is notable that toxicity of the ILs is mainly ascribed to the alkyl chain and that the toxicity of imidazolium and pyridinium ILs increases with their cation chain length $[12,13]$. ILs are compounds composed solely of ions with immeasurable combinations of anions and cations. They possess widely tuneable properties, such as hydrophobicity [14], polarity and solvent power $[15,16]$.

In the last decade, numerous studies focused on the dissolution of natural polymers in ILs demonstrating a great potential of ILs as solvents [17-21]. Cellulose was one of the most studied biopolymers exhibiting a high solubility in a variety of ILs [22]. A wide range of carbohydrate solubilities was scrutinised using different ILs, presenting that one of the main benefits of using ILs to dissolve carbohydrates is that ILs can be tailored to accomplish dissolution or functionalisation of these polymers [22].

Due to the ILs solvent power, their use in the development of alternative methods for the extraction and processing of carbohydrates and other compounds from lignocellulosic biomass was recently explored intensively. The aim of this work is to describe the current state-ofthe-art on the fractionation of lignocellulosic biomass in ILs as a pre-treatment methodology.

The cations and anions of ILs used in this review are presented in Figures 1 and 2, respectively.

\section{Biomass dissolution}

Initially, Fort et al. demonstrated that solvent systems based on $[\mathrm{bmim}][\mathrm{Cl}] / \mathrm{DMSO}-d_{6}(84 / 16 \mathrm{wt} \%)$ are capable to partially dissolve wood chips [23]. They described swelling and the size reduction of wood particles during the dissolution basing on the colour intensity and viscosity of the solution mixture. Meanwhile, Kilpelainen et al. reported a complete dissolution of $8 \mathrm{wt} \%$ of dried wood sawdust samples (Norway spruce and Southern pine) in both $[\mathrm{bmim}][\mathrm{Cl}]$ and $[\mathrm{amim}][\mathrm{Cl}]$ ILs, in the temperature range from 80 to $130^{\circ} \mathrm{C}$ after 8 hours [24]. The complete dissolution of wood in these ILs was attributed to the water content and the particle size of wood samples. Water was found to significantly reduce the solubility of wood in ILs [19] and smaller particles were reported as better to be dissolved in water [24]. Furthermore, Sun et al. demonstrated that both softwood (southern yellow pine) and hardwood (red oak) can be dissolved in $[\mathrm{emim}]\left[\mathrm{CH}_{3} \mathrm{COO}\right]$ [25]. More than $90 \%(\mathrm{w} / \mathrm{w})$ of the added wood was dissolved after mild grinding, at $110^{\circ} \mathrm{C}$ within 16 hours. The authors concluded that $[\mathrm{emim}]\left[\mathrm{CH}_{3} \mathrm{COO}\right]$ is more efficient in dissolving biomass than $[\mathrm{bmim}][\mathrm{Cl}]$ and $[\mathrm{amim}][\mathrm{Cl}]$. A high-throughput screening in the dissolution of cellulose and wood chips in ILs with $5 \%(\mathrm{w} / \mathrm{w})$ at $90^{\circ} \mathrm{C}$ for 12 hours was made by Spiess et al. [26]. The investigation was performed at identical conditions in a single experiment to allow a comparison of a variety of ILs. They found out that $[\mathrm{emim}][\mathrm{Cl}],[\mathrm{bmim}][\mathrm{Cl}]$ and $[\mathrm{emim}]$ $\left[\mathrm{Et}_{2} \mathrm{PO}_{4}\right]$ were only able to partially dissolve different wood chips (spruce, silver fir, common beech and chestnut). Additionally, $[\mathrm{emim}]\left[\mathrm{CH}_{3} \mathrm{COO}\right]$ was defined as the most efficient for dissolving cellulose, and [amim] $[\mathrm{Cl}]$ was found to be the most suitable for use in biomass, dissolving all tested wood. Only Silver fir was not completely dissolved in [emim] $\left[\mathrm{CH}_{3} \mathrm{COO}\right]$ [26]. By heating wheat straw and pine wood at $100^{\circ} \mathrm{C}$ after 24 hours, [emim] $\left[\mathrm{CH}_{3} \mathrm{COO}\right]$ demonstrated to be a poor solvent [27]. At the same conditions, $[\mathrm{bmim}][\mathrm{Cl}]$ was the most efficient in the dissolution of straw and [emim] $[\mathrm{Cl}]$ tended to be the most promising solvent for both types of biomass. For the best results, the additional investigation with transparent solutions did not exclude presence of biomass fibres after filtration indicating an incomplete dissolution [27]. In fact, Lee et al. stated a very low solubility of wood flour $(<5 \mathrm{~g} / \mathrm{kg})$ and a high solubility of microcrystalline cellulose $(>100 \mathrm{~g} / \mathrm{kg}$ ) in [emim] $\left[\mathrm{CH}_{3} \mathrm{COO}\right]$, proving that the presence of lignin restricts the solubility of wood flour in this IL [28]. In the dissolution of beech and spruce wood at $115^{\circ} \mathrm{C}$, [emim] $\left[\mathrm{CH}_{3} \mathrm{COO}\right]$ showed to be more suitable for the first one, but complete dissolution was observed for none of the examined biomasses even during a 72-hour process [29]. An incomplete dissolution of pine wood in this IL at $120^{\circ} \mathrm{C}$ and $155^{\circ} \mathrm{C}$ within 3 hours was also reported [30]. These findings were the opposite of those presented earlier by Singh et al [31]. Basing on the microscopic observations, Torr et al. clearly demonstrated that [emim] $\left[\mathrm{CH}_{3} \mathrm{COO}\right]$ is capable to completely dissolve all major components found in the plant cells of switchgrass after 
<smiles>CCCCn1cc[n+](C)c1</smiles>

[bmim]<smiles>CCn1cc[n+](C)c1</smiles>

[emim]<smiles>C=CCn1cc[n+](C)c1</smiles>

[amim]<smiles>C[N+](C)(C)CCO</smiles>

[Ch]<smiles>C[n+]1ccn(Cc2ccccc2)c1</smiles>

[bzmim]<smiles>CCCC[n+]1cccc(C)c1</smiles>

[bmpy]<smiles>C[NH+](C)CCO</smiles>

[DMEA]<smiles>CCN(CC)C(C)C[N+](CC)(CC)OCCOCCOC</smiles>

$\left[\mathrm{Me}(\mathrm{OEt})_{3} \mathrm{Et}_{3} \mathrm{~N}\right]$<smiles>Cn1cc[n+](C)c1</smiles><smiles>CCCCCCn1cc[n+](C)c1</smiles><smiles>CCCn1cc[n+](C)c1</smiles>

[pmim]<smiles>C=CCn1cc[n+](CCCC)c1</smiles>

[abim]<smiles>CC[n+]1cccc(CO)c1</smiles>

[eMeOHpy]<smiles>CCCn1cc[nH+]c1</smiles>

[bHim]

Figure 1 Cations referred in this work listed by order of appearance. [bmim] - 1-butyl-3-methylimidazolium, [emim] - 1-ethyl-3methylimidazolium, [amim] - 1-allyl-3-methylimidazolium, [Ch] - cholinium, [bzmim] - 1-benzyl-3-methylimidazolium, [HEA] - 2hydroxyethylammonium, [bmpy] - 1-butyl-3-methylpyridinium, $\left[\mathrm{Me}(\mathrm{OEt})_{3} \mathrm{Et}_{3} \mathrm{~N}\right]$ - triethyl-(2-(2-methoxyethoxy)ethoxy)ethylammonium, [DMEA] - N,N-dimethylethanolammonium, [mmim] - 1,3-dimethylimidazolium, [hmim] - 1-hexyl-3-methylimidazolium, [pmim] - 1-propyl-3methylimidazolium, [abim] - 1-allyl-3-butylimidazolium, [eMeOHpy] - 1-ethyl-3-(hydroxymethyl)pyridine, [bHim] - 1-butylimidazolium.

3 hours at $120^{\circ} \mathrm{C}[31]$. On the other hand, [bmim] $\left[\mathrm{CH}_{3} \mathrm{COO}\right]$ was tested to dissolve poplar wood and a dissolution yield of $96 \mathrm{wt} \%$ was obtained at $130^{\circ} \mathrm{C}$ after 12 hours, while $[\mathrm{bmim}][\mathrm{Cl}]$ only achieved $23 \mathrm{wt} \%$ of poplar dissolution [32]. This indicates that $\left[\mathrm{CH}_{3} \mathrm{COO}\right]$ anion has a great influence on the dissolution of biomass. In the dissolution of sugarcane bagasse at $100^{\circ} \mathrm{C}$ within 0.5-8 hours, once again $[\mathrm{emim}]\left[\mathrm{CH}_{3} \mathrm{COO}\right] \mathrm{dem}$ onstrated to be more effective than other ILs such as [bmim] $[\mathrm{Cl}]$ and $[\mathrm{emim}][\mathrm{DEP}][33]$.

A reduced time of biomass dissolution was attained using microwave or ultrasound irradiation instead of conventional heating $[25,34]$. The enhancement in the dissolution obtained was attributed to the ionic structure of ILs that absorbs efficiently these types of irradiation. In consequence the frequency of collisions between the anions and cations of ILs and the wood macromolecules increases leading to fast and effective dissolutions [34]. Application of a prior ball-milling treatment to the biomass in order to reduce the molecular weight of the lignocellulosic complex can also improve dissolution $[35,36]$. Unfortunately, these mechanical treatment processes are low effective and are inappropriate for an industrial application.

To understand the rules governing the fractionation process, the use of polarity approach can be considered. To do so, the quantitative Kamlet-Taft parameters [37-39] were broadly used in the literature. Using KamletTaft parameters it was found that the anion basicity influences the lignocellulosic biomass dissolution $[40,41]$. A correlation between higher dissolution capacities of ILs and higher value of $\beta$ parameter was determined [40]. 
<smiles>CCOC(=O)OCCOP(=O)(OCC)OCC</smiles><smiles>O=S(=O)(O)C(F)(F)F</smiles>

[OTf]<smiles>CCC(=O)O</smiles>

[PrOO]<smiles>O=C(O)C(F)(F)F</smiles>

$\left[\mathrm{CF}_{3} \mathrm{COO}\right]$<smiles>CS(=O)(=O)[O-]</smiles>

$\left[\mathrm{MeSO}_{3}\right]$<smiles>O=S(=O)(O)O</smiles>

$\left[\mathrm{HSO}_{4}\right]$<smiles>NCCCC[C@H](N)C(=O)[O-]</smiles><smiles>C[C@H](N)C(=O)[O-]</smiles>

[Ala]<smiles>CSCC[C@H](N)C(=O)O</smiles>

$\mathrm{H}_{2}$<smiles>O=C(O)CCC(=O)O</smiles><smiles></smiles><smiles>CCP(=O)([O-])[O-]</smiles>

[EtPO $\left.{ }_{3}\right]$<smiles>O=C(O)[C@@H]1CCCN1</smiles>

[Pro]<smiles>N[C@@H](CO)C(=O)[O-]</smiles>

[Ser]<smiles>[R]c1ccc(CS(=O)(=O)[O-])cc1</smiles>

[ABS]<smiles>N[C@@H](Cc1ccccc1)C(=O)O</smiles>

[Phe]<smiles>C[C@H](O)[C@H](N)C(=O)[O-]</smiles>

[Thr]

$\left[\mathrm{OHCH}_{2} \mathrm{COO}\right]$<smiles>O=S(=O)([O-])Cc1ccccc1I</smiles>

[XS]<smiles>CCCCP(=O)([O-])O</smiles><smiles>O=S(=O)(NS(=O)(=O)C(F)(F)F)C(F)(F)F</smiles>

$\left[\mathrm{EtOSO}_{3}\right]$<smiles>CCOS(=O)(=O)[O-]</smiles>

Figure 2 Anions used for the pre-treatment of biomass presented in this work by order of appearance. [Cl] - $\mathrm{Chloride}_{1}\left[\mathrm{CH}{ }_{3} \mathrm{COO}\right]-$ acetate, $\left[\mathrm{Et}_{2} \mathrm{PO}_{4}\right]$ - diethylphosphate, $\left[\mathrm{Me}_{2} \mathrm{PO}_{4}\right]$ - dimethylphosphate, $\left[\mathrm{MeOSO} \mathrm{O}_{3}\right]$ - methylsulphate, [OTf] - trifluoromethanesulphonate, [PrOO] propionate, $\left[\mathrm{CF}_{3} \mathrm{COO}\right]$ - trifluoroacetate, $\left[\mathrm{MeSO}_{3}\right]$ - methanesulphonate, $\left[\mathrm{HSO}_{4}\right]$ - hydrogen sulphate, $\left[\mathrm{PO}(\mathrm{O}) \mathrm{H}_{2}\right]$ - phosphinate, $[\mathrm{HCOO}]$ - formate, $\left[\mathrm{BF}_{4}\right]$ - tetrafluoroborate, $\left[\mathrm{PF}_{6}\right]$ - hexafluorophosphate, [Lys] - lysinate, [Gly] - glycinate, [Ala] - alaninate, [Ser] - serinate, [Thr] - threoninate, [Met] methioninate, $[\mathrm{Pro}]$ - prolinate, $[\mathrm{Phe}]$ - phenylalaninate, $\left[\mathrm{OHCH} \mathrm{H}_{2} \mathrm{COO}\right]$ - glycolate, $\left[\left(\mathrm{CH}_{2} \mathrm{COO}\right)_{2}\right]$ - succinate, $[\mathrm{ABS}]$ - alkylbenzenesulphonate, $[\mathrm{XS}]$ xylenesulphonate, $\left[\mathrm{MePO}_{3}\right]$ - methylphosphonate, $\left[\mathrm{EtPO}_{3}\right]$ - ethylphosphonate, $\left[i-\mathrm{PrPO}_{3}\right]$ - i-propylphosphonate, $\left[\mathrm{BuPO}_{3}\right]$ - butylphosphonate, $\left[\mathrm{NTf}_{2}\right]$ - bis(trifluoromethylsulfonyl)amide, $\left[\mathrm{EtOSO}_{3}\right]$ - ethylsulphate.

Brandt et al. observed high dissolution power for [bmim] $\left[\mathrm{CH}_{3} \mathrm{COO}\right],[\mathrm{bmim}][\mathrm{Cl}]$ and $[\mathrm{bmim}][\mathrm{DMP}]$ ILs. They demonstrated that acetate IL is the most effective for swelling and dissolution [40]. This is justified by a very high $\beta$ value exhibited by $\left[\mathrm{CH}_{3} \mathrm{COO}\right]$ anion (1.20), which is a considerably stronger hydrogen bond acceptor. On the contrary, [bmim][OTf] with a low $\beta$ value $(0.48)$ revealed a very poor swelling process, starting at $120^{\circ} \mathrm{C}$. The swelling was also slow with $[\mathrm{bmim}]\left[\mathrm{MeSO}_{4}\right]$ and [bmim] $\left[\mathrm{Me}_{2} \mathrm{PO}_{4}\right]$. Even worst dissolution was demonstrated by using $[\mathrm{bmim}]\left[\mathrm{N}(\mathrm{CN})_{2}\right]$ that dissolved neither cellulose nor lignocellulosic material [40]. Other, [emim][TFA] and 
[Ch][PrOO] ILs showed no evidence of dissolving lignocellulose as they were tested to dissolve bamboo biomass without success even after 24 hours at $120^{\circ} \mathrm{C}$ [42]. On the other hand, [emim][Gly], an amino-acid based IL had the ability to dissolve the bamboo biomass due to a high hydrogen bond basicity of amino-acid derived anions. After 8 hours at the same temperature, complete dissolution of bamboo with [emim][Gly] was observed [42].

The presented results are affected by different variables of the IL dissolution process including the type and size of biomass, IL/biomass ratio, temperature and time of dissolution, water content in the solution mixture and others. The complete biomass dissolution in ILs is very dependent upon these factors which, in turn, should be optimised for the specific IL-biomass dissolution process. Nevertheless, [bmim] $[\mathrm{Cl}]$, [amim] $[\mathrm{Cl}]$, [emim] $[\mathrm{Cl}]$ and $[\mathrm{emim}]\left[\mathrm{CH}_{3} \mathrm{COO}\right]$ demonstrated to be the most used and efficient ILs in dissolving lignocellulosic biomass, considerably. The $[\mathrm{emim}]\left[\mathrm{CH}_{3} \mathrm{COO}\right]$ is generally recommended since it exhibits minor environmental issues comparing to ILs composed by halide anion $[43,44]$. The biomass dissolution in ILs has been reviewed $[45,46]$ and there is still room for progress in the dissolution performance by seeking new ILs with improved properties.

\section{The influence of ILs' properties on the biomass dissolution}

The ability of ILs to dissolve carbohydrates and lignin is considered as an effective disruption of the intricate network of non-covalent interactions between these polymers. Rogers and co-workers suggested that a high chloride concentration and activity of $[\mathrm{bmim}][\mathrm{Cl}]$ is responsible for breaking an extensive and well organised hydrogen-bonding network of cellulose and thus promoting dissolution [19]. Remsing et al. using ${ }^{13} \mathrm{C}$ and ${ }^{35 / 37} \mathrm{Cl}$ NMR demonstrated that the interaction between the carbohydrate and the anion of an IL is predominant compared to the interactions of carbohydrate with the cation [47]. It was reported that the dissolution of carbohydrates in [bmim] $[\mathrm{Cl}]$ involves the formation of hydrogen bonds between chloride ions of the IL and hydroxyl protons of sugar units from carbohydrates in a 1:1 stoichiometry. The IL cation has also some influence on the dissolution by interacting with cellulose hydroxyl oxygen groups [34]. In the case of lignocellulose dissolution the principle is the same, once the main fraction of these materials comprises carbohydrates [31]. However, the presence of lignin and extractives in lignocellulose restricts the solubility and the appearance of a brownish viscous mixture solution is observed during the process [26]. ILs not only disrupt the hydrogen bonding interaction of crystalline cellulose in wood, but also interact and solvate the aromatic characters of lignin by $\pi-\pi$ and $n-\pi$ interactions, generally performed by the IL cation
$[34,48,49]$. This phenomenon is enhanced by a more effective stirring that increases the hydrodynamic stress of the lignocellulosic particles and mass transfer to the particle surface improving the dissolution process [26]. The microwave irradiation also enhances the dissolution, since depolymerisation of cross-linked phenylpropanoid units of lignin and hydrogen bonding interactions between the wood matrix and the IL anion are intensified [34]. The ultrasound irradiation seems to induce the same effect on biomass dissolution [50]. On the other hand, by breaking the native structure with ball-milling, a reduction of molecular weights of lignin and carbohydrate polymers is observed [35]. Thus, an effective reduction of polymers leads to a subsequent dissolution enhancement in ILs.

The selection of ILs for lignocellulosic biomass dissolution is difficult, due to the different physical and chemical properties that IL presents. It was referred that ILs constructed by bulky cation and halide anion may decrease the concentration of active chloride ion and thus the solvating capacity for both cellulose and lignin is reduced [19]. The comparison of the efficiency of [emim] $[\mathrm{Cl}]$ and $[\mathrm{bmim}][\mathrm{Cl}]$ in the dissolution of rice straw allows to notice that [emim] cation, as smaller sized than [bmim] cation, might be more effective due to its higher degree of interaction with the cellulose chain [33,51]. A smaller anion is also preferable to be able to diffuse faster within the lignocellulosic matrix as in the case of chloride anion. Nevertheless, the improvements in lignocellulose dissolution are related with the hydrogen bond basicity of the IL anion as referred above. ILs with a strong hydrogen bond basicity are effective in weakening the hydrogen-bonding network of the polymer chains $[40,52]$. As it was stated before the increased basicity of the $\left[\mathrm{CH}_{3} \mathrm{COO}\right]$ anion makes it more efficient at disrupting the inter- and intramolecular hydrogen bonding in biopolymers than $\mathrm{Cl}$ anion [25]. To predict the pretreatment efficiency of a certain IL in disrupting lignocellulose, $\beta$ Kamlet-Taft parameter is an useful tool as demonstrated by Brandt et al. for [bmim] $\left[\mathrm{CH}_{3} \mathrm{COO}\right]$ and $[\mathrm{bmim}][\mathrm{Cl}][40]$. As it was aforementioned, they confirmed better efficiency of $\left[\mathrm{CH}_{3} \mathrm{COO}\right]$ IL $(\beta=1.20)$ than the chloride IL $(\beta=0.83)$ in the dissolution of pine wood chips. Indeed, ILs with $\beta \geq 1.0$ support high yields of fermentable sugars following pre-treatment [41]. As it is stated above, glycinate ionic liquid demonstrates high hydrogen basicity. The glycinate anion is characterised to have a weak electron withdrawing group $\left(-\mathrm{NH}_{2}\right)$ on $\beta$ carbon, although this negative inductive effect does not influence the hydrogen bond formation by the carboxylate group $\left(-\mathrm{COO}^{-}\right)$with lignocellulosic biomass [42]. In the case of [emim][TFA] the strong electron withdrawing groups $\left(-\mathrm{F}^{-}\right)$decrease the electron density of $\mathrm{COO}^{-}$, thereby it reduces the formation of hydrogen bonds 
between biomass and IL during dissolution [42]. ILs with anions showing a low hydrogen bond basicity, such as $[\mathrm{bmim}]\left[\mathrm{MeSO}_{4}\right], \quad[\mathrm{bmim}]\left[\mathrm{HSO}_{4}\right], \quad[\mathrm{bmim}]\left[\mathrm{MeSO}_{3}\right]$ are unable to perform a complete dissolution of the biomass, since interaction with cellulose is weak [53]. Other examples are [bmim] [OTf] and $[\mathrm{bmim}]\left[\mathrm{N}(\mathrm{CN})_{2}\right]$ which are incapable to break the hydrogen bonds in the matrix and therefore do not expand it at all or only minimally [40]. Generally, increased hydrogen bond basicity of the anion leads to the incorporation of water molecules in the IL structure [54], reducing the dissolution of biomass in IL. Therefore, drying of the IL prior to use is required regardless the biomass moisture. However, not only hydrogen basicity of IL is important, but also its structure affects the dissolution process. Muhammad et al. presented that the $[\mathrm{Ch}][\mathrm{PrOO}] \mathrm{IL}$, in spite of a high hydrogen basicity, has a poor dissolution ability [42]. This behaviour was explained by the internal interaction between the hydroxyl end group of IL cation and its anion. Furthermore, the absence of aromatic ring in the cation structure had a negative effect on the dissolution unable to interact with lignin.

The viscosity of ILs is also an important parameter, because it can impact the mixing and mass transfer of lignocellulose and IL itself. Abe et al. verified that ILs characterised by low viscosity are able to extract higher amounts of carbohydrates from the bran [52]. This may occur due to better dispersion state of bran in less viscous ILs. It was also reported that ILs with an adequate polarity and a low viscosity demonstrate good ability to extract polysaccharides in a short time. They showed that the low viscosity and highly polar IL, $[\mathrm{emim}][\mathrm{PO}(\mathrm{O})$ $\mathrm{H}_{2}$ ], allows for rapid extraction of cellulose and other carbohydrates from bran under mild conditions [52]. Kilpelainen et al. attempted the dissolution of wood in [benzylmim] $[\mathrm{Cl}]$, once the benzyl ring from the IL cation could interact with the phenyl aromatic rings of lignin by $\pi-\pi$ interactions [24]. In fact, a major drawback of [benzylmim] $[\mathrm{Cl}]$ application is related to high viscosity of this IL [24].

The lower melting point of $[\mathrm{emim}]\left[\mathrm{CH}_{3} \mathrm{COO}\right]$, in comparison with $[\mathrm{emim}][\mathrm{Cl}]$ and $[\mathrm{bmim}][\mathrm{Cl}]$, also facilitate the dissolution of biomass and handling of the mixture, which makes [emim] $\left[\mathrm{CH}_{3} \mathrm{COO}\right]$ a better solvent than chloride-based ILs in biomass processing [25]. It is worth noting that, at room temperature, [emim] $[\mathrm{Cl}]$ and [bmim $][\mathrm{Cl}]$ are in solid state in contrast to the liquid state of $[\mathrm{emim}]\left[\mathrm{CH}_{3} \mathrm{COO}\right]$. Therefore, higher temperatures are required for $[\mathrm{emim}][\mathrm{Cl}]$ and $[\mathrm{bmim}][\mathrm{Cl}]$, although even then these ILs present high viscosities [19].

\section{The biomass regeneration process}

Dissolution step is the initial step guaranteeing the successful processing of biomass. However, due to the complex matrix of biomass, the adequate recovery of each fraction is needed for the production of energy, chemicals and biomaterials in the frame of biorefinery concept. Generally, the process guiding to the biomass fractions' recovery occurs as follows: at initial stage, lignocellulosic biomass is generally added to an IL, with a certain solid/liquid ratio, and is treated at the specified temperature and time applying a mechanical stirring to the mixture. From the literature review presented above, the dissolution can be partial or complete, although it is recommended to drive to the complete biomass dissolution to improve the pre-treatment efficiency. The next step is one of the most important as it corresponds to the regeneration of biomass fractions with the addition of a precipitating solvent (also designated as antisolvent), such as water, acetone, dichloromethane, and acetonitrile [23]. Fort et al. described the dissolution of wood chips in $[\mathrm{bmim}][\mathrm{Cl}]$ with addition of the referred antisolvents [23]. They obtained the regenerated biomass fraction composed essentially by cellulose. The regenerated cellulose-rich material was found to have purities, physical properties, and processing characteristics comparable to those of cellulose standard. The regeneration yield of biomass ranged from 30 to $60 \mathrm{wt} \%$, for a pre-treatment temperature of $100^{\circ} \mathrm{C}$ during 16 hours [23]. The regeneration yields presented in all the reviewed works are strongly dependent on the IL, biomass, antisolvent and pre-treatment conditions used. The regeneration yields obtained are depicted in Tables 1, 2 and Additional file 1: Table S1. Wang et al. stated that the addition of water resulted in the reconstitution of a brown gel [34]. After gel filtration a clear and dark brown solution was obtained and by washing with water/DMSO several times, the gel became white indicating the main presence of carbohydrates [34].

After the regeneration, the crystallinity of cellulose is abruptly reduced in comparison with that of cellulose from the original lignocellulosic material. Cellulose in the pre-treated biomass is no longer constrained in a rigid structure and has similar level of the molecular flexibility as the surrounding hemicellulose [30]. By microscopic observations, Singh et al. verified the precipitation of fibrous structures of cellulose (300-500 mM long) after addition of water [31]. To assist the lignin removal from the regenerated product, fluorescence techniques were used. Disruption of the lignin-carbohydrate complex occurred simultaneously with cellulose crystallinity reduction [31]. Analysing X-Ray diffraction (XRD) patterns of the regenerated material from bamboo pretreatment, Muhammad et al. observed a clear change in crystallinity of cellulose in dissolution and regeneration processes [42]. Li et al. compared the pre-treatment of the switchgrass using $[\mathrm{emim}]\left[\mathrm{CH}_{3} \mathrm{COO}\right]$ and a dilute 
Table 1 Pre-treatment of softwood biomass in ILs

\begin{tabular}{|c|c|c|c|c|c|c|c|c|c|c|c|c|c|c|c|c|}
\hline \multicolumn{2}{|l|}{ Ionic liquid } & \multicolumn{4}{|c|}{ Biomass } & \multicolumn{3}{|c|}{ Conditions } & \multicolumn{5}{|c|}{ Regenerated biomass } & \multirow{2}{*}{$\begin{array}{l}\text { Lignin } \\
\text { extraction } \\
\text { yield } \%\end{array}$} & \multirow{2}{*}{$\begin{array}{l}\text { IL recover } \\
\% w / w\end{array}$} & \multirow[t]{2}{*}{ Ref. } \\
\hline Type & $\begin{array}{l}\mathrm{H}_{2} \mathrm{O} \\
w+\%\end{array}$ & Type & $\begin{array}{c}\text { Moisture } \\
\text { wt } \%\end{array}$ & Size $\mathrm{mm}$ & Load \% & $\begin{array}{c}\text { Time } \\
h\end{array}$ & $\mathrm{~T}^{\circ} \mathrm{C}$ & Antisolvent & $\begin{array}{c}\text { Recovery } \\
(\% \mathrm{w} / \mathrm{w})\end{array}$ & C wt\% & $\begin{array}{c}\mathrm{H} \\
\mathrm{wt} \%\end{array}$ & $\begin{array}{c}\mathrm{L} \\
w t \%\end{array}$ & $\begin{array}{c}\mathrm{O} \\
\mathrm{wt} \%\end{array}$ & & & \\
\hline [abim][Cl] & $\mathrm{a}$ & Dawn redwood & $\mathrm{b}$ & $<60$ mesh & $15(w / w)$ & 0.5 & 90 & $\mathrm{MeOH}$ & 97.2 & - & - & - & - & - & 97.3 & $\overline{[55]}$ \\
\hline [amim] $[\mathrm{Cl}]$ & c & Southern pine & $<1$ & $0.1-2$ & $8 w t$ & 5 & 120 & $\mathrm{H}_{2} \mathrm{O}$ or $\mathrm{MeOH}_{\text {excess }}$ & 99 & $17^{d}$ & - & - & - & & 99 & {$[56]$} \\
\hline [amim][Cl] & c & $\begin{array}{c}\text { Norway spruce } \\
\text { TMP }\end{array}$ & $<1$ & $0.1-2$ & $8 w t$ & 5 & 120 & $\mathrm{H}_{2} \mathrm{O}$ or $\mathrm{MeOH}_{\text {excess }}$ & 97 & $21^{d}$ & - & - & - & & 98 & [56] \\
\hline [amim] $[\mathrm{Cl}]$ & a & Dawn redwood & b & $<60$ mesh & $15(w / w)$ & 0.5 & 90 & $\mathrm{MeOH}$ & 98.3 & - & - & - & - & - & - & {$[55]$} \\
\hline 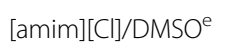 & $f$ & Pine & g & $0.45-0.65$ & $5 \mathrm{wt}$ & 3 & 100 & $\mathrm{H}_{2} \mathrm{O}$ & - & 70 & - & - & - & - & - & [34] \\
\hline [amim][CI]/DMSO & f & Pine & g & $0.45-0.65$ & $5 w t$ & 6 & 100 & $\mathrm{H}_{2} \mathrm{O}$ & - & 76 & - & - & - & - & - & [34] \\
\hline [amim][CI]/DMSO & f & Pine & g & $0.45-0.65$ & $5 w t$ & 15 & 100 & $\mathrm{H}_{2} \mathrm{O}$ & - & 78 & - & - & - & - & - & [34] \\
\hline [amim][CI]/DMSO & f & Pine & g & $0.45-0.65$ & $5 \mathrm{wt}$ & 24 & 100 & $\mathrm{H}_{2} \mathrm{O}$ & - & 71 & - & - & - & - & - & [34] \\
\hline [amim][CI]/DMSO & f & Catalpa & $g$ & $0.45-0.65$ & $5 w t$ & 3 & 100 & $\mathrm{H}_{2} \mathrm{O}$ & - & 25 & - & - & - & - & - & [34] \\
\hline$[\mathrm{amim}][\mathrm{Cl}] / \mathrm{DMSO}^{\mathrm{e}}$ & f & Catalpa & g & $0.45-0.65$ & $5 w t$ & 6 & 100 & $\mathrm{H}_{2} \mathrm{O}$ & - & 49 & - & - & - & - & - & [34] \\
\hline [amim][CI]/DMSOe & $f$ & Catalpa & g & $0.45-0.65$ & $5 w t$ & 15 & 100 & $\mathrm{H}_{2} \mathrm{O}$ & - & 50 & - & - & - & - & - & [34] \\
\hline 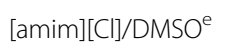 & $f$ & Catalpa & g & $0.45-0.65$ & $5 \mathrm{wt}$ & 24 & 100 & $\mathrm{H}_{2} \mathrm{O}$ & - & 56 & - & - & - & - & - & [34] \\
\hline [amim][CI]/DMSO & f & Pine & g & $0.45-0.65$ & $5 w t$ & 3 & 100 & $\mathrm{H}_{2} \mathrm{O}$ & 6 & - & - & - & - & - & - & [34] \\
\hline [amim][CI]/DMSO & f & Pine & g & $0.45-0.65$ & $5 w t$ & 6 & 100 & $\mathrm{H}_{2} \mathrm{O}$ & 9 & - & - & - & - & - & - & [34] \\
\hline [amim][CI]/DMSO & $f$ & Pine & $g$ & $0.45-0.65$ & $5 w t$ & 15 & 100 & $\mathrm{H}_{2} \mathrm{O}$ & 16 & - & - & - & - & - & - & [34] \\
\hline$[\mathrm{amim}][\mathrm{Cl}] / \mathrm{DMSO}^{\mathrm{e}}$ & f & Pine & g & $0.45-0.65$ & $5 w t$ & 24 & 100 & $\mathrm{H}_{2} \mathrm{O}$ & 19 & - & - & - & - & - & - & [34] \\
\hline$[\mathrm{amim}][\mathrm{Cl}] / \mathrm{DMSO}^{\mathrm{e}}$ & f & Pine & g & $0.45-0.65$ & $5 w t$ & 0.5 & $100^{h}$ & $\mathrm{H}_{2} \mathrm{O}$ & 6 & - & - & - & - & - & - & [34] \\
\hline [amim][CI]/DMSO & f & Pine & g & $0.45-0.65$ & $5 \mathrm{wt}$ & 1 & $100^{h}$ & $\mathrm{H}_{2} \mathrm{O}$ & 10 & - & - & - & - & - & - & [34] \\
\hline 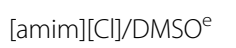 & f & Pine & g & $0.45-0.65$ & $5 \mathrm{wt}$ & 2 & $100^{h}$ & $\mathrm{H}_{2} \mathrm{O}$ & 17 & - & - & - & - & - & - & [34] \\
\hline [amim][CI]/DMSO & $f$ & Pine & g & $0.45-0.65$ & $5 w t$ & 4 & $100^{\mathrm{h}}$ & $\mathrm{H}_{2} \mathrm{O}$ & 18 & - & - & - & - & - & - & [34] \\
\hline$[\mathrm{amim}][\mathrm{Cl}] / \mathrm{DMSO}^{\mathrm{e}}$ & $f$ & Pine & g & $0.45-0.65$ & $1 \mathrm{wt}$ & 15 & 100 & $\mathrm{H}_{2} \mathrm{O}$ & 25 & - & - & - & - & - & - & [34] \\
\hline [amim][CI]/DMSO & $f$ & Pine & $g$ & $0.45-0.65$ & $2 w t$ & 15 & 100 & $\mathrm{H}_{2} \mathrm{O}$ & 20 & - & - & - & - & - & - & [34] \\
\hline$[\mathrm{amim}][\mathrm{Cl}] / \mathrm{DMSO}^{\mathrm{e}}$ & f & Pine & g & $0.45-0.65$ & $3 w t$ & 15 & 100 & $\mathrm{H}_{2} \mathrm{O}$ & 19 & - & - & - & - & - & - & [34] \\
\hline [amim][CI]/DMSO & f & Pine & g & $0.45-0.65$ & $4 w t$ & 15 & 100 & $\mathrm{H}_{2} \mathrm{O}$ & 17 & - & - & - & - & - & - & [34] \\
\hline [amim][CI]/DMSO & $f$ & Pine & g & $0.45-0.65$ & $5 w t$ & 15 & 100 & $\mathrm{H}_{2} \mathrm{O}$ & 16 & - & - & - & - & - & - & [34] \\
\hline [amim][CI]/DMSO & f & Pine & g & $0.45-0.65$ & $5 w t$ & 2 & 100 & $\mathrm{H}_{2} \mathrm{O}$ & - & 76 & - & - & - & - & - & [34] \\
\hline$[\mathrm{amim}][\mathrm{Cl}] / \mathrm{DMSO}^{\mathrm{e}}$ & $f$ & Pine & g & $0.45-0.65$ & $5 \mathrm{wt}$ & 2 & 100 & acetone- $\mathrm{H}_{2} \mathrm{O}$ & - & 76 & - & - & - & - & - & {$[34]$} \\
\hline$[\mathrm{amim}][\mathrm{Cl}] / \mathrm{DMSO}^{\mathrm{e}}$ & $f$ & Pine & g & $0.45-0.65$ & $5 \mathrm{wt}$ & 2 & 100 & DMSO- $\mathrm{H}_{2} \mathrm{O}$ & - & 85 & - & - & - & - & - & [34] \\
\hline [amim][CI]/DMSO & $f$ & Pine & $g$ & $0.45-0.65$ & $5 w t$ & 2 & $110^{\mathrm{h}}$ & $\mathrm{H}_{2} \mathrm{O}$ & 25 & - & - & - & - & - & - & [34] \\
\hline$[\mathrm{bmim}]\left[\mathrm{CH}_{3} \mathrm{COO}\right]$ & f & Spruce wood & nd. & $0.295-0.833$ & $5(w / w)$ & $1,3,15$ & 120 & $20 \mathrm{~mL} \mathrm{H} \mathrm{H}_{2} \mathrm{O}$ & $85-97$ & $47.5^{i}$ & $20.4^{j}$ & 28.5 & - & - & - & {$[57]$} \\
\hline
\end{tabular}


Table 1 Pre-treatment of softwood biomass in ILs (Continued)

\begin{tabular}{|c|c|c|c|c|c|c|c|c|c|c|c|c|c|c|c|c|}
\hline$[\mathrm{bmim}]\left[\mathrm{CH}_{3} \mathrm{COO}\right]$ & $f$ & Spruce wood & nd. & $<20$ & $5(w / w)$ & $1,3,15$ & 120 & $20 \mathrm{~mL} \mathrm{H} \mathrm{H}_{2} \mathrm{O}$ & $100-93$ & $47.5^{i}$ & $20.4^{j}$ & 28.5 & - & - & - & {$[57]$} \\
\hline$[\mathrm{bmim}]\left[\mathrm{CH}_{3} \mathrm{COO}\right] / \mathrm{H}_{2} \mathrm{O}$ & $\sim 20$ & Pine sapwood & 8.9 & $0.18-0.85$ & $10(w / v)$ & 22 & 120 & $10 \mathrm{~mL} \mathrm{MeOH}$ & 87 & $40.4^{i}$ & $24.7^{j}$ & 21.1 & $0.6^{k}$ & 30.7 & - & [53] \\
\hline$[\mathrm{bmim}][\mathrm{Cl}]$ & nd. & $\begin{array}{l}\text { Southern } \\
\text { yellow pine }\end{array}$ & 1 & $0.25-0.50$ & $5(w / w)$ & 16 & 110 & $\begin{array}{c}0.1 \mathrm{~mL} \text { acetone: } \\
\mathrm{H}_{2} \mathrm{O}(1: 1)\end{array}$ & - & - & - & - & - & - & - & [25] \\
\hline$[\mathrm{bmim}][\mathrm{Cl}]$ & nd. & $\begin{array}{l}\text { Southern } \\
\text { yellow pine }\end{array}$ & 1 & $<0.125$ & $5(w / w)$ & 16 & 110 & $\begin{array}{c}100 \mathrm{~mL} \text { acetone: } \\
\mathrm{H}_{2} \mathrm{O}(1: 1)\end{array}$ & - & - & - & - & - & - & - & [25] \\
\hline$[\mathrm{bmim}]\left[\mathrm{HSO}_{4}\right] / \mathrm{H}_{2} \mathrm{O}$ & $\sim 20$ & Pine sapwood & 8.9 & $0.18-0.85$ & $10(w / v)$ & 22 & 120 & $10 \mathrm{~mL} \mathrm{MeOH}$ & 55.0 & $37.9^{i}$ & $7.8^{j}$ & 8.8 & $0.2^{k}$ & 81.7 & - & [53] \\
\hline [emim] $\left[\mathrm{CH}_{3} \mathrm{COO}\right]$ & nd. & $\begin{array}{l}\text { Southern } \\
\text { yellow pine }\end{array}$ & 1 & $0.500-1.000$ & $5(w / w)$ & 16 & 110 & $\begin{array}{c}100 \mathrm{~mL} \text { acetone: } \\
\mathrm{H}_{2} \mathrm{O}(1: 1)\end{array}$ & - & - & - & - & - & - & - & [25] \\
\hline [emim] $\left[\mathrm{CH}_{3} \mathrm{COO}\right]$ & nd. & $\begin{array}{l}\text { Southern } \\
\text { yellow pine }\end{array}$ & 1 & $0.250-0.500$ & $5(w / w)$ & 16 & 110 & $\begin{array}{c}100 \mathrm{~mL} \text { acetone: } \\
\mathrm{H}_{2} \mathrm{O}(1: 1)\end{array}$ & - & - & - & - & - & - & - & [25] \\
\hline [emim] $\left[\mathrm{CH}_{3} \mathrm{COO}\right]$ & nd. & $\begin{array}{l}\text { Southern } \\
\text { yellow pine }\end{array}$ & 1 & $0.125-0.250$ & $5(w / w)$ & 16 & 110 & $\begin{array}{c}100 \mathrm{~mL} \text { acetone: } \\
\mathrm{H}_{2} \mathrm{O}(1: 1)\end{array}$ & - & - & - & - & - & - & - & [25] \\
\hline$[\mathrm{emim}]\left[\mathrm{CH}_{3} \mathrm{COO}\right]$ & nd. & $\begin{array}{l}\text { Southern } \\
\text { yellow pine }\end{array}$ & 1 & $<0.125$ & $5(w / w)$ & 16 & 110 & $\begin{array}{c}100 \mathrm{~mL} \text { acetone: } \\
\mathrm{H}_{2} \mathrm{O}(1: 1)\end{array}$ & 52 & $\begin{array}{c}76.5 \\
\text { (holocellulose) }\end{array}$ & & 23.5 & - & 31.4 & - & [25] \\
\hline [emim] $\left[\mathrm{CH}_{3} \mathrm{COO}\right]$ & nd. & $\begin{array}{l}\text { Southern } \\
\text { yellow pine }\end{array}$ & 1 & $<0.125$ & $8(w / w)$ & 16 & 110 & $\begin{array}{c}100 \mathrm{~mL} \text { acetone: } \\
\mathrm{H}_{2} \mathrm{O}(1: 1)\end{array}$ & - & - & - & 9.3 & - & - & - & [25] \\
\hline [emim] $\left[\mathrm{CH}_{3} \mathrm{COO}\right]$ & e & Spruce wood & nd. & $0.295-0.833$ & $5(w / w)$ & $1,3,15$ & 120 & $20 \mathrm{~mL} \mathrm{H} \mathrm{H}_{2} \mathrm{O}$ & $86-96$ & $48.3^{i}$ & $20.4^{j}$ & 28.1 & - & - & - & [57] \\
\hline [emim] $\left[\mathrm{CH}_{3} \mathrm{COO}\right]$ & e & Spruce wood & nd. & $<20$ & $5(w / w)$ & $1,3,15$ & 120 & $20 \mathrm{~mL} \mathrm{H} \mathrm{H}_{2} \mathrm{O}$ & $100-89$ & $48.3^{i}$ & $20.4^{j}$ & 28.1 & - & - & - & [57] \\
\hline [emim] $\left[\mathrm{CH}_{3} \mathrm{COO}\right]$ & nd. & $\begin{array}{l}\text { Compression } \\
\text { pine wood }\end{array}$ & air-dried & 20-40 mesh & $5(w / w)$ & 3 & 120 & $20 \mathrm{~mL} \mathrm{H} \mathrm{H}_{2} \mathrm{O}$ & 89 & $30.3^{i}$ & $20.8^{j}$ & 39.2 & - & - & - & [30] \\
\hline$[\mathrm{emim}]\left[\mathrm{CH}_{3} \mathrm{COO}\right]$ & nd. & $\begin{array}{l}\text { Compression } \\
\text { pine wood }\end{array}$ & air-dried & 20-40 mesh & $5(w / w)$ & 3 & 155 & $20 \mathrm{~mL} \mathrm{H} \mathrm{H}_{2} \mathrm{O}$ & 68 & $34.0^{\mathrm{i}}$ & $11.4^{j}$ & 51.3 & - & - & - & [30] \\
\hline$[\mathrm{emim}]\left[\mathrm{CH}_{3} \mathrm{COO}\right]$ & nd. & $\begin{array}{l}\text { Opposite } \\
\text { pine wood }\end{array}$ & air-dried & 20-40 mesh & $5(w / w)$ & 3 & 120 & $20 \mathrm{~mL} \mathrm{H} \mathrm{H}_{2} \mathrm{O}$ & 94 & $42.6^{i}$ & $18.2^{j}$ & 31.1 & - & - & - & [30] \\
\hline [emim] $\left[\mathrm{CH}_{3} \mathrm{COO}\right]$ & nd. & $\begin{array}{l}\text { Opposite } \\
\text { pine wood }\end{array}$ & air-dried & 20-40 mesh & $5(w / w)$ & 3 & 155 & $20 \mathrm{~mL} \mathrm{H} \mathrm{H}_{2} \mathrm{O}$ & 73 & $48.8^{i}$ & $11.0^{j}$ & 32.3 & - & - & - & [30] \\
\hline
\end{tabular}


Table 2 Pre-treatment of hardwood biomass in ILs

\begin{tabular}{|c|c|c|c|c|c|c|c|c|c|c|c|c|c|c|c|c|}
\hline \multicolumn{2}{|l|}{ Ionic liquid } & \multicolumn{4}{|c|}{ Biomass } & \multicolumn{3}{|c|}{ Conditions } & \multicolumn{5}{|c|}{ Regenerated biomass } & \multirow{2}{*}{$\begin{array}{l}\text { Lignin } \\
\text { extraction } \\
\text { yield \% }\end{array}$} & \multirow{2}{*}{$\begin{array}{l}\text { IL recover } \\
\% w / w\end{array}$} & \multirow[t]{2}{*}{ Ref. } \\
\hline Type & $\begin{array}{l}\mathrm{H}_{2} \mathrm{O} \\
\text { wt\% }\end{array}$ & Type & $\begin{array}{c}\text { Moisture } \\
\text { wt } \%\end{array}$ & Size $\mathrm{mm}$ & Load \% & $\underset{\mathrm{h}}{\mathrm{Time}}$ & $\mathrm{T}^{\circ} \mathrm{C}$ & Antisolvent & $\begin{array}{c}\text { Recovery } \\
(\% \mathrm{w} / \mathrm{w})\end{array}$ & $\begin{array}{c}\mathrm{C} \\
w t \%\end{array}$ & $\begin{array}{c}\mathrm{H} \\
\mathbf{w t} \%\end{array}$ & $\underset{w t \%}{L}$ & $\begin{array}{c}0 \\
w t \%\end{array}$ & & & \\
\hline$[\mathrm{amim}][\mathrm{Cl}]$ & $\mathrm{a}$ & Eucalyptus grandis & $<1$ & $0.1-2$ & $8 w t$ & 5 & 120 & $\mathrm{H}_{2} \mathrm{O}$ or $\mathrm{MeOH}_{\text {excess }}$ & 96 & $21^{\mathrm{b}}$ & - & - & - & & 100 & $\overline{[56]}$ \\
\hline$[\operatorname{amim}][\mathrm{Cl}] / \mathrm{DMSO}^{c}$ & d & Poplar & e & $0.45-0.65$ & $5 w t$ & 3 & 100 & $\mathrm{H}_{2} \mathrm{O}$ & - & 49 & - & - & - & - & - & [34] \\
\hline$[\mathrm{amim}][\mathrm{Cl}] / \mathrm{DMSO}^{c}$ & d & Poplar & e & $0.45-0.65$ & $5 w t$ & 6 & 100 & $\mathrm{H}_{2} \mathrm{O}$ & - & 48 & - & - & - & - & - & [34] \\
\hline$[\mathrm{amim}][\mathrm{Cl}] / \mathrm{DMSO}^{c}$ & $d$ & Poplar & e & $0.45-0.65$ & $5 \mathrm{wt}$ & 15 & 100 & $\mathrm{H}_{2} \mathrm{O}$ & - & 49 & - & - & - & - & - & [34] \\
\hline$[\mathrm{amim}][\mathrm{Cl}] / \mathrm{DMSO}^{c}$ & d & Poplar & e & $0.45-0.65$ & $5 w t$ & 24 & 100 & $\mathrm{H}_{2} \mathrm{O}$ & - & 47 & - & - & - & - & - & [34] \\
\hline$[\mathrm{bmim}]\left[\mathrm{CH}_{3} \mathrm{COO}\right]$ & $0.68(w / w)$ & $\begin{array}{l}\text { Maple wood } \\
\text { flour }\end{array}$ & nd. & 0.250 & $5(w / w)$ & 6 & 90 & - & - & $64^{f}$ & $57^{9}$ & - & - & 25 & - & [58] \\
\hline$[\mathrm{bmim}]\left[\mathrm{CH}_{3} \mathrm{COO}\right]$ & $0.68(w / w)$ & $\begin{array}{l}\text { Maple wood } \\
\text { flour }\end{array}$ & nd. & 0.250 & $5(w / w)$ & 12 & 90 & - & - & $74^{f}$ & $65^{9}$ & - & - & 35 & - & [58] \\
\hline$[\mathrm{bmim}]\left[\mathrm{CH}_{3} \mathrm{COO}\right]$ & $0.68(w / w)$ & $\begin{array}{l}\text { Maple wood } \\
\text { flour }\end{array}$ & nd. & 0.250 & $5(w / w)$ & 24 & 90 & - & - & $74^{f}$ & $64^{9}$ & - & - & 49 & - & [58] \\
\hline$[\mathrm{bmim}]\left[\mathrm{CH}_{3} \mathrm{COO}\right]$ & h & Poplar & i & $\sim 2$ & $5(w / w)$ & 2 & 130 & acetone $_{\text {excess }}$ & 22.20 & - & - & - & - & - & - & [32] \\
\hline$[\mathrm{bmim}]\left[\mathrm{CH}_{3} \mathrm{COO}\right]$ & $h$ & Poplar & $\mathrm{i}$ & $\sim 2$ & $5(w / w)$ & 5 & 130 & acetone $_{\text {excesss }}$ & 38.70 & - & - & - & - & - & - & [32] \\
\hline$[\mathrm{bmim}]\left[\mathrm{CH}_{3} \mathrm{COO}\right]$ & h & Poplar & $\mathrm{i}$ & $\sim 2$ & $5(w / w)$ & 12 & 130 & acetone $_{\text {excess }}$ & 85.30 & - & - & 25.08 & - & 31.90 & - & [32] \\
\hline$[\mathrm{bmim}]\left[\mathrm{CH}_{3} \mathrm{COO}\right] / \mathrm{H}_{2} \mathrm{O}$ & $10(w / w)$ & $\begin{array}{l}\text { Maple wood } \\
\text { flour }\end{array}$ & nd. & 0.250 & $5(w / w)$ & 12 & 90 & - & - & $48^{f}$ & $51^{9}$ & - & - & $21-24$ & - & [58] \\
\hline$[\mathrm{bmim}]\left[\mathrm{CH}_{3} \mathrm{COO}\right] / \mathrm{H}_{2} \mathrm{O}$ & $\sim 20$ & Willow & 7.6 & $0.18-0.85$ & $10(w / v)$ & 22 & 120 & $10 \mathrm{~mL} \mathrm{MeOH}$ & 71 & $36.3^{j}$ & $13.9^{k}$ & 19.9 & $0.7^{1}$ & 46.7 & - & [53] \\
\hline$[\mathrm{bmim}][\mathrm{Cl}]$ & h & Poplar & $\mathrm{i}$ & $\sim 2$ & $5(w / w)$ & 2 & 130 & acetone $_{\text {excess }}$ & 11.8 & - & - & - & - & - & - & [32] \\
\hline$[\mathrm{bmim}][\mathrm{Cl}]$ & h & Poplar & $\mathrm{i}$ & $\sim 2$ & $5(w / w)$ & 5 & 130 & acetone $_{\text {excess }}$ & 13.4 & - & - & - & - & - & - & [32] \\
\hline$[\mathrm{bmim}][\mathrm{Cl}]$ & h & Poplar & i & $\sim 2$ & $5(w / w)$ & 12 & 130 & acetone $_{\text {excess }}$ & 20.6 & - & - & - & - & - & - & [32] \\
\hline$[\mathrm{bmim}]\left[\mathrm{HSO}_{4}\right] / \mathrm{H}_{2} \mathrm{O}$ & $\sim 20$ & Willow & 7.6 & $0.18-0.85$ & $10(w / v)$ & 22 & 120 & $10 \mathrm{~mL} \mathrm{MeOH}$ & 48.0 & $39.1^{j}$ & $5.1^{k}$ & 3.6 & $0.5^{1}$ & 93.5 & - & [53] \\
\hline$[\mathrm{bmim}]\left[\mathrm{MeOSO}{ }_{3}\right]$ & $0.02(w / w)$ & $\begin{array}{l}\text { Maple wood } \\
\text { flour }\end{array}$ & nd. & 0.250 & $5(w / w)$ & 12 & 90 & - & - & $1.1^{f}$ & $5.1^{9}$ & - & - & 19.0 & - & [58] \\
\hline$[\mathrm{bmim}]\left[\mathrm{MeOSO}_{3}\right] / \mathrm{H}_{2} \mathrm{O}$ & $10(w / w)$ & $\begin{array}{l}\text { Maple wood } \\
\text { flour }\end{array}$ & nd. & 0.250 & $5(w / w)$ & 12 & 90 & - & - & $6.0^{f}$ & $6.0^{9}$ & - & - & $21-24$ & - & [58] \\
\hline$[\mathrm{emim}]\left[\mathrm{CH}_{3} \mathrm{COO}\right]$ & nd. & Red Oak & m & $0.500-1.000$ & $5(w / w)$ & 16 & 110 & $\begin{array}{c}100 \text { mL acetone: } \\
\mathrm{H}_{2} \mathrm{O}(1: 1)\end{array}$ & - & - & - & - & - & - & - & [25] \\
\hline [emim] $\left[\mathrm{CH}_{3} \mathrm{COO}\right]$ & nd. & Red Oak & $\mathrm{m}$ & $0.250-0.500$ & $5(w / w)$ & 16 & 110 & $\begin{array}{c}100 \mathrm{~mL} \text { acetone: } \\
\mathrm{H}_{2} \mathrm{O}(1: 1)\end{array}$ & - & - & - & 15.5 & - & - & - & [25] \\
\hline [emim] $\left[\mathrm{CH}_{3} \mathrm{COO}\right]$ & nd. & Red Oak & $\mathrm{m}$ & $0.125-0.250$ & $5(w / w)$ & 16 & 110 & $\begin{array}{c}100 \mathrm{~mL} \text { acetone: } \\
\mathrm{H}_{2} \mathrm{O}(1: 1)\end{array}$ & - & - & - & - & - & - & - & [25] \\
\hline [emim] $\left[\mathrm{CH}_{3} \mathrm{COO}\right]$ & $0.09(w / w)$ & $\begin{array}{l}\text { Maple wood } \\
\text { flour }\end{array}$ & nd. & 0.250 & $5(w / w)$ & 6 & 90 & - & - & $59^{f}$ & $45^{9}$ & - & - & 26 & - & [58] \\
\hline [emim] $\left[\mathrm{CH}_{3} \mathrm{COO}\right]$ & $0.09(w / w)$ & $\begin{array}{l}\text { Maple wood } \\
\text { flour }\end{array}$ & nd. & 0.250 & $5(w / w)$ & 12 & 90 & - & - & $65^{f}$ & $56^{9}$ & - & - & 32 & - & [58] \\
\hline
\end{tabular}


Table 2 Pre-treatment of hardwood biomass in ILs (Continued)

\begin{tabular}{|c|c|c|c|c|c|c|c|c|c|c|c|c|c|c|c|c|}
\hline$[\mathrm{emim}]\left[\mathrm{CH}_{3} \mathrm{COO}\right]$ & $0.09(w / w)$ & $\begin{array}{l}\text { Maple wood } \\
\text { flour }\end{array}$ & nd. & 0.250 & $5(w / w)$ & 24 & 90 & - & - & $70^{f}$ & $64^{9}$ & - & - & 37 & - & $\overline{[58]}$ \\
\hline [emim] $\left[\mathrm{CH}_{3} \mathrm{COO}\right]$ & d & $\begin{array}{l}\text { Maple wood } \\
\text { flour }\end{array}$ & 5.0 & 0.25 & $33.3(w / w)$ & 1 & 125 & $20 \mathrm{~mL} \mathrm{H} \mathrm{H}_{2} \mathrm{O}$ & 82.8 & 42.5 & $18.1^{\mathrm{n}}$ & 25.8 & - & 13.5 & - & [41] \\
\hline [emim] $\left[\mathrm{CH}_{3} \mathrm{COO}\right]$ & d & Poplar & 2.4 & $1-2$ & $33.3(w / w)$ & 1 & 125 & $20 \mathrm{~mL} \mathrm{H}_{2} \mathrm{O}$ & 87.4 & 42.5 & $18.8^{n}$ & 28.5 & - & 10.1 & - & [41] \\
\hline [emim] $\left[\mathrm{CH}_{3} \mathrm{COO}\right]$ & nd. & Poplar & nd. & 20-80 mesh & $5(w / w)$ & $12-14$ & 50 & $\mathrm{H}_{2} \mathrm{O}$ & - & $3^{j}$ & $11^{\mathrm{n}}$ & 23 & - & - & - & [59] \\
\hline$[\mathrm{emim}]\left[\mathrm{CH}_{3} \mathrm{COO}\right]$ & nd. & Poplar & nd. & 20-80 mesh & $5(w / w)$ & 1 & 120 & $\mathrm{H}_{2} \mathrm{O}$ & - & $29^{j}$ & $10^{n}$ & 25 & - & - & - & [59] \\
\hline $\begin{array}{c}\text { [emim] }\left[\mathrm{CH}_{3} \mathrm{COO}\right] / \\
\mathrm{H}_{2} \mathrm{O}\end{array}$ & $10(w / w)$ & $\begin{array}{l}\text { Maple wood } \\
\text { flour }\end{array}$ & nd. & 0.250 & $5(w / w)$ & 12 & 90 & - & - & $32^{f}$ & $32^{9}$ & - & - & $21-24$ & - & [58] \\
\hline [emim][Cl] & d & Eucalyptus & $10-15$ & $2-40$ & $5(w / w)$ & 1 & 150 & $5 \mathrm{~mL} \mathrm{H} \mathrm{H}_{2} \mathrm{O}$ & - & \multicolumn{2}{|c|}{$33^{\circ}$} & - & - & - & - & [60] \\
\hline$[\mathrm{mmim}]\left[\mathrm{Me}_{2} \mathrm{PO}_{4}\right]$ & d & Rubber wood & p & 0.2 & $25(w / w)$ & 0.5 & 25 & $\mathrm{MeOH}$ & - & - & - & - & - & $2.34^{9}$ & - & [61] \\
\hline$[\mathrm{mmim}]\left[\mathrm{Me}_{2} \mathrm{PO}_{4}\right]$ & d & Rubber wood & $\mathrm{p}$ & 0.2 & $13(w / w)$ & 0.5 & 25 & $\mathrm{MeOH}$ & - & - & - & - & - & $3.37^{9}$ & - & [61] \\
\hline$[\mathrm{mmim}]\left[\mathrm{Me}_{2} \mathrm{PO}_{4}\right]$ & d & Rubber wood & p & 0.2 & $8(w / w)$ & 0.5 & 25 & $\mathrm{MeOH}$ & - & - & - & - & - & $3.87^{9}$ & - & {$[61]$} \\
\hline$[\mathrm{mmim}]\left[\mathrm{Me}_{2} \mathrm{PO}_{4}\right]$ & d & Rubber wood & p & 0.2 & $6(w / w)$ & 0.5 & 25 & $\mathrm{MeOH}$ & - & - & - & - & - & $4.02^{9}$ & - & {$[61]$} \\
\hline$[\mathrm{mmim}]\left[\mathrm{Me}_{2} \mathrm{PO}_{4}\right]$ & d & Rubber wood & p & 0.2 & $5(w / w)$ & 0.5 & 25 & $\mathrm{MeOH}$ & - & - & - & - & - & $4.27^{q}$ & - & {$[61]$} \\
\hline$[\mathrm{mmim}]\left[\mathrm{Me}_{2} \mathrm{PO}_{4}\right]$ & d & Rubber wood & $\mathrm{p}$ & 0.2 & $5(w / w)$ & 0.5 & 25 & $\mathrm{MeOH}$ & - & - & - & - & - & $4.27^{9}$ & - & [61] \\
\hline$[\mathrm{mmim}]\left[\mathrm{Me}_{2} \mathrm{PO}_{4}\right]$ & d & Rubber wood & $\mathrm{p}$ & 0.2 & $5(w / w)$ & 1 & 25 & $\mathrm{MeOH}$ & - & - & - & - & - & $4.76^{9}$ & - & [61] \\
\hline$[\mathrm{mmim}]\left[\mathrm{Me}_{2} \mathrm{PO}_{4}\right]$ & d & Rubber wood & p & 0.2 & $5(w / w)$ & 1.5 & 25 & $\mathrm{MeOH}$ & - & - & - & - & - & $5.16^{\mathrm{a}}$ & - & [61] \\
\hline$[\mathrm{mmim}]\left[\mathrm{Me}_{2} \mathrm{PO}_{4}\right]$ & d & Rubber wood & $\mathrm{p}$ & 0.2 & $5(w / w)$ & 2 & 25 & $\mathrm{MeOH}$ & - & - & - & - & - & $5.68^{9}$ & - & [61] \\
\hline$[\mathrm{mmim}]\left[\mathrm{Me}_{2} \mathrm{PO}_{4}\right]$ & d & Rubber wood & p & 0.2 & $5(w / w)$ & 2.5 & 25 & $\mathrm{MeOH}$ & - & - & - & - & - & $5.71^{9}$ & - & {$[61]$} \\
\hline$[\mathrm{mmim}]\left[\mathrm{Me}_{2} \mathrm{PO}_{4}\right]$ & $d$ & Rubber wood & p & 0.2 & $5(w / w)$ & 2 & 25 & $\mathrm{MeOH}$ & - & - & - & - & - & $5.68^{9}$ & - & {$[61]$} \\
\hline$[\mathrm{mmim}]\left[\mathrm{Me}_{2} \mathrm{PO}_{4}\right]$ & $d$ & Rubber wood & p & 0.2 & $5(w / w)$ & 2 & 40 & $\mathrm{MeOH}$ & - & - & - & - & - & $6.36^{\mathrm{q}}$ & - & {$[61]$} \\
\hline$[\mathrm{mmim}]\left[\mathrm{Me}_{2} \mathrm{PO}_{4}\right]$ & d & Rubber wood & $p$ & 0.2 & $5(w / w)$ & 2 & 60 & $\mathrm{MeOH}$ & - & - & - & - & - & $11.01^{9}$ & - & [61] \\
\hline$[\mathrm{mmim}]\left[\mathrm{Me}_{2} \mathrm{PO}_{4}\right]$ & d & Rubber wood & p & 0.2 & $5(w / w)$ & 2 & 80 & $\mathrm{MeOH}$ & - & - & - & - & - & $12.50^{9}$ & - & [61] \\
\hline$[\mathrm{mmim}]\left[\mathrm{Me}_{2} \mathrm{PO}_{4}\right]$ & d & Rubber wood & $\mathrm{p}$ & 0.2 & $5(w / w)$ & 2 & 100 & $\mathrm{MeOH}$ & - & - & - & - & - & $13.03^{9}$ & - & [61] \\
\hline
\end{tabular}

$\mathrm{C}$ - cellulose; $\mathrm{H}$ - hemicellulose; $\mathrm{L}$ - lignin; $\mathrm{O}$ - others; ${ }^{\text {a }}$ dried under vacuum at $40^{\circ} \mathrm{C}$ for $48 \mathrm{~h}^{\mathrm{b}}{ }^{\mathrm{b}}$ glucose yield after enzymatic hydrolysis; ${ }^{\mathrm{c}} 16 \mathrm{wt}^{\mathrm{C}} \%$ DMSO; ${ }^{\mathrm{d}}$ used as received; ${ }^{\mathrm{e}}$ dried at $105^{\circ} \mathrm{C}$ overnight; ${ }^{\mathrm{f}}$ glucose yield after enzymatic hydrolysis regarding the original glucan content; ${ }^{9}$ xylose yield after enzymatic hydrolysis regarding the original xylan content; ${ }^{i}$ vacuum dried at room temperature for $12 \mathrm{~h} ;{ }^{\prime}$ dried at $100^{\circ} \mathrm{C}$ for $12 \mathrm{~h} ;$ ${ }^{\mathrm{j}}$ glucan basis; ${ }^{\mathrm{k}}$ xylan, mannan, galactan and arabinan basis; ${ }^{\mathrm{a}}$ ash basis; ${ }^{\mathrm{m}}$ dried overnight $90^{\circ} \mathrm{C}_{;}{ }^{\mathrm{n}}$ xylan basis; ${ }^{\circ}$ reducing sugar yield regarding the initial content in pre-treated biomass; ${ }^{\mathrm{p}}$ dried overnight in a vacuum oven at $100^{\circ} \mathrm{C}$; ${ }^{a}$ lignin yield considering the total biomass input. 
acid [62]. For both untreated and dilute acid pre-treated switchgrass samples little or no change in cellulose crystallinity was observed, but for the sample obtained after pre-treatment with IL the crystallinity was altered significantly. They concluded that cellulose could suffer a structural transformation from cellulose I to cellulose II that provides higher performances of enzymatic hydrolysis. If the IL is not efficient in breaking the interactions between lignin and other wood components from cellulose, the structural transformation of cellulose I to cellulose II is not be observed [62]. The crystallinity index (CrI) calculated by XRD for the IL pre-treatment switchgrass was found to be significantly lower (2.6) than that for both untreated (26.2) and dilute acid pre-treated (39.1) switchgrass. Contrary to Singh et al. observations, the IL pretreated switchgrass showed no fibrous structure, but a porous surface was observed over several length scales, by scanning electron microscope [62]. In fact, a less crystalline form of pre-treated samples with $[\mathrm{emim}]\left[\mathrm{CH}_{3} \mathrm{COO}\right]$ is typical, since similar changes were observed for different biomass, namely corn stover, maple wood flour, poplar and switchgrass using the same IL [41]. The [emim] $\left[\mathrm{CH}_{3} \mathrm{COO}\right]$ demonstrated to be more effective than $[\mathrm{emim}][\mathrm{Cl}]$, [amim $][\mathrm{Cl}][\mathrm{bmim}][\mathrm{Cl}]$ and $[\mathrm{HEA}][\mathrm{HCOO}]$ in reducing the crystallinity of cotton stalks for different particle sizes tested $[63,64]$. The $[\mathrm{emim}][\mathrm{Cl}]$ was verified to need more time to effectively disrupt the crystalline structure of biomass in comparison with $[\mathrm{emim}]\left[\mathrm{CH}_{3} \mathrm{COO}\right]$ [64]. The efficiency in disrupting the crystalline structure of eucalyptus and sugarcane bagasse was observed to be superior for [emim] $\left[\mathrm{CH}_{3} \mathrm{COO}\right]$ than for [bmpy] [Cl] [65].

Cholinium amino acids ionic liquids were recently applied on rice straw pre-treatment and led to a substantial increase of the cellulose CrI instead of the normal decrease [66]. These contrasting effects on CrI resulted in differences in the ability of these ILs to dissolve cellulose where the tested ILs are inefficient. Thus, an increase in the CrI cellulose of the regenerated materials is only caused by a considerable removal of amorphous components, such as lignin, with no significant dissolution of cellulose [66]. The regeneration method also influences the cellulose crystallinity where a vigorous stirring was required. It may partially inhibit the induction of the crystalline ordering within the regenerated sample and may form an amorphous material [24].

Furthermore, by treating switchgrass with [emim] $\left[\mathrm{CH}_{3} \mathrm{COO}\right]$ at $160^{\circ} \mathrm{C}$, Arora et al. investigated the surface morphology of switchgrass by measuring the BET (Brunauer-Emmett-Teller) surface area, and the porosity using the BJH (Barret-Joyner-Halenda) method [67]. Comparing to the untreated switchgrass, the BET surface area of the pre-treated switchgrass increased by a factor of 30. At the same time, the pore volume also increased 30 -fold with an average measured pore size of 10-15 nm for $[\mathrm{emim}]\left[\mathrm{CH}_{3} \mathrm{COO}\right]$ of the pre-treated switchgrass [67]. Dibble et al. showed that a smaller particle size of the regenerated material was obtained by treating corn stover with the same IL [68]. Morphological changes were also observed for pre-treated wood flour with [emim] $\left[\mathrm{CH}_{3} \mathrm{COO}\right]$ and [bmim] $\left[\mathrm{CH}_{3} \mathrm{COO}\right]$ [58]. This is a great advantage of biomass pre-treatment with ILs, since cellulose surface area decreases and thus, it provides good accessibility to cellulase and enhances the catalytic efficiency of such enzyme [43,69].

The regeneration process was explained by Zavrel et al. describing that ions of the IL are extracted into the aqueous phase through hydrogen bonding, dipolar and Coulombic forces [26,70]. Basically, water molecules form hydrodynamic shells around ions of the IL disrupting the direct interactions of IL ions with cellulose. Thus, intra- and inter-molecular hydrogen bonds are rebuilt and cellulose precipitates [26]. However, not only cellulose can be dissolved but also other compounds of lignocellulose interact with the IL ions, such as hemicellulose and lignin. Singh et al. stated that the addition of water to switchgrass pre-treated in $[\mathrm{emim}]\left[\mathrm{CH}_{3} \mathrm{COO}\right]$ results in the precipitation of carbohydrates for downstream processing and lignin appears to be partially extracted in the IL/water mixture [31]. The degree of delignification and interaction of lignin with the precipitating solvent, IL, or cellulose dictate the purity of the regenerated cellulose for further saccharification and sugar yield [31]. Leskinen et al. evaluated the precipitation and composition of the regenerated samples from wood sawdust treatment with [amim][Cl] [35]. In the obtained regenerated material the lignin content increased due to the absence of delignification and simultaneous dissolution of some polysaccharide components. However, Nguyen et al. presented that lignin is firstly removed in the pre-treatment of rice straw with [emim] $\left[\mathrm{CH}_{3} \mathrm{COO}\right]$ [51]. This may indicate differences in the mode of dissolution between [amim] $[\mathrm{Cl}]$ and [emim] $\left[\mathrm{CH}_{3} \mathrm{COO}\right]$ or it may also result from differences between biomass used in both studies. A more accurate correlation between lignin removal and the reduction of cellulose crystallinity was approached in a work of Tan et al. [71] Lignin content in the regenerated material was found to be proportional to the CrI. Thus, when more lignin is retained in the regenerated material, higher $\mathrm{CrI}$ is observed. The possible explanation comes from the movement restriction of cellulose in the presence of lignin that causes the dissolved cellulose to rearrange into the same conformation upon recrystallisation. Thus, the crystallinity of cellulose remains relatively high if pretreatment was not efficient in lignin removal [71]. For lignocellulosic materials that contain relatively large amounts of lignin, higher temperature is required to change the structural crystallinity of cellulose I to cellulose II [59]. 
In addition to the ability of an IL to reduce $\mathrm{CrI}$ and lignin content, other factors such as the promotion of inter-crystalline swelling and reduction in fibre size may play an important role in determining the efficiency of an IL as a pre-treatment solvent for lignocellulosic biomass [58]. Although the disruption of the cellulose crystallinity is crucial to provide the biomass suitable for enzymatic digestion, lignin removal is even more critical for improving enzymatic hydrolysis of cellulose [72].

As mentioned above, the regenerated material is mainly composed by cellulose, since this macromolecule is not soluble in antisolvent. However, a $100 \%(w / w)$ regeneration of cellulose seems not to be possible. During the pre-treatment process cellulose might undergo degradation and form smaller components soluble in the IL [71]. Moreover, the regeneration process is dependent upon molecular weight, where the dissolved higher molecular weight and partially dissolved wood components in ILs are the first to precipitate [35]. The smallest molecular weights could not precipitate after antisolvent addition being dissolved in the liquid stream.

The choice of the antisolvent is also an important factor, which affects the yield of the regenerated wood. $\mathrm{Li}$ et al. studied the yield of regenerated wood with water and methanol as antisolvents [56]. They determined that the regeneration yield was found to be higher in water than in methanol due to the easiness and strength of the hydrogen bond formation between antisolvent and biomass fraction [56]. Indeed, polar protic solvents such as water, short-chain alcohols (methanol and ethanol) and even acetic acid are able to precipitate efficiently the dissolved material [35]. In the case of using the relatively polar chloroform as precipitating solvent, the efficiency of regeneration was found to be good. However, considering limitation such as obstacles in treating waste streams containing chlorinated solvents and environmental issues, hazardous chemicals should be avoided. Acetonitrile can also be used to precipitate biomass offering two advantages. The first benefit comes from its volatility and an easy removal from the IL. The second advantage corresponds to the brighter fractions obtained by precipitation that would allow for easier bleaching if required [35]. As previously mentioned the reconstituted material presents a gelatinous phase, thus it is hard to separate it from the viscous liquid after regeneration. Dibble et al. developed an antisolvent mixture with specific proportions of an alcohol (ethanol) and ketone (acetone) that provided the regeneration of solid precipitates with porous appearance and easily dispersed in the liquid with no gel formation [68]. A rapid separation was attained and a lower volume of antisolvent mixture was used in comparison with other antisolvent used. Mixtures of precipitating solvents can also be used in order to improve lignin extraction yields with simultaneous high regeneration yields of the carbohydrate fraction. Muhammad et al. suggested a mixture of acetone and water in 7:3 ratio that reached almost $100 \mathrm{wt} \%$ of lignin (indulin AT from Sigma Aldrich) solubility [42]. Wang et al. observed that addition of DMSO to water as a precipitating solvent mixture increased the cellulose content in the regenerated material in comparison with acetone/water mixture. Thus, DMSO was reported to have greater lignin extraction capacity than acetone [34].

\section{The process condition effects}

Specific interactions between ILs and biomass are known to be dependent on the IL, as well as on several conditions inherent to pre-treatment, such as temperature, time, type and particle size of biomass, solid/liquid ratio and water content. Major effects of these parameters in the biomass pre-treatment are described in the following sections, which contribute for a better understanding of pretreatment with ILs.

\section{Particle size}

The particle size of biomass sample is one of crucial issues in lignocellulosic pre-treatment because such a parameter directly impacts on the contact and diffusion of chemicals into the lignocellulosic materials [73,74].

Kilpelainen et al. concluded that dissolution of wood chips (size in excess of $5 \mathrm{~mm} \times 5 \mathrm{~mm} \times 1 \mathrm{~mm}$ ) at high temperatures in $[\mathrm{bmim}][\mathrm{Cl}]$ and $[\mathrm{amim}][\mathrm{Cl}]$ is complete [24]. Thus, smaller particles should be more suitable to be used in the IL pre-treatment process [24]. The increased surface area of the smaller particles and the increase of mechanical pulping to breakdown the internal structure are factors that improve the efficiency of biomass pre-treatment in ILs [25].

Different responses are observed when different particle sizes of biomass are used. Sun et al. determined the solubilities of different sized wood particles in [emim] $\left[\mathrm{CH}_{3} \mathrm{COO}\right]$ and [emim] $[\mathrm{Cl}]$ ILs [25]. The good dissolution efficiency of [emim] $\left[\mathrm{CH}_{3} \mathrm{COO}\right]$ was preserved despite of the increase in the particle size of wood from smaller than $0.125 \mathrm{~mm}$ ( $99 \%$ solubility) to $0.5-1 \mathrm{~mm}$ (93\% solubility). The different wood size solubilities were more pronounced for $[\mathrm{emim}][\mathrm{Cl}]$. At wood size smaller than $0.125 \mathrm{~mm}$ the dissolution reached $52.6 \%$ and with particles size of $0.25-0.5 \mathrm{~mm}$ only $26.0 \%$ of dissolution was achieved. This suggests that $[\mathrm{emim}]\left[\mathrm{CH}_{3} \mathrm{COO}\right]$ is more efficient and it would be much more economical to use since the energy needed to reduce the biomass particle size could be minimised [25]. Furthermore, Nguyen et al. investigated the influence of particle size using the same IL in the pre-treatment of rice straw [51]. The study was conducted with three size ranges, smaller than $2 \mathrm{~mm}, 2-5 \mathrm{~mm}$ and larger than $10 \mathrm{~mm}$ determining the cellulose recovery and glucose conversion 
yields after pre-treatment. The treatment with the finest particle size appears to have a considerable loss of cellulose content. Nevertheless, these samples showed the highest glucose conversion, but it was ineffective due to low cellulose content in the sample. The glucose conversion of the $2-5 \mathrm{~mm}$ particle-sized samples was significantly higher than that of $>10 \mathrm{~mm}$ particle-sized samples and similar to the value of lower than $2 \mathrm{~mm}$ particle-sized samples [51].

In a recent study, Bahcegul et al. proved that the ideal particle size of a certain biomass for pre-treatment might change depending on the type of the IL used [64]. Once again $[\mathrm{emim}]\left[\mathrm{CH}_{3} \mathrm{COO}\right]$ and $[\mathrm{emim}][\mathrm{Cl}]$ were used to compare the efficiency in the pre-treatment of cotton stalks in four different particle sizes $(<0.15 \mathrm{~mm}$, $0.15-0.5 \mathrm{~mm}, 0.5-1.0 \mathrm{~mm}$ and $1.0-2.0 \mathrm{~mm}$ ). They observed a decrease in the glucose yield for cotton stalks with the smallest particle size $(<0.15 \mathrm{~mm})$ in comparison with larger particle sizes after pre-treatment with [emim $]\left[\mathrm{CH}_{3} \mathrm{COO}\right]$. This could indicate that particle size of biomass in pre-treatment with $[\mathrm{emim}]\left[\mathrm{CH}_{3} \mathrm{COO}\right]$ might influence the amount of cellulose recovery. On the other hand, [emim] [Cl] works more efficiently with smaller biomass particle sizes in respect to glucose yield. This opposite trend is explained by the different dissolution rates of the tested ILs. The $[\mathrm{emim}]\left[\mathrm{CH}_{3} \mathrm{COO}\right]$ showed a faster dissolution rate for the smaller particle size allowing more extensive depolymerisation to lower molecular weight water soluble compounds. Therefore, a lower glucose yield was observed since part of cellulose was retained as soluble compounds in the liquid phase after biomass regeneration. After enzymatic hydrolysis, it was confirmed that different sizes of biomass could be ideal for different ILs [64]. Bahcegul et al. also evaluated the lignin extraction after pre-treating the referred size particles of cotton stalks [64]. For all tested particle sizes in the pre-treatment with $[\mathrm{emim}]\left[\mathrm{CH}_{3} \mathrm{COO}\right]$, less lignin content was determined for each pre-treated sample. However, the highest lignin contents were observed for larger biomass particle sizes $(0.5-1.0 \mathrm{~mm}$ and 1.0 $2.0 \mathrm{~mm}$ ). Therefore, it is clear that pre-treatment with [emim] $\left[\mathrm{CH}_{3} \mathrm{COO}\right]$ is more efficient using smaller particle sizes. The same observation was not found in pretreatment with $[\mathrm{emim}][\mathrm{Cl}]$, since cotton stalk samples with different particle sizes had similar lignin content after pre-treatment [64].

The crystalline structure presented by cellulose after pre-treatment is also correlated with the biomass particle size used. As referred above, transformation from cellulose I to cellulose II could be observed using [emim] $\left[\mathrm{CH}_{3} \mathrm{COO}\right]$. In the pre-treatment of cotton stalk with this IL, Bahcegul et al. demonstrated by XRD analysis that this phenomenon could only be observed for the smallest particle size studied $(<0.15 \mathrm{~mm})$ [64].
Therefore, it can be inferred that smaller particle sizes are more appropriate to obtain pre-treated samples with higher enzymatic digestibility.

The pre-treatment efficiency is improved using small particle sizes of biomass. However, size reduction of biomass for a pre-treatment process is questionable to achieve sustainability due to inherent high costs. Notwithstanding, ILs such as $[\mathrm{emim}]\left[\mathrm{CH}_{3} \mathrm{COO}\right]$ seem to preserve the pre-treatment efficiency for larger particles indicating the possibility to reduce the energy demand on the grinding stage of biomass. Viell et al. studied the disintegration and dissolution kinetics of different particle sizes of beech and spruce wood in [emim] $\left[\mathrm{CH}_{3} \mathrm{COO}\right]$ [29]. They concluded that the dissolution is size-independent. They discovered that $[\mathrm{emim}]\left[\mathrm{CH}_{3} \mathrm{COO}\right]$ provided a quick swelling and disintegration of wood tissue. Consequently, this phenomenon creates a large specific surface area which is favourable for the processing of larger wood chips. Beech wood was dissolved more effectively and even larger wood chips of $10 \mathrm{~mm}$ length practically exhibited the same dissolution kinetics as particles with lower length [29].

\section{Temperature effect}

Generally, the temperature increase accelerates swelling and dissolution rates of lignocellulose in ILs $[25,26,34,40]$. This phenomenon is possible due to destabilisation effect of temperature on the hydrogen bonds in the threedimensional cellulose structure [26]. By decreasing temperature, longer times are required for an efficient swelling and dissolution of biomass [75]. Wang et al. described some physical aspects of wood chips dissolution in [amim] $[\mathrm{Cl}]$ using a hot stage polarizing microscope [34]. Below $50^{\circ} \mathrm{C}$ the wood samples had the same fibrous structure as its original state. The beginning of the swelling was noticed at $70^{\circ} \mathrm{C}$ and the dissolution occurred at $100^{\circ} \mathrm{C}$. The dissolution rate increased at $120^{\circ} \mathrm{C}$ and most of the fibrous structure disappeared after only 10 minutes at this temperature resulting in a slightly dark mixture. After 30 minutes at $120^{\circ} \mathrm{C}$ no further changes were detected, and within a period of 4 hours, a fully black field observed indicated only a partial dissolution of the wood chips in [amim] [Cl] [34]. Due to the importance of the reduction of the moisture in the mixture to enhance the pretreatment process, temperatures above $100^{\circ} \mathrm{C}$ are generally used. Muhammad et al. dissolved bamboo biomass in the [emim][Gly] IL containing $4.56 \mathrm{wt} \%$ of water, during 6 hours at $120^{\circ} \mathrm{C}$ [42]. It was observed that the water content decreased to $0.75 \mathrm{wt} \%$ after 350 minutes of heating facilitated the dissolution process of the bamboo biomass. The reduction of IL viscosity by increasing the temperature is also a factor favouring the swelling of lignocellulose particles and the mixing during the pre-treatment process [43,71]. Indeed, the physico-chemical properties 
of the IL, such as viscosity and melting point, are temperature dependent and govern conditions of the pretreatment process in ILs. The $[\mathrm{amim}][\mathrm{Cl}]$ as low viscosity IL can be used at lower temperatures. On the other hand, ILs with aromatic side chains such as [benzylmim][Cl] require somewhat higher temperatures due to a high melting point and higher viscosity $[24,26]$.

After dissolution the biomass regeneration is also affected by temperature. In fact, some studies showed higher regeneration yields at higher temperatures $[43,76]$. This is opposite to the statement that higher temperatures led to the compound degradation and consequently minor regeneration yields were obtained $[34,41,71]$. This controversy is explained by the different morphologies and compositions of the biomass used, which in turn present different responses to the temperature increase. A treatment of pine, using [amim] [Cl] between $90^{\circ} \mathrm{C}$ and $120^{\circ} \mathrm{C}$, showed the highest regeneration rate at $120^{\circ} \mathrm{C}$, but at the same temperature no regeneration product was obtained after catalpa treatment indicating the occurrence of biomass degradation [34]. Furthermore, pine was treated at $140^{\circ} \mathrm{C}$ and most of the dissolved biomass underwent degradation, similar to catalpa at $120^{\circ} \mathrm{C}$ [34]. However, without using much higher temperatures that cause biomass degradation, the complete dissolution in ILs might not be possible [35]. Thus, the temperature applied in pre-treatment is dependent on the biomass and should be adjusted to an optimal condition of pre-treatment.

A study with sugarcane bagasse treated with [bmim] $[\mathrm{Cl}]$ at different temperatures $\left(110-160^{\circ} \mathrm{C}\right)$ showed that below $150^{\circ} \mathrm{C}$ the crystallinity of cellulose-rich regenerated product is slightly lower than that of the original material [76]. In all tested experiments no complete dissolution was observed. However, temperatures above $150^{\circ} \mathrm{C}$ demonstrated to reduce significantly the crystallinity and to increase the saccharification rate and extent. Therefore, complete dissolution might not be required to maximize saccharification efficiency at temperatures above $150^{\circ} \mathrm{C}$ [76].

The increase in temperature from $60^{\circ} \mathrm{C}$ to $120^{\circ} \mathrm{C}$ for 2 hour pre-treatments of sugarcane bagasse with [emim] $\left[\mathrm{CH}_{3} \mathrm{COO}\right]$ resulted in a water-soluble product that revealed a 10-fold magnitude extraction yield from the original biomass and a 2 -fold glucose yield in the enzymatic hydrolysis of regenerated bagasse [69]. However, the xylose yield decreased as temperature increased from 100 to $120^{\circ} \mathrm{C}$ indicating hemicellulose degradation in low-molecular weight compounds extracted to the liquid phase [69]. Arora et al. used the temperature from 110 to $160^{\circ} \mathrm{C}$ for a 3 -hour pre-treatment of switchgrass using the same IL [67]. The obtained sugar yields increased with temperature allowing to achieve the best saccharide yield at $160^{\circ} \mathrm{C}, 12$ times higher than that observed at $110^{\circ} \mathrm{C}$. Hemicellulose was the most significant compound released from the pre-treatment process [67]. It seems that higher temperatures expedite an autocatalytic process of hemicellulose which is accelerated for temperatures above $100^{\circ} \mathrm{C}$ [71], although this process is very dependent on the biomass and the IL used. On the other hand, Labbé et al. described that at high temperatures, [emim] $\left[\mathrm{CH}_{3} \mathrm{COO}\right]$ is capable to cleave the acetyl groups covalently attached mostly to the hemicellulose component of yellow poplar [77]. Therefore, at higher temperature ILs could effectively disrupt the carbohydrate-lignin linkages releasing hemicellulose.

High temperatures were also beneficial for lignin extraction in ILs. Tan et al. observed an improved delignification of sugarcane bagasse using alkylbenzenesulphonate IL ([emim] $[\mathrm{ABS}]$ ) with increasing temperature from $170^{\circ} \mathrm{C}$ to $190^{\circ} \mathrm{C}$ [78]. The same trend was also confirmed in wood flour and triticale straw using $[\mathrm{emim}]\left[\mathrm{CH}_{3} \mathrm{COO}\right]$ $[28,79]$. It is assumed that the most efficient delignification temperature is strongly related to the average glass transition temperature of $165^{\circ} \mathrm{C}$ for a given lignin polymer [80]. However, that temperature is dictated by the chemical composition of lignin (monolignol composition and concentrations) and varies significantly between the different types of lignocellulosic biomass [67]. In the pre-treatment process at higher temperatures, lignin is susceptible to self-condensation reactions. The condensation of lignin is accompanied by an increase in molecular weight, which results in precipitation during the process and subsequently lignin is recovered in the regenerated material. Moreover, inhibition of lignin dissolution after condensation is another issue that contribute to the higher percentage of lignin recovered in the regenerated material $[81,82]$. Nevertheless, if higher temperatures were complemented with long dissolution times, the condensed lignin could start to decompose and subsequently dissolve [83].

Indeed, higher temperatures aid in improving the pretreatment efficiency, but at the same time results in more degradation of carbohydrates and ILs themselves, as well as in modification of lignin properties. Moreover, the higher energy demand when using elevated temperatures is a drawback for sustainable and economic processes. Therefore, the choice of temperature for the pre-treatment process must be considered and optimised depending upon the biomass and IL used.

\section{Reaction time effect}

The pre-treatment duration time is related to the applied temperature in order to accomplish an efficient pretreatment. It can be assumed that good results are expected with a simultaneous short duration of time and high temperatures or using prolonged treatments at relatively low temperatures. Yoon et al. pre-treated the sugarcane bagasse with $[\mathrm{emim}]\left[\mathrm{CH}_{3} \mathrm{COO}\right]$ and proposed a 
model based on Response Surface Methodology (RSM) to predict the reducing sugar yield by changing temperature, time and biomass loading [43]. An improvement in reducing sugar yield at longer pretreatment at lower temperature $\left(120^{\circ} \mathrm{C}\right)$ was noticed. However, prolonged pre-treatment could lead to decrease in reducing sugar yield under higher temperatures (more than $135^{\circ} \mathrm{C}$ ), explained by a depolymerisation process of the biomass components [43]. Sun et al. observed that complete dissolution of southern yellow pine and red oak in $[\mathrm{emim}]\left[\mathrm{CH}_{3} \mathrm{COO}\right]$ at $110^{\circ} \mathrm{C}$ was achieved after 46 and 25 hours, respectively [25]. However, the improved dissolution capacity provided by a longer pretreatment time is inevitably accompanied by some degradation of either the dissolved biopolymers or the $\mathrm{IL}$ $[25,67]$. After ultrasonic pre-treatment of kenaf powder with [emim] $\left[\mathrm{CH}_{3} \mathrm{COO}\right]$ at $110^{\circ} \mathrm{C}$, the hemicellulose content decreases in the regenerated biomass to $6 \mathrm{wt} \%$ after 120 minutes [50]. The reduced biomass recovery was attributed to partial hydrolysis of hemicellulose. Therefore, not only compound degradation occurs, but also the hydrolysis of hemicellulose to reducing sugars that are then lost in the washing stream [50]. Nguyen et al. demonstrated that an increase in the solubility time of rice straw in $[\mathrm{emim}]\left[\mathrm{CH}_{3} \mathrm{COO}\right]$ caused a higher cellulose recovery, at least after 24 hours [51]. However, after 48 hours of pre-treatment, the regenerated particles were difficult to collect due to long time applied to profoundly break down cellulose chains from rice straw into soluble oligosaccharides. There was no regeneration in amorphous cellulose form, thus decreased cellulose recovery was observed [51]. In fact, the mean molecular weight of dissolved compounds was found to decrease as the treatment time was extended [84], thus the compound regeneration was more difficult. Pre-treatment of sugarcane bagasse with [emim] $\left[\mathrm{CH}_{3} \mathrm{COO}\right]$ tends to form a coagulate at higher temperatures for a prolonged duration time. This leads to a difficult regeneration of the dissolved sugarcane bagasse from the coagulate [43]. Significant amount of residual [emim] $\left[\mathrm{CH}_{3} \mathrm{COO}\right]$ could be imprisoned in the coagulate, which might cause cellulase inactivation and consequently lead to a decrease in reducing sugar yield [85]. Furthermore, when higher temperatures are applied in biomass pre-treatment for elevated periods of processing, cellulose degradation is more pronounced [71,86]. Thus, shorter retention times are recommended when high temperatures used, although this must be balanced with the IL stability and potential side reactions [40]. Tan et al. demonstrated that, for a shorter pre-treatment time, the glucose recovery yield increased almost linearly from $26.2 \%$ to $96.7 \%$ as the temperature increased from 60 to $100^{\circ} \mathrm{C}$ by pretreating oil palm frond with [bmim][Cl] [86]. Nevertheless, $[\mathrm{emim}]\left[\mathrm{CH}_{3} \mathrm{COO}\right]$ demonstrates more efficiency in disrupting the lignocellulosic structure in a shorter period of time, since it has a faster diffusion rate resulting in higher glucose recovery yields [64]. The crystallinity degree of cellulose-rich material after regeneration was also found to decrease to an amorphous state as pre-treatment time increased [69].

Long pre-treatment times were reported to favour lignin extraction [66,71,78]. The diffusion of IL into the biomass is improved and aids the dissolution and extraction of lignin from biomass [71]. Lee et al. presented a pre-treatment of wood flour with $[\mathrm{emim}]\left[\mathrm{CH}_{3} \mathrm{COO}\right]$ with varying time from 0.5 to 70 hours at $90^{\circ} \mathrm{C}$ [28]. Around $40 \%$ of the lignin was extracted from wood flour within 5 hours and more than $85 \%$ was extracted after 70 hours providing a cellulose-rich regenerated material with only $3.2 \%$ of lignin content for the last pretreatment [28]. The same IL and temperature were applied in pre-treatment of triticale straw resulting in $21.1 \%$ of lignin extraction within 5 hours. An increase of lignin extraction yield up to $30.3 \%$ was noticed after 24 hours of treatment [79]. The results from both studies allow indicate that the lignin extraction is improved as the pre-treatment time increases. However, the time required could be different regarding the biomass used. Viell et al. observed the effect of longer dissolution time as more pronounced for beech wood than for spruce wood after pre-treatment with $[\mathrm{emim}]\left[\mathrm{CH}_{3} \mathrm{COO}\right]$ [29]. This corresponded not only to a better dissolution rate of beech wood, but also to a higher lignin recovery [29].

\section{Biomass type and concentration}

The degree of biomass recalcitrance varies as a function of the biomass itself (i.e., grass, softwood, and hardwood), and is influenced by inherent variations in terms of age, harvest method, extent of drying and storage conditions [62]. Furthermore, the lignocellulosic biomass comprises different chemical and physical characteristics, such as composition of cellulose, hemicellulose and lignin, accessible surface area, crystallinity, degree of polymerisation, and others [41]. All of these features affect the pre-treatment efficiency, thus special attention is recommended to the type and concentration of biomass in the pre-treatment with ILs.

Generally, softwood demonstrates lower density than hardwood leading to much facile solubility in ILs [24]. Pre-treatment of pine, poplar, Chinese parasol and catalpa wood chips with $[\mathrm{amim}][\mathrm{Cl}]$ showed that pine was highly effective for pre-treatment providing high cellulose extraction yields, good dissolution and regeneration of pre-treated biomass. Furthermore, Li et al. compared the pre-treatment of three different biomass (southern pine, Norway spruce thermochemical powder and Eucalyptus grandis) with $[\mathrm{amim}][\mathrm{Cl}]$. They concluded that under the same conditions the efficiency decreased in the 
following sequence: southern pine > Norway spruce thermochemical powder $>$ Eucalyptus grandis [56]. The higher density of Eucalyptus grandis leads to a more difficult access of ILs reducing the pre-treatment efficiency [56]. Therefore, biomass species of lower density are desirable. Thus for higher density biomass, more energy input is required by increasing the temperature and time of the process. However, Sun et al. found that red oak (hardwood) had a slightly higher dissolution in [emim $]\left[\mathrm{CH}_{3} \mathrm{COO}\right]$ than southern yellow pine (softwood) [25]. This result can be associated with higher lignin content in softwoods, which influences the dissolution, as well as variations in the lignin-carbohydrate interactions, lignin distribution or lignin structure in hardwoods and softwoods [25]. The different results are affected by the use of [emim] $\left[\mathrm{CH}_{3} \mathrm{COO}\right]$ instead of $[\mathrm{amim}][\mathrm{Cl}]$ highlighting that the different properties of each IL can lead to different pre-treatment approaches regarding the nature of the biomass used.

The solid/liquid ratio (concentration of biomass) has an influence on the dissolution capacity of ILs, regeneration efficiency, enzymatic accessibility to biomass, glucose recovery and even on the conditions applied on pre-treatment process. Sun et al. studied a 4 to $10 \%$ $(\mathrm{w} / \mathrm{w})$ of wood load in $[\mathrm{emim}]\left[\mathrm{CH}_{3} \mathrm{COO}\right]$ at $110^{\circ} \mathrm{C}$ for 16 hours and thus found an optimum concentration of $5 \%(w / w)$ [25]. It was demonstrated that as the initial wood load increases, a lower percentage of the added wood is dissolved [25]. In fact, low concentrations of biomass favour the dispersion of molecules in solution and lead to high dissolution and regeneration rates. Wang et al. reported a decreasing trend in the dissolution amount from 35 to $26 \%$ when 1 and $5 \mathrm{wt} \%$ of initial wood load in [amim] [Cl] were tested, albeit a similar decrease was also observed for the same experiments [34]. The enzymatic accessibility of recovered cellulose could be also affected by high solid/liquid ratio. Furthermore, a higher solid loading can result in problems with agitation of the mixture and cause heat and mass transfer limitations in the mixture as well as a significantly decrease in the IL accessibility to the biomass $[71,86]$. These results show that pre-treatment in ILs could have limitations with respect to the wood load capacity necessary to reach an efficient process. However, Tan et al. demonstrated that a high solid loading could improve the pre-treatment efficiency [71]. This can be explained by more frequent contact and collision between the biomass particles due to mixing at higher concentrations in viscous ILs that promotes cellulose dissolution. Yoon et al. optimise the conditions for the pre-treatment of sugarcane bagasse in [emim] $\left[\mathrm{CH}_{3} \mathrm{COO}\right]$ [43]. For this, the proposed optimal conditions were $145^{\circ} \mathrm{C}$ for $15 \mathrm{mi}$ nutes with a biomass loading of $14 \mathrm{wt} \%$. They demonstrated a glucose recovery dependence on the overall heat transfer in the mixture enhanced by frequent collision of biomass particles [86]. Under higher biomass concentrations, the chemical equilibrium of the reaction might favour the cellulose dissolution at a higher temperature improving the glucose recovery [43]. Wu et al. accomplished relatively good efficiency in the pretreatment of corn stover, maple wood flour, poplar and switchgrass with $[\mathrm{emim}]\left[\mathrm{CH}_{3} \mathrm{COO}\right]$ using solid/liquid ratio of $33 \%(\mathrm{w} / \mathrm{w})$ [41]. They described that, at this specific biomass loading, the molar ratio of [emim] $\left[\mathrm{CH}_{3} \mathrm{COO}\right]$ to glucose in cellulose $(6: 1)$ is comparable to the possible number of hydrogen bonds (acceptor and donor) for each glucose unit in cellulose. With this stoichiometry there are enough $\left[\mathrm{CH}_{3} \mathrm{COO}\right]$ anions to interact with the hydroxyl groups of each glucose unit and to disrupt effectively the crystalline structure of cellulose during the pre-treatment process. If the biomass concentration was higher, the crystalline disrupting of cellulose would be incomplete and thus the efficiency of the pretreatment could decrease [41]. When the concentration of biomass compromises the pre-treatment efficiency due to a high viscosity of the moiety, ultrasound irradiation seems advisable to be used. Such a solution is intended to improve the diffusion of ILs into the biomass to attain an efficient disruption [50].

Notwithstanding, the increase of biomass concentration in ILs is a challenging task for process intensification (to reduce the energy demand, as well as the size of the equipment) therefore the pre-treatment process optimisation is needed.

\section{Water presence influence}

In the dissolution process, careful attention to water content should be considered originated either from the IL or from the natural biomass moisture. The water content in ILs (above $1 \mathrm{wt} \%$ ) was found to reduce the solubility of cellulose [19]. Less than 1 wt\% water content is reliable for efficient cellulose dissolutions by ILs. Water concentration higher than that provides enough water molecules to compete with IL anions to form hydrogen bonds with cellulose thus promoting only partial dissolution of lignocellulosic biomass $[19,24]$. In the case of using chloride-based ILs, the presence of water should be more restrictive to not coordinate with chloride ions [48]. However, a certain amount of water seems to be necessary to promote lignin dissolution in $[\mathrm{bmim}][\mathrm{Cl}]$ [40]. On the other hand, the presence of water in the acetate-based ILs reduces their hydrogen bond acceptor capability thus compromising the dissolution efficiency [58]. Therefore, ILs should be dried prior performing biomass pre-treatment. If the biomass used is air-dried, a greater amount of water content would be introduced into the dissolution process thus decreasing the solvent capacity of ILs and subsequently the pre-treatment 
efficiency [40,87]. For dried biomass a rigorous drying process should be applied, which is demanding in cost and energy.

\section{The pre-treatment of biomass}

The subject of the biomass processing using ILs is very recent. The pre-treatment with ILs enables one to: (i) alter the physicochemical properties of the biomass macromolecular components; (ii) extract a specific macromolecular component that is provided by the property of ILs; and (iii) perform different fractionation approaches after biomass dissolution in ILs. Main conditions and results of biomass pre-treatments in ILs are compiled in Tables 1, 2 and Additional file 1: Table S1. The pre-treatment is dependent on the IL, lignocellulosic biomass (type, moisture, size and load), temperature, time of pre-treatment and precipitating solvent used. In this section the advances of the IL pre-treatment technology are intended to be described in detail including a positive impact on the maximal exploitation of lignocellulosic biomass concerning the biorefinery concept. The
Figure 3 depicts the pre-treatment of biomass using ILs, the further fractionation and downstream processes.

Until now, [emim] $\left[\mathrm{CH}_{3} \mathrm{COO}\right]$ seems to be the most suitable IL for the pre-treatment of lignocellulosic biomass, since it possesses good solvent power for these materials and hence it is also referred to in the most studies of this research field. Several studies were performed focused on the evaluation of the pre-treatment behaviour of different hardwood and softwood species with $[\mathrm{emim}]\left[\mathrm{CH}_{3} \mathrm{COO}\right][25,28,29,32,58,88]$. Sun et al. performed a $5 \%(\mathrm{w} / \mathrm{w})$ dissolution of southern yellow pine in [emim] $\left[\mathrm{CH}_{3} \mathrm{COO}\right]\left(110^{\circ} \mathrm{C}, 16\right.$ hours $)$ and approximately $59 \%$ of the original carbohydrates was recovered in the regenerated material after adding an acetone/water mixture as the antisolvent [25]. Additionally, around $31 \%$ of the original lignin was obtained in free form and $38 \%$ linked to carbohydrates as part of the reconstituted wood, leading to a lignin reduction of 26.1\%. The same treatment was also performed for red oak with a $34.9 \%$ reduction of lignin was reached. Hence, the regenerated materials contained less lignin

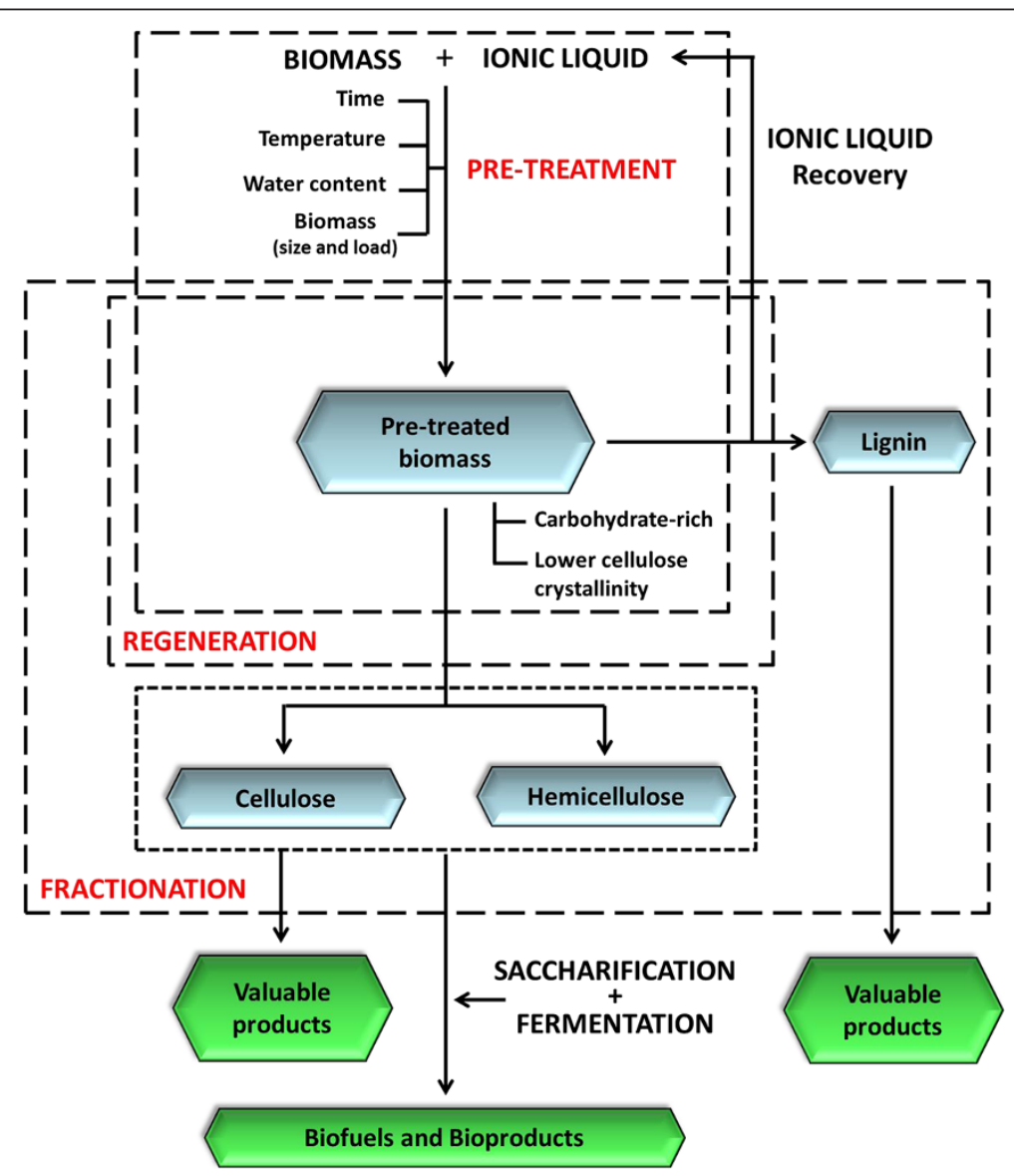

Figure 3 Schematic representation of the pre-treatment of biomass using ILs and further regeneration and fractionation into cellulose, hemicellulose and lignin. Saccharification and fermentation processes can be integrated to produce biofuels and bioproducts from cellulose and hemicellulose. Valuable products can also be generated by processing cellulose, hemicellulose and lignin fractions within the biorefinery process. 
than the original wood, with a fairly good delignification at relatively low temperature reported. However, significant losses of carbohydrates and lignin during the fractionation process were observed. In the case of pine pre-treatment, total losses of $41 \%$ and $31 \%$ of the original carbohydrates and lignin were calculated, respectively [25]. Lee et al. extracted approximately $63 \%$ of the initial lignin from the wood flour, at $130^{\circ} \mathrm{C}$ after 90 minutes of treatment using the same IL [28]. However, they also extracted $16 \%$ of the cellulose and $26 \%$ of the xylan from the initial wood flour content. Therefore, the process showed significant delignification with small losses of carbohydrates after the pre-treatment [28]. In a different study, by the temperature decrease to $90^{\circ} \mathrm{C}$ and the time of pre-treatment increase to 24 hours for the same biomass loading, nearly $50 \%$ of the lignin was extracted from the initial wood flour sample [58]. Such a result confirms a great effect of the applied conditions (temperature and time) in the pre-treatment of lignocellulosic biomass. Torr et al. evaluated the pre-treatment of compression pine wood (Pinus radiata) at $120^{\circ} \mathrm{C}$ and $155^{\circ} \mathrm{C}$ for 3 hours [30]. When water was used as the antisolvent, no lignin extraction was observed. These findings were the opposite to those found earlier by Sun et al. [25]. The authors justified different results as a consequence of the antisolvent used. The reported pretreatment removed mainly hemicelluloses for both tested temperatures leading to the recovery of a pre-treated material with high cellulose and lignin contents. With an extensive study of the pre-treated biomass using HSQC NMR technique, Torr et al. verified the existence of deacetylation of hemicellulose, possible depolymerisation of polysaccharides, loss of lignin ether linkages and formation of lignin condensation products [30].

Pine, poplar, Chinese parasol and catalpa wood powders were pre-treated using a solvent mixture of [amim] $[\mathrm{Cl}] / \mathrm{DMSO}$ at the optimised conditions of $110^{\circ} \mathrm{C}$ for 2 hours and a 3 wt\% wood concentration under microwave irradiation [34]. In each sample, wood chip/IL suspension was prepared by the addition of $16 \mathrm{wt} \% \mathrm{DMSO}$ to reduce the viscosity of the mixture and facilitate filtration in biomass processing. The addition of DMSO had no obvious impact on the solubility of the wood chips in the IL. Better results were reported for pine pre-treatment, in which more regenerated material was obtained (56\%) and the cellulose content reached $85 \%$, being nearly $20 \%$ higher than that in the regenerated poplar, Chinese parasol and catalpa chips [34]. This result is explained by a higher solubility of pine wood in [amim $][\mathrm{Cl}]$ that provided the best performance in the pre-treatment. The original pine wood was composed of $49 \%$ cellulose and the extraction rate of this pretreatment could reach $62 \%$ of the total cellulose. After pre-treatment, a $14 \%$ loss of the original wood was registered. Wang et al. described that biomass loss occurs from water-soluble low molecular matter that results from degradation of wood, washing and filtration steps during the process [34]. Vo et al. also reported a pre-treatment of poplar wood (5 wt\%), but with [emim] $\left[\mathrm{CH}_{3} \mathrm{COO}\right]$ at $130^{\circ} \mathrm{C}$ for 12 hours, achieving a decrease of a $30 \%$ lignin content of pre-treated biomass relative to the original content [32]. Other pre-treatments with woods including poplar, oak, fir and acacia were performed with $[\mathrm{emim}]\left[\mathrm{CH}_{3} \mathrm{COO}\right]$, emim] $\left[\mathrm{COOCF}_{3}\right]$, [emim $]\left[\mathrm{BF}_{4}\right]$ and $[\mathrm{bmim}]\left[\mathrm{PF}_{6}\right]$ ILs at $90^{\circ} \mathrm{C}$ for 24 hours with $2 \%(\mathrm{w} / \mathrm{w})$ solid/liquid ratio [88]. The work of Vo et al. demonstrates that $[\mathrm{emim}]\left[\mathrm{CH}_{3} \mathrm{COO}\right]$ had the best performance, since the total carbohydrates of the pretreated biomass were completely hydrolysed by cellulase [88]. The compiled data of pre-treatments using wood biomass, namely softwood and hardwood are presented in Tables 1 and 2, correspondingly.

Arora et al. showed that a 3-hour pre-treatment of switchgrass at $160^{\circ} \mathrm{C}$ with [emim] $\left[\mathrm{CH}_{3} \mathrm{COO}\right]$ resulted in delignification of $73.5 \%$ [67]. The regenerated solid is comprised of $31 \%$ glucan $(80 \%$ of the original glucan from switchgrass) with $8 \%$ glucan $(20.5 \%$ of original glucan concentration in switchgrass) in the liquid fraction. In contrast, the majority of the xylan (19\%) ended up in the liquid stream, which was $73 \%$ of the original xylan concentration of switchgrass. This means that the depolymerisation of xylan occurred and by HPAEC analysis, it was concluded that depolymerisation resulted in the formation of oligosaccharides instead of monosaccharides. Only 5\% of lignin in the regenerated solid was detected [67]. Therefore, as stated previously, in the presence of IL, higher temperature favours hemicellulose hydrolysis when using $[\mathrm{emim}]\left[\mathrm{CH}_{3} \mathrm{COO}\right]$ in the pretreatment. Using the same biomass (from the same origin) and IL, as well as the same conditions of pre-treatment, Li et al. [62] showed different results. The pre-treatment process partially removed lignin and hemicellulose from the original switchgrass and produced a regenerated material composed by $67.7 \%$ glucan, $13.6 \%$ lignin and $7.6 \%$ xylan content. The lignin extraction achieved $69.2 \%$ of total lignin removal including $12.0 \%$ of acid soluble lignin and 57.2\% of Klason lignin [62]. Much better results were obtained by Arora et al. [67] They were explained by a prior to and extended pre-extraction of switchgrass using ethanol comparing to those performed by $\mathrm{Li}$ et al. [62] When switchgrass was pre-treated with $\left[\mathrm{Me}(\mathrm{OEt})_{3}\right.$ $\left.\mathrm{Et}_{3} \mathrm{~N}\right]\left[\mathrm{CH}_{3} \mathrm{COO}\right]$ at $110^{\circ} \mathrm{C}$ for 15 minutes, the content of Klason lignin in the regenerated material was reduced to $24 \mathrm{wt} \%$ from the initial value of $34 \mathrm{wt} \%$ [89]. Although $\left[\mathrm{Me}(\mathrm{OEt})_{3} \mathrm{Et}_{3} \mathrm{~N}\right]\left[\mathrm{CH}_{3} \mathrm{COO}\right]$ presented an improved solubility of alkali lignin as compared to [emim] $\left[\mathrm{CH}_{3} \mathrm{COO}\right]$ [89], the bulky cation $\left[\mathrm{Me}(\mathrm{OEt})_{3} \mathrm{Et}{ }_{3} \mathrm{~N}\right]$ was demonstrated to have lower efficiency in the switchgrass 
pre-treatment in comparison with the smaller [emim] cation.

The pre-treatment of crop residues were also performed using different ILs. The [emim] $\left[\mathrm{CH}_{3} \mathrm{COO}\right]$ was suitable for a 48 -hour pre-treatment of rice straw providing $82 \%$ of cellulose recovery with subsequently $88 \%$ conversion to glucose after $130^{\circ} \mathrm{C}$ [51]. The same biomass was treated for 5 hours at $120^{\circ} \mathrm{C}$ with [bmim] $\left[\mathrm{CH}_{3} \mathrm{COO}\right]$ and lignin content was reduced by $8.2 \%$. Xylan content was also decreased from $21.7 \%$ for untreated rice straw to $15.1 \%$ for the pre-treated biomass [90]. Rice straw was pre-treated using the amino acid-based IL namely, [Ch][Lys], [Ch][Gly], [Ch][Ala], [Ch][Ser], [Ch] [Thr], [Ch][Met], [Ch][Pro] and [Ch][Phe] [66]. In all cases, the content of cellulose increased from $37.7 \%$ in the original biomass to $48-62 \%$ after pre-treatment and the content of acid-insoluble lignin decreased from $16.9 \%$ of original lignin content to $10-12 \%$ in the regenerated material (depending on the IL used). A strong correlation between enzyme performance and delignification of rice straw was observed. A total of $94 \%$ and $65 \%$ cellulose and xylan digestibility, respectively, were obtained after pre-treatment with [Ch][Lys], [Ch][Gly], [Ch][Ala], and [Ch][Met] that were the most efficient in lignin extraction $(>55 \%)$ [66]. Cotton stalk was subjected to pre-treatments with several ionic liquids such as $[\mathrm{HEA}][\mathrm{HCOO}],[\mathrm{amim}][\mathrm{Cl}],[\mathrm{bmim}][\mathrm{Cl}],[\mathrm{emim}][\mathrm{Cl}]$ and [emim] $\left[\mathrm{CH}_{3} \mathrm{COO}\right]$. The extracted lignin ranged between $31 \%$ and $46 \%$, where maximum removal yields were obtained for pre-treatments with $[\mathrm{emim}]\left[\mathrm{CH}_{3} \mathrm{COO}\right]$ and [amim] $[\mathrm{Cl}]$, determined to be $45 \%$ and $46 \%$, respectively [63]. Kenaf pre-treatment was additionally performed with five types of ILs, such as $[\mathrm{amim}][\mathrm{Cl}],[\mathrm{bmim}][\mathrm{Cl}]$, [emim][Cl], [emim][DEP] and [emim] $\left[\mathrm{CH}_{3} \mathrm{COO}\right]$ [50]. The cellulose saccharification ratio was about $20 \%$ for kenaf powders pre-treated in $[\mathrm{amim}][\mathrm{Cl}],[\mathrm{bmim}][\mathrm{Cl}]$, $[\mathrm{emim}][\mathrm{Cl}]$ and $[\mathrm{emim}][\mathrm{DEP}]$ by conventional heating at $110^{\circ} \mathrm{C}$ for 2 hours. The glucose yield was further increased when ultrasonic radiation was used for the same ILs with a $60-95 \%$ glucose yield after 120 minutes at only $25^{\circ} \mathrm{C}$. The cellulose saccharification ratio of kenaf powder in [emim] $\left[\mathrm{CH}_{3} \mathrm{COO}\right]$ was $86 \%$ after 15 minutes of ultrasonic pre-treatment at $25^{\circ} \mathrm{C}$, compared to only $47 \%$ in the case of the thermal pre-treatment in the same IL. However, it seems that the ultrasonic pretreatment leads to a higher loss material in the liquid phase than for the conventional oil heating pretreatment [50]. Wu et al. reported a $33 \%(\mathrm{w} / \mathrm{w})$ loading of corn stover pre-treated with $[\mathrm{emim}]\left[\mathrm{CH}_{3} \mathrm{COO}\right]$ as an efficient pre-treatment, in terms of the biomass loading, since it removed $15 \%$ of the total lignin from the original biomass [41]. The best result was obtained by a pretreatment with a biomass loading of $4.8 \%$ at $125^{\circ} \mathrm{C}$ for 1 hour giving a lignin extraction of $43.5 \%$. The regenerated material was determined to compose a 63.4\% carbohydrate and still remained 13.3\% lignin [41]. At $130^{\circ} \mathrm{C}$ wheat straw was pre-treated with [emim] [DEP] $(4 \% \mathrm{w} / \mathrm{w})$ resulting in a porous and amorphous regenerated material, with only $54.8 \%$ of reducing sugar yield attained possibly due to only a 30-minute pretreatment process [91]. The dissolution of sugarcane bagasse in $[\mathrm{bmim}][\mathrm{Cl}]$ at high temperatures, such as $140^{\circ} \mathrm{C}$ and $150^{\circ} \mathrm{C}$, was reported to be incomplete [76]. The undissolved material was first separated before regeneration of the dissolved material, the composition of which was practically the same as that of the original biomass. The results showed a composition of a regenerated material (without undissolved biomass) of $77 \%$ cellulose at $140^{\circ} \mathrm{C}$ and $82 \%$ at $150^{\circ} \mathrm{C}$. The lignin and hemicellulose content proportionally decreased as the temperature increased. At $150^{\circ} \mathrm{C}$, the lower lignin and hemicellulose content of the regenerated material can be attributed to both preferential dissolution of cellulose and to an increased degradation of hemicellulose and lignin during the pre-treatment process. The pre-treatment efficiency was then evaluated by enzymatic hydrolysis and the best results were obtained for a pre-treatment at $150^{\circ} \mathrm{C}$ for 90 minutes [76]. Sant'Ana da Silva et al. demonstrated that only a 30 -minute sugarcane pre-treatment at $120^{\circ} \mathrm{C}$ with $[\mathrm{emim}]\left[\mathrm{CH}_{3} \mathrm{COO}\right]$ gave a regenerated biomass very susceptible for saccharification [69]. Yields above 95\% and $76 \%$ of glucose and xylose were achieved, respectively. The [emim] $\left[\mathrm{CH}_{3} \mathrm{COO}\right]$ IL was mixed with energy cane bagasse at a 20:1 ratio [92]. It was observed that $15.1 \%$ of the total mass was lost during pre-treatment with IL and $52.6 \%$ of the loss was attributed to lignin removal. Composition of analysis revealed that $32.1 \%$ of the initial lignin was removed in IL-treated energy cane samples. Specifically, $41.7 \%$ of the initial acid insoluble lignin was removed from energy cane. The loss of glucan in IL-treated samples was less than $9 \%$ and cellulose digestibility of pre-treated sample at 24 hours was approximately 25 and 22 times higher than untreated and water-treated samples, respectively. The hemicellulose digestibility followed the same trend as that observed for cellulose [92]. Tan et al. used oil palm frond that was pre-treated with $[\mathrm{bmim}][\mathrm{Cl}]$ at different pre-treatment conditions [86]. The pre-treatment variables studied were temperature, time and solid loading. Under the pre-treatment conditions of $4 \mathrm{wt} \%$ solid loading at $100^{\circ} \mathrm{C}$, the lignin removal efficiency reached its maximum in less than a half hour. The lignin content decreased from $33.63 \%$ in original biomass to $17.91 \%$, i.e., close to $50 \%$ of the lignin was extracted. During the pre-treatment process the cellulose loss was determined to be around 4-9\% [33]. Indeed, ILs are able to depolymerise polysaccharides in biomass to compounds with low molecular weight. ILs with greater depolymerisation power cause 
greater loss of reducing sugar during pre-treatment providing higher mass loss of carbohydrates. The dissolved polysaccharides undergo different degrees of depolymerisation and reducing sugar loss when pre-treated with different types of ILs. Sugarcane bagasse was pre-treated with $[\mathrm{bmim}][\mathrm{Cl}]$ and $6.7 \mathrm{mg} \cdot \mathrm{mL}^{-1}$ of reducing sugars was detected in IL. In the case of the pre-treatment with [emim][DEP], $2.7 \mathrm{mg} \cdot \mathrm{mL}^{-1}$ of reducing sugars were detected in IL, whereas [emim] $\left[\mathrm{CH}_{3} \mathrm{COO}\right]$ was ineffective in depolymerisation of polysaccharides during pretreatment (insignificant amount of reducing sugar was detected) [33]. Tan et al. claimed that depolymerisation of cellulose occurs under acidic conditions in the ionic liquid media during pre-treatment [71]. The acidic conditions are created by degradation products, namely acetic acid and carboxylic acid released from hemicellulose hydrolysis upon pre-treatment. Under acidic conditions IL had the ability to hydrolyse cellulose causing significant losses. The loss products are essentially formed by carbohydrate oligomers and monomers that are soluble in the antisolvent and failed to be regenerated [71]. Van Spronsen et al. presumed that water is formed at temperatures higher than $100^{\circ} \mathrm{C}$ from dehydration [27]. The components of lignocellulosic biomass were then exposed for hydrolysis. Hemicellulose could be further hydrolysed into acetic acid, which subsequently may act as a catalyst to the hydrolysis process of cellulose and the remaining hemicellulose [27]. The lesser depolymerisation observed for $[\mathrm{emim}]\left[\mathrm{CH}_{3} \mathrm{COO}\right]$ could be explained by the buffering effect exhibited by a very basic $\left[\mathrm{CH}_{3} \mathrm{COO}\right]$ anion. Its ability to combine with protons to form acetic acid may limit the acid-catalysed hydrolysis of hemicellulose polymers [53]. If the resultant products of degradation and hydrolysis are low macromolecular weight compounds, the probability of its recovery in the regeneration process is lower. Additional file 1: Table S1 presents the pretreatment results for grasses, agricultural and forest residues, and industrial residues.

The extraction and recovery of lignin are also in evidence in some pre-treatment studies using ILs with the main goal envisaged for lignin valorisation. Tan et al. studied treatment at atmospheric pressure and high temperature $\left(170-190^{\circ} \mathrm{C}\right)$ with the IL containing [emim] and alkylbenzenesulphonate and xylenesulphonate anions [78]. They demonstrated that lignin can be extracted from sugarcane bagasse with high yields. Lignin was recovered from the IL by alkali extraction and a yield of lignin above $93 \%$ from the original lignin was obtained. $\mathrm{NaOH}$ aqueous solution as the antisolvent was used leading to the simultaneous extraction of lignin. The cellulose-rich pulp obtained (with hemicellulose content) corresponded to a $45-55 \%(\mathrm{w} / \mathrm{w})$ from the original sugarcane bagasse. However, the possible formation of lignin carbonium ions during the heating dissolution process was noted. The formed carbonium ions were able to react with the xylenesulphonate anions, and thus lignin with xylenesulphonate adducts were produced. Additionally, during delignification some amount of hemicellulose was also removed [78]. In the pre-treatment of triticale straw using $5 \%(\mathrm{w} / \mathrm{w})$ of biomass treated at $90^{\circ} \mathrm{C}$ for 24 hours under $\mathrm{N}_{2}$, ILs, such as [emim] $\left[\mathrm{CH}_{3} \mathrm{COO}\right]$, [bmim][Cl], N,N-dimethylethanolammonium formate ([DMEA] $[\mathrm{HCOO}]$ ), N,N-dimethylethanolammonium acetate ([DMEA] $\left.\left[\mathrm{CH}_{3} \mathrm{COO}\right]\right), N, N$-dimethylethanolammonium glycolate ([DMEA] $\left[\mathrm{OHCH}_{2} \mathrm{COO}\right]$ ) and $N, N$-dimethyle thanolammonium succinate ([DMEA $]\left[\left(\mathrm{CH}_{2} \mathrm{COO}\right)_{2}\right]$ were evaluated [79]. Lignin extraction was performed more efficiently by $[\mathrm{emim}]\left[\mathrm{CH}_{3} \mathrm{COO}\right]$ and $[\mathrm{bmim}][\mathrm{Cl}]$. The other four ILs, [DMEA][HCOO], [DMEA] $\left[\mathrm{CH}_{3} \mathrm{COO}\right]$, [DMEA] $\left[\mathrm{OHCH}_{2} \mathrm{COO}\right]$ and [DMEA] $\left[\left(\mathrm{CH}_{2} \mathrm{COO}\right)_{2}\right]$ were observed to have poor extraction performances. The extraction of lignin with $[\mathrm{emim}]\left[\mathrm{CH}_{3} \mathrm{COO}\right]$ was $30.3 \%$ of the original lignin from the triticale straw. This result was 2 and 10fold higher than for [bmim] $[\mathrm{Cl}]$ and [DMEA] [HCOO] lignin extractions, respectively. The $[\mathrm{bmim}][\mathrm{Cl}] \mathrm{IL}$ is less efficient than [emim] $\left[\mathrm{CH}_{3} \mathrm{COO}\right]$ for delignification of straw. Additionally, [DMEA][HCOO], [DMEA] $\left[\mathrm{CH}_{3} \mathrm{COO}\right]$, [DMEA] $\left[\mathrm{OHCH}_{2} \mathrm{COO}\right]$ and [DMEA] $\left[\left(\mathrm{CH}_{2} \mathrm{COO}\right)_{2}\right]$ are not suitable for this purpose [79]. The pre-treatment with [emim] $\left[\mathrm{CH}_{3} \mathrm{COO}\right]$ also revealed a small change in the cellulose content in the regenerated biomass. Partial degradation of xylan led to a loss of approximately $7 \%$ cellulose and $31 \%$ xylan after pre-treatment. Wheat straw and flax shives were also pre-treated with $[\mathrm{emim}]\left[\mathrm{CH}_{3} \mathrm{COO}\right]$ under the same conditions and it was identified that $29.6 \%$ and $14.0 \%$ of lignin was extracted, respectively, from these biomasses [79]. One of the most important conclusions coming from this study is the fact that the type of biomass affects the extraction of lignin strongly, mostly due to the differences in composition and structural interactions occurring in various biomasses. Muhammad et al. presented [emim] [Gly] as an effective solvent for delignification of bamboo biomass due to a significant lignin reduction of $85.3 \%$ of total lignin content. The pre-treatment was performed at $120^{\circ} \mathrm{C}$ for 8 hours $(5 \% \mathrm{w} / \mathrm{w})$ [42]. Use of acetone/water mixture $(7 / 3 \mathrm{vol} / \mathrm{vol})$ as the antisolvent was found to be advantageous due to the cellulose precipitation and a high lignin extraction yield obtained [42]. Other study focused on the lignin isolation was made by Shamsuri et al. who used the $[\mathrm{mmim}]\left[\mathrm{MeSO}_{4}\right]$ IL to extract lignin from rubber wood [61]. Depending on the concentration of the IL, the time and temperature of the pre-treatment varied. The best concentration for the highest lignin yield was found at 0.5 moles at $100^{\circ} \mathrm{C}$ after 120 minutes with $0.224 \mathrm{~g}$ lignin soluble. At these conditions, it was possible to isolate only $13.03 \mathrm{wt} \%$ lignin of the rubber wood. This result indicates that [mmim] 
$\left[\mathrm{MeSO}_{4}\right]$ is not efficient in lignin extraction from rubber wood. There is a large loss of rubber wood lignin in the waste liquid (after lignin isolation), possibly due to its high water solubility and/or its relatively small molecule dimensions remained in the waste liquid. However, the isolated lignin was demonstrated to be nearly pure by FTIR study [61]. A relatively low extracted lignin content from wood flour was obtained with the $[\mathrm{bmim}]\left[\mathrm{MeSO}_{4}\right]$ treatment. On the other hand, $[\mathrm{bmim}]\left[\mathrm{MeSO}_{4}\right]$ was capable of dissolving a high concentration of commercial free lignin. In the case of $[\mathrm{bmim}]\left[\mathrm{MeSO}_{4}\right]$, insufficient lignin extraction from wood flour could be explained by a limited access of the IL to lignin in the wood flour causing a restricted extraction [58]. Considering pre-treatment of rice straw, recent renewable amino acid-based ILs, such as [Ch][Gly], [Ch][Phe] and [Ch][Lys] were found to favour the lignin extraction at $90^{\circ} \mathrm{C}$ [66]. [Ch][Gly] removed $59.5 \%$ of the total lignin, while [Ch][Phe] extracted only $41.5 \%$. Surprisingly, [Ch][Lys] showed the highest capacity to extract lignin from rice straw giving a $60.4 \%$ yield, in spite of a moderate solubility of lignin in [Ch][Lys] [66].

The next direction in studies on the biomass processing is focused on the extraction of carbohydrate fractions using ILs. Abe et al. attempted to use short dissolution time (up to 2 hours) and low temperature $\left(25^{\circ} \mathrm{C}\right.$ and $50^{\circ} \mathrm{C}$ ) in the extraction of carbohydrates from bran using phosphonate or phosphinate-derived ILs [52]. Cellulose, hemicellulose, and residual starch were the major components dissolved by these ILs. The insoluble portion was expected to contain lignin and its complexes. The polar and low viscous $[\mathrm{emim}]\left[\mathrm{PO}(\mathrm{O}) \mathrm{H}_{2}\right]$ IL was chosen among the investigated ILs for this study. A $42 \%$ yield of the extraction of carbohydrates present in bran was obtained at very mild conditions of $50^{\circ} \mathrm{C}$ within 2 hours [52]. Another example of extraction of carbohydrates was presented by Pezoa et al. who examined pretreatment of eucalyptus and lenga residues using [emim] [Cl] [60]. They achieved a carbohydrate extraction of 46$48 \%$ from the total carbohydrates present in wheat and corn residues, after a pre-treatment at $150^{\circ} \mathrm{C}$ for 60 minutes. In the case of eucalyptus, the same conditions gave a $33 \%$ yield of total sugars. However, the lenga pre-treatment at a temperature of $150^{\circ} \mathrm{C}$ and an incubation time of 30 minutes yielded $40 \%$ of the original carbohydrates. At $170^{\circ} \mathrm{C}$ a carbohydrate degradation was also observed that is not beneficial if the goal is to preserve carbohydrates for subsequent enzymatic hydrolysis [60].

When different conditions are applied to the pretreatment process, a multivariate analysis is advisable to obtain predicted conditions that ensure maximum efficiency for a certain biomass pre-treatment with the particular IL. Yoon et al. used the statistical RSM for the operating conditions of pre-treatment of sugarcane bagasse with [emim] $\left[\mathrm{CH}_{3} \mathrm{COO}\right]$ [43]. Temperature, time and solid loading were explanatory variables tested and the reducing sugar yield (enzymatic hydrolysis) was the response variable. As it was already stated for sugarcane bagasse pre-treatment in $[\mathrm{emim}]\left[\mathrm{CH}_{3} \mathrm{COO}\right]$ conditions were optimised to be $145^{\circ} \mathrm{C}, 15$ minutes and $14 \mathrm{wt} \%$ of biomass loading. At these conditions, a predicted reducing sugar yield was $71.0 \%$, but the experimental reducing sugar yield reached $69.7 \%$. However, considering delignification, this optimised pre-treatment was ineffective. The crystallinity of cellulose was altered rather than the lignin removal during pre-treatment. Part of the lignin suffered from modification to a more acid soluble type after pre-treatment being precipitated together with carbohydrates in the regenerated material [43]. Another RSM study allowed to determine the optimised conditions in the case of oil palm frond pre-treatment with $[\mathrm{bmim}][\mathrm{Cl}]$ by evaluation of the glucose yield [86]. The theoretical optimal conditions were determined to be $80^{\circ} \mathrm{C}, 15$ minutes retention time and a $10 \%(\mathrm{w} / \mathrm{w})$ biomass loading. This optimised result gave a reduction of $13 \%$ and $38 \%$ in terms of temperature and time of pre-treatment, respectively, as well as an increase of 19\% biomass loading, in comparison with the best result attained from the experimental work. The theoretical optimised conditions were tested and the predicted values from RSM study were validated obtaining a $100 \%$ glucose yield after enzymatic hydrolysis [86]. The RSM statistical approach seems to be advisable to perform optimised pre-treatments of a certain biomass with a specific IL.

ILs apart from being used in the biomass pretreatment, can also be applied as a tool for the fractionation of lignocellulosic materials into the three main components (Table 3). In a recent fractionation approach cellulose, hemicellulose and lignin were obtained separately as solid fractions [93]. A sugarcane bagasse pre-treatment was performed with $2 \%(\mathrm{w} / \mathrm{w})$ of sugarcane bagasse at $110^{\circ} \mathrm{C}$ for 4 hours. The complete dissolution of biomass in $[\mathrm{bmim}][\mathrm{Cl}]$ achieved followed by the addition of acetone/water $(9: 1, \mathrm{v} / \mathrm{v})$ as antisolvent. Acetone soluble lignin was extracted to the liquid stream whereas cellulose, hemicellulose and alkaline lignin were fractionated from the solid fraction using a $3 \% \mathrm{NaOH}$ solution and ethanol. The biomass was fractionated to $36.78 \%$ cellulose, $26.04 \%$ hemicellulose, and $10.51 \%$ lignin, giving $47.17 \%$ and $33.85 \%$ of the original polysaccharides and $54.62 \%$ of the original lignin. High purity fractions were obtained for cellulose (92.15\% glucose) and even for the hemicellulose fractions (73.25\% xylose, $8.31 \%$ arabinose and $16.58 \%$ glucose). The glucose content in hemicellulose is derived from the cellulose hydrolysis during pre-treatment in IL and alkaline 
extraction [93]. A different fractionation approach was performed using $[\mathrm{amim}][\mathrm{Cl}]$ in the pre-treatement of bamboo biomass [94]. After a 12-hour pre-treatment at $100^{\circ} \mathrm{C}$, water was used to regenerate the dissolved biomass. The regenerated material was separated from the liquid phase containing water, IL and non-regenerated biomass. A subsequent two-step alkaline extraction accompanied by an ethanol selective fractionation was performed. Cellulose-rich material, two fractions of hemicellulose and two fractions of lignin were obtained. The cellulose-rich fraction demonstrated high cellulose content attaining 92.02 wt\% purity. On the other hand, the lignin fractions presented traced amounts of carbohydrates (1.43 wt\%-2.80 wt\%) demonstrating high efficiency of the fractionation. Furthermore, the alkaline extraction led to the separation of hemicellulose fractions with different content in xylose and arabinose. A major content of arabinoxylan was obtained in one hemicellulosic fraction (80.52 wt\% xylan and $7.04 \mathrm{wt} \%$ arabinan) while another fraction had an enriched content of glucan derived from cellulose (52.97 wt\% xylan and 42.75 wt $\%$ glucan). However, only $40.26 \%(w / w)$ of the original biomass was recovered resulting in $60 \%$ (w/w) material loss being the major limitation of the presented process. Moreover, degradation of lignin and hemicellulose during the pre-treatment with [amim] [Cl] promoted not only high material loss, but also increase in the polydispersity of the fractionated samples [94]. Another literature report that provides information about fractionation was designed for pulverised and coarse Norway spruce (Picea abies) and Eucalyptus grandis wood dissolved in [amim][Cl] [35]. Leskinen et al. demonstrated fractionation based on the molecular weight of macromolecules [35]. In this study the selectivity of precipitation was found to be not significantly dependent upon antisolvents. The selectivity of the fractionation was also dependent on the biomass used, as well as on type of milling used before pre-treatment with [amim] $[\mathrm{Cl}]$. Cellulose was the first to precipitate as a delignified and bleachable macromolecule. The group also examined water extraction of the high molecular weight acetylated galactoglucomannan (hemicellulosic compound). The major advantage of an effective milling and ball-milling before pre-treatment with ILs is the disintegration of extensive lignin-carbohydrate complex that allows the separation of lignin and polysaccharides [35]. A selective fractionation was also performed by pre-treating rice hulls with several ILs, such as [emim] $\left[\mathrm{CH}_{3} \mathrm{COO}\right]$, [amim] $[\mathrm{Cl}]$ and $[\mathrm{hmim}][\mathrm{Cl}]$ [95]. After the dissolution process, water was added and the regenerated material was recovered. The filtrate was further used and ethanol was added to give a second precipitated material. The pre-treatment with $[\mathrm{emim}]\left[\mathrm{CH}_{3} \mathrm{COO}\right]$ at $110^{\circ} \mathrm{C}$ for 8 hours was found to completely remove lignin from rice hulls and lignin was recovered in a second precipitation using ethanol as an antisolvent. Under the same conditions with $[\mathrm{hmim}][\mathrm{Cl}]$ used, approximately $20 \%$ of the cellulose in the rice hull sample can be precipitated out using water as an antisolvent, while more than $60 \%$ of the hemicellulose can be precipitated with ethanol [95]. The pre-treatment with [amim] [Cl] at the abovementioned conditions was demonstrated to remove about $75 \%$ of hemicellulose content from rice hulls. Furthermore, in this fractionation approach, ash was also removed and quantified. The pre-treatment with $[\mathrm{hmim}][\mathrm{Cl}]$ removed $10-20 \%$ of the ash and therefore provided the highest removal among the tested ILs [95]. Basing on the provided literature, it can be concluded that different fractionation approaches can be applied using the specific properties of ILs to achieve a precise goal in the biomass processing.

The pre-treatment with ILs is not only more selective for biomass fraction separation, but also can be considered as more economic with respect to the energy consumed in the performance of the whole process. Yoon et al. evaluated the energy consumption of the pretreatment with $[\mathrm{emim}]\left[\mathrm{CH}_{3} \mathrm{COO}\right]\left(145^{\circ} \mathrm{C}, 15\right.$ minutes, $14 \%(\mathrm{w} / \mathrm{v})$ of biomass loading) in comparison with alkali $\left(115^{\circ} \mathrm{C}, 38\right.$ minutes, $9 \%(\mathrm{w} / \mathrm{v})$ of biomass loading) and acid $\left(150^{\circ} \mathrm{C}, 30\right.$ minutes, $15 \%(\mathrm{w} / \mathrm{v})$ of biomass loading) pre-treatments [33]. The authors calculated a theoretical maximum yield of reducing sugars of $55.6 \pm 0.2 \%$ for pre-treatment with $[\mathrm{emim}]\left[\mathrm{CH}_{3} \mathrm{COO}\right]$, and $57.2 \pm 0.3 \%$ and $22.2 \pm 0.4 \%$ for alkali and acid pre-treatments, respectively. Considering these theoretical values, the pretreatment with [emim] $\left[\mathrm{CH}_{3} \mathrm{COO}\right]$ consumes $1262.3 \mathrm{~J}$. In the cases of the acid and alkali pre-treatments a total energy was calculated to be $1847.9 \mathrm{~J}$ and $2611.8 \mathrm{~J}$, correspondingly. It was also determined that $1.80 \mathrm{MJ}$ is necessary to pre-treat $1 \mathrm{Kg}$ of sugarcane bagasse with [emim] $\left[\mathrm{CH}_{3} \mathrm{COO}\right]$, in contrast to higher values of 4.11 $\mathrm{MJ}$ and $3.48 \mathrm{MJ}$ in the cases of alkali and acid pretreatments, respectively. These results indicate that biomass pre-treatment with ILs can be more energetically efficient than other conventional pre-treatments, such as acid and alkali pre-treatments [33].

\section{The biomass pre-treatment with aqueous-IL mixtures}

A novel approach in the pre-treatments with ILs was highlighted recently $[53,55,58,96,97]$. The principle aim is water addition to the dissolution process, on the contrary to Swatloski et al. who reported that water compromises the dissolution efficiency of biomass in the IL dissolution [13]. The use of aqueous-IL solutions was found to be advantageous as it led to: (i) a smaller amount of IL to be used; (ii) easier processing operations due to the reduced viscosity; and (iii) facilitated recycling of the mixture instead of pure IL as requirement of the 
Table 3 Fractionation approaches of lignocellulosic biomass in ILs

\begin{tabular}{|c|c|c|c|c|c|c|c|c|c|c|c|c|c|c|c|c|c|c|c|c|c|c|c|}
\hline \multicolumn{2}{|c|}{ Ionic liquid } & \multicolumn{4}{|c|}{ Biomass } & \multicolumn{3}{|c|}{ Conditions } & \multicolumn{4}{|c|}{ Cellulose-rich material } & \multicolumn{4}{|c|}{$\begin{array}{c}\text { Hemicellulose-rich } \\
\text { material }\end{array}$} & \multicolumn{4}{|c|}{ Lignin-rich material } & \multirow{2}{*}{$\begin{array}{c}\text { Total } \\
\text { biomass } \\
\text { recovery } \\
\% w / w\end{array}$} & \multirow{2}{*}{$\begin{array}{c}\text { IL } \\
\text { recovery } \\
\% w / w\end{array}$} & \multirow[t]{2}{*}{ Ref. } \\
\hline Type & $\begin{array}{l}\mathrm{H}_{2} \mathrm{O} \\
\mathrm{wt} \%\end{array}$ & Type & $\begin{array}{c}\text { Moisture } \\
\text { wt } \%\end{array}$ & $\begin{array}{l}\text { Size } \\
\mathrm{mm}\end{array}$ & $\begin{array}{c}\text { Load } \\
\%\end{array}$ & $\underset{h}{T}$ & $\begin{array}{l}\mathrm{T} \\
{ }^{\circ} \mathrm{C}\end{array}$ & Antisolvent & $\begin{array}{c}\mathrm{C} \\
\mathrm{wt} \%\end{array}$ & $\begin{array}{c}\mathrm{H} \\
\mathrm{wt} \%\end{array}$ & $\begin{array}{c}\mathrm{L} \\
w t \%\end{array}$ & $\begin{array}{c}0 \\
w t \%\end{array}$ & $\begin{array}{c}\mathrm{C} \\
\mathrm{wt} \%\end{array}$ & $\begin{array}{c}\mathrm{H} \\
\mathbf{w t} \%\end{array}$ & $\begin{array}{c}\mathrm{L} \\
\mathrm{wt} \%\end{array}$ & $\begin{array}{c}0 \\
\mathrm{wt} \%\end{array}$ & $\begin{array}{c}\mathrm{C} \\
\mathrm{wt} \%\end{array}$ & $\begin{array}{c}\mathrm{H} \\
\mathrm{wt} \%\end{array}$ & $\begin{array}{c}\mathrm{L} \\
\mathrm{wt} \%\end{array}$ & $\begin{array}{c}0 \\
\mathrm{wt} \%\end{array}$ & & & \\
\hline $\begin{array}{c}{[\mathrm{amim}]} \\
{[\mathrm{Cl}]}\end{array}$ & a & Rice hulls & $\mathrm{b}$ & $\begin{array}{l}1.168- \\
1.651\end{array}$ & $\begin{array}{c}10 \\
(w / w)\end{array}$ & 4 & 90 & $40 \mathrm{~mL} \mathrm{H}_{2} \mathrm{O}$ & $0^{c}$ & - & - & - & - & $58^{c}$ & - & - & - & - & - & - & 23 & - & {$[$ [95] } \\
\hline$\underset{[\mathrm{Cl}]}{[\mathrm{amim}]}$ & a & Rice hulls & $\mathrm{b}$ & $\begin{array}{l}1.168- \\
1.651\end{array}$ & $\begin{array}{c}10 \\
(w / w)\end{array}$ & 8 & 90 & $40 \mathrm{~mL} \mathrm{H} \mathrm{H}_{2} \mathrm{O}$ & $2^{c}$ & - & - & - & - & $56^{c}$ & - & - & - & - & - & - & 16 & - & [95] \\
\hline$\underset{[\mathrm{Cl}]}{[\mathrm{amim}]}$ & a & Rice hulls & $\mathrm{b}$ & $\begin{array}{l}1.168- \\
1.651\end{array}$ & $\begin{array}{c}10 \\
(w / w)\end{array}$ & 4 & 110 & $40 \mathrm{~mL} \mathrm{H} \mathrm{H}_{2} \mathrm{O}$ & $7^{c}$ & - & - & - & - & $52^{c}$ & - & - & - & - & - & - & 13 & - & [95] \\
\hline$\underset{[\mathrm{Cl}]}{[\mathrm{amim}]}$ & a & Rice hulls & $\mathrm{b}$ & $\begin{array}{l}1.168- \\
1.651\end{array}$ & $\begin{array}{c}10 \\
(w / w)\end{array}$ & 8 & 110 & $40 \mathrm{~mL} \mathrm{H} \mathrm{H}_{2} \mathrm{O}$ & $33^{c}$ & - & - & - & - & $75^{c}$ & - & & - & - & - & - & 30 & - & [95] \\
\hline $\begin{array}{l}{[\mathrm{amim}]} \\
{[\mathrm{Cl}]}\end{array}$ & nd. & $\begin{array}{l}\text { Extracted } \\
\text { bamboo }\end{array}$ & d & nd. & $5(w / v)$ & 12 & 100 & $\mathrm{H}_{2} \mathrm{O}_{\text {excess }}$ & $92.02^{\mathrm{e}}$ & $7.98^{f}$ & - & - & $\begin{array}{l}8.53^{-} \\
42.75^{\mathrm{e}}\end{array}$ & $\begin{array}{l}56.14- \\
87.87^{f}\end{array}$ & - & - & $\begin{array}{l}0.12- \\
0.49^{e}\end{array}$ & $\begin{array}{l}0.94- \\
2.36^{f}\end{array}$ & - & - & 40.26 & - & [94] \\
\hline$[\mathrm{bmim}] \mathrm{Cl}$ & nd. & $\begin{array}{c}\text { Sugarcane } \\
\text { bagasse }\end{array}$ & h & $\begin{array}{l}40-60 \\
\text { mesh }\end{array}$ & $\begin{array}{c}2 \\
(w / w)\end{array}$ & 4 & 110 & $\begin{array}{c}\text { acetone/ } \\
\mathrm{H}_{2} \mathrm{O}(9: 1, \mathrm{v} / \mathrm{V})\end{array}$ & $92.15^{e}$ & $7.26^{9}$ & 4.56 & - & $16.58^{e}$ & $82.44^{i}$ & 3.54 & & & & & & 73 & $>95$ & [93] \\
\hline $\begin{array}{c}{[\mathrm{emim}]} \\
{\left[\mathrm{CH}_{3} \mathrm{COO}\right]}\end{array}$ & $\begin{array}{l}< \\
0.3\end{array}$ & $\begin{array}{l}\text { Corn } \\
\text { stover }\end{array}$ & 5.0 & 4 & $9.43 w t$ & 3 & 140 & $\begin{array}{c}\mathrm{EtOH} / \mathrm{LL} \\
(\mathrm{mol} / \mathrm{mol})\end{array}$ & $45.5^{j}$ & $29.9^{k}$ & $9.4^{1}$ & 15.2 & $12.8 \mathrm{e}$ & $23.5^{\mathrm{m}}$ & $18.8^{n}$ & 45.0 & - & - & $37.0^{\circ}$ & 63.0 & 82.8 & 89 & [68] \\
\hline $\begin{array}{c}{[\mathrm{emim}]} \\
{\left[\mathrm{CH}_{3} \mathrm{COO}\right]}\end{array}$ & a & Rice hulls & b & $\begin{array}{l}1.168- \\
1.651\end{array}$ & $\begin{array}{c}10 \\
(w / w)\end{array}$ & 4 & 90 & $40 \mathrm{~mL} \mathrm{H}_{2} \mathrm{O}$ & & - & - & - & - & $0^{c}$ & - & & - & & $21^{c}$ & - & 11 & - & [95] \\
\hline $\begin{array}{c}{[\mathrm{emim}]} \\
{\left[\mathrm{CH}_{3} \mathrm{COO}\right]}\end{array}$ & a & Rice hulls & b & $\begin{array}{l}1.168- \\
1.651\end{array}$ & $\begin{array}{c}10 \\
(w / w)\end{array}$ & 8 & 90 & $40 \mathrm{~mL} \mathrm{H} \mathrm{H}_{2} \mathrm{O}$ & - & - & - & - & - & $66^{c}$ & - & - & - & - & $13^{c}$ & - & 11 & - & [95] \\
\hline $\begin{array}{c}{[\mathrm{emim}]} \\
{\left[\mathrm{CH}_{3} \mathrm{COO}\right]}\end{array}$ & a & Rice hulls & b & $\begin{array}{l}1.168- \\
1.651\end{array}$ & $\begin{array}{c}10 \\
(w / w)\end{array}$ & 4 & 110 & $40 \mathrm{~mL} \mathrm{H} \mathrm{H}_{2} \mathrm{O}$ & - & - & - & - & - & $40^{c}$ & - & - & - & - & $47^{c}$ & - & 10 & - & [95] \\
\hline $\begin{array}{l}{[\mathrm{emim}]} \\
{\left[\mathrm{CH}_{3} \mathrm{COO}\right]}\end{array}$ & a & Rice hulls & b & $\begin{array}{l}1.168- \\
1.651\end{array}$ & $\begin{array}{c}10 \\
(w / w)\end{array}$ & 8 & 110 & $40 \mathrm{~mL} \mathrm{H}_{2} \mathrm{O}$ & - & - & - & - & - & $29^{c}$ & - & - & - & - & $100^{c}$ & - & 7 & - & [95] \\
\hline $\begin{array}{c}{[\mathrm{hmim}]} \\
{[\mathrm{Cl}]}\end{array}$ & a & Rice hulls & b & $\begin{array}{l}1.168- \\
1.651\end{array}$ & $\begin{array}{c}10 \\
(\mathrm{w} / \mathrm{w})\end{array}$ & 4 & 90 & $40 \mathrm{~mL} \mathrm{H} \mathrm{H}_{2} \mathrm{O}$ & - & - & - & - & - & $0^{c}$ & - & - & - & - & - & - & 3 & - & [95] \\
\hline$\underset{[\mathrm{Cl}]}{[\mathrm{hmim}]}$ & a & Rice hulls & b & $\begin{array}{l}1.168- \\
1.651\end{array}$ & $\begin{array}{c}10 \\
(w / w)\end{array}$ & 8 & 90 & $40 \mathrm{~mL} \mathrm{H} \mathrm{H}_{2} \mathrm{O}$ & - & - & - & - & - & $54^{c}$ & - & - & - & - & - & - & 6 & - & [95] \\
\hline $\begin{array}{c}{[\mathrm{hmim}]} \\
{[\mathrm{Cl}]}\end{array}$ & a & Rice hulls & b & $\begin{array}{l}1.168- \\
1.651\end{array}$ & $\begin{array}{c}10 \\
(\mathrm{w} / \mathrm{w})\end{array}$ & 4 & 110 & $40 \mathrm{~mL} \mathrm{H} \mathrm{H}_{2} \mathrm{O}$ & - & - & - & - & - & $63^{c}$ & - & - & - & - & - & - & 17 & - & [95] \\
\hline$\underset{[\mathrm{Cl}]}{[\mathrm{hmim}]}$ & a & Rice hulls & b & $\begin{array}{l}1.168- \\
1.651\end{array}$ & $\begin{array}{c}10 \\
(w / w)\end{array}$ & 8 & 110 & $40 \mathrm{~mL} \mathrm{H}_{2} \mathrm{O}$ & - & - & - & - & - & $70^{c}$ & - & - & - & - & - & - & 23 & - & [95] \\
\hline
\end{tabular}

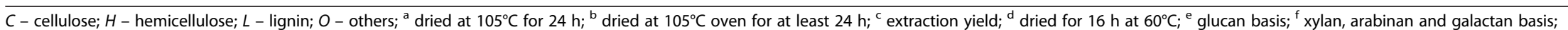

${ }^{g}$ xylan, arabinan, mannan and galactan basis; ${ }^{\text {h }}$ dried for $16 \mathrm{~h}$ at $55^{\circ} \mathrm{C}_{;}{ }^{i}$ xylan, arabinan, galactan and rhamnan basis; ${ }^{j} 87 \%$ total glucan; ${ }^{k} 66 \%$ total xylan and arabinan; ${ }^{\prime} 35 \%$ total lignin; ${ }^{\mathrm{m}} 14 \%$ total xylan; ${ }^{\mathrm{n}} 17 \%$ total lignin; ${ }^{\circ} 5.9 \%$ total lignin. 
separation of IL and water could be omitted as reducing costs of the pre-treatment $[96,97]$.

One of the first works in this subject was performed by Doherty et al. who blended 5 and $10 \%(\mathrm{w} / \mathrm{w})$ of water with [emim] $\left[\mathrm{CH}_{3} \mathrm{COO}\right]$, [bmim] $\left[\mathrm{CH}_{3} \mathrm{COO}\right]$ and [bmim] $\left[\mathrm{MeSO}_{4}\right]$ to pre-treat wood flour [58]. After a 12-hour pre-treatment at $90^{\circ} \mathrm{C}$, a decrease in glucose and xylose yields was observed with increased addition of water. The added water displayed a moderate inter-crystalline swelling effect and the wood fibres were still largely intact. The crystallinity and lignin content of the pretreated wood flour were verified to be higher than that of pre-treatments with pure ILs. In fact, the addition of water decreased the ability of the ILs to disrupt the crystallinity of cellulose present in wood, affected both intra- and inter-crystalline swelling, as well as fibre size reduction. The lignin extraction varied from $21 \%$ to $24 \%$ $(\mathrm{w} / \mathrm{w})$ for all pre-treatments with tested ILs blended with $10 \%(\mathrm{w} / \mathrm{w})$ of water [58]. Different results were stated by Brandt et al. who pre-treated Miscanthus chips using [bmim] $\left[\mathrm{MeSO}_{4}\right]$ with $20.5 \%(\mathrm{w} / \mathrm{w})$ of water [53]. In these conditions the pre-treated biomass presented high digestibility. In contrast, the pre-treatment with dried [bmim] $\left[\mathrm{MeSO}_{4}\right]$ with water content below $0.3 \mathrm{wt} \%$ resulted in the formation of degraded biomass-IL composite that was not enzymatically digestible. Therefore, a certain amount of water is necessary for successful pretreatment of Miscanthus with $[\mathrm{bmim}]\left[\mathrm{MeSO}_{4}\right]$. However, after pre-treatment, $\left[\mathrm{MeSO}_{4}\right]$ suffered from structural changes in the presence of water. It seems that water hydrolyses the ester bonds in $\left[\mathrm{MeSO}_{4}\right]$ to form $\mathrm{MeOH}$ and $\left[\mathrm{HSO}_{4}\right]$ under the pre-treatment conditions applied. To avoid the formation of a quaternary mixture of two ionic liquids ([bmim] $\left[\mathrm{MeSO}_{4}\right]$ and $[\mathrm{bmim}]\left[\mathrm{HSO}_{4}\right]$ ) plus two solvents (water and methanol), $[\mathrm{bmim}]\left[\mathrm{HSO}_{4}\right]$ with $20.5 \%(\mathrm{w} / \mathrm{w})$ of water as pre-treatment agent was chosen. After a 22-hour pre-treatment with this IL-aqueous mixture, most of lignin and hemicellulose was dissolved in the liquid phase and $91 \%$ of the original glucan was recovered in the resulted pulp. The authors also stated that part of the dissolved hemicellulose undergoes hydrolysis during pre-treatment. From the liquid phase, around $50 \%$ of the Klason lignin was recovered by precipitation with water. Brandt et al. also tested pretreatment with $[\mathrm{emim}]\left[\mathrm{CH}_{3} \mathrm{COO}\right]$ blending $20 \mathrm{vol} \%$ of water. The efficiency of this pre-treatment was similar to that of the aqueous-[bmim] $\left[\mathrm{HSO}_{4}\right]$ solution, although the sugar yields after enzymatic hydrolysis were found to be lower [53].

Wei et al. studied the pre-treatment of legume straw with aqueous-[bmim] [Cl] mixture [55]. This work was devoted to check the effect of temperature $\left(50-170^{\circ} \mathrm{C}\right)$, time (0.5-4 hours), water content in the mixture $(0-80 \%)$ and pressure (0.1-3.2 $\mathrm{MPa})$ in the dissolution of legume straw. At temperatures below $90^{\circ} \mathrm{C}$ almost no water evaporation was observed due to possible strong interactions between water and $[\mathrm{bmim}][\mathrm{Cl}]$. For temperatures above $100^{\circ} \mathrm{C}$ the vaporised steam condenses and is recycled in the liquid phase. It was demonstrated that dissolution was increased as temperature increases. The various periods of time applied in the pre-treatment had no effect on the dissolution. Pre-treatment performed at high pressures, such as 3.2 $\mathrm{MPa}$, increased the legume straw dissolution while retaining the initial lignin content found in the original biomass [55]. A 20\% water content in the IL provided the best dissolution of legume straw. These results enabled an optimised pre-treatment at $150^{\circ} \mathrm{C}$ for 2 hours under ambient pressure, with a maximum of a $29.1 \mathrm{wt} \%$ legume straw dissolved in the aqueous-[bmim] $[\mathrm{Cl}]$ mixture with water content of 20 $\mathrm{wt} \%$. The optimised process demonstrated a lignin extraction of $48.2 \%$ from the original lignin content in the legume straw. However, only $32.4 \%$ was recovered by adding water as a precipitate solvent. The biomass regeneration provided cellulose with an amorphous structural conformation as occurred in pre-treatments with dried ILs [55]. The authors also evaluated the ability of aqueous-[bmim] $[\mathrm{Cl}]$ mixture in dissolving cotton pulp and no dissolution was observed. It was assumed that a strong interaction between cellulose and IL may exist with a proper amount of water to promote the dissolution of biomass [55].

Triticale and wheat straws were also pre-treated by aqueous-IL solutions and the results obtained were compared to pre-treatments using pure ILs $[96,97]$. Fu et al. observed a strong correlation between cellulose digestibility, lignin removal and crystallinity index of cellulose for the pre-treatment of triticale straw in aqueous[emim] $\left[\mathrm{CH}_{3} \mathrm{COO}\right]$ solution [96]. Upon decreasing the water content $(95 \%$ to $0 \% \mathrm{w} / \mathrm{w})$, an increased amount of lignin was extracted simultaneously with a crystalline reduction of the cellulose. However, after pre-treatment performances $\left(150^{\circ} \mathrm{C}, 90\right.$ minutes) cellulose digestibility was substantially enhanced for aqueous-[emim] $\left[\mathrm{CH}_{3} \mathrm{COO}\right]$ with $50 \%$ water content $(\mathrm{w} / \mathrm{w})$ achieving the highest sugar yield $(81.0 \%)$, higher than that observed for pure $[\mathrm{emim}]\left[\mathrm{CH}_{3} \mathrm{COO}\right](67.4 \%)$. Therefore, the pretreatment efficiency is higher for pure IL in respect to lignin removal and crystallinity reduction. Nevertheless, if the goal of pre-treatment is to enhance the digestibility of carbohydrates and maximise the release of fermentable sugars, the pre-treatment with aqueous-[emim] $\left[\mathrm{CH}_{3} \mathrm{COO}\right]$ was demonstrated to be more efficient, since it retains more carbohydrates and subsequently enhances its digestibility [96]. Fu et al. provided a deeper study on the pre-treatment with aqueous-IL solutions performing an RSM statistical approach with wheat straw and $[\mathrm{emim}]\left[\mathrm{CH}_{3} \mathrm{COO}\right]$ as the biomass and $\mathrm{IL}$ 
chosen [97]. They studied the effects of pre-treatment temperature $\left(130-170^{\circ} \mathrm{C}\right)$, time $(0.5-5.5$ hour $)$ and water content (0-100\%) on lignin removal and cellulose/xylan digestibility. The optimised conditions were determined to be $158^{\circ} \mathrm{C}, 3.6$ hours with $50.5 \%$ water content $(\mathrm{w} / \mathrm{w})$ where $71.4 \%$ of the fermentable sugars recovery was determined as the predicted value. In comparison with the pre-treatment with pure $[\mathrm{emim}]\left[\mathrm{CH}_{3} \mathrm{COO}\right]$, the temperature and time were found to also be beneficial for the digestibility of carbohydrates from the pre-treatment with aqueous-[emim] $\left[\mathrm{CH}_{3} \mathrm{COO}\right]$. In this study, lignin was largely extracted and the crystallinity reduced in pre-treatment with aqueous-[emim] $\left[\mathrm{CH}_{3} \mathrm{COO}\right]$ leading to a significant enhancement of the enzymatic hydrolysis. However, it seems that a higher temperature and time of pre-treatment are preferable to achieve the same efficiency as pre-treatment with pure ILs [97]. Nevertheless, the results for pre-treatment with aqueousIL solution were similar to that observed in pure IL pre-treatment, but with less intensity. Due to the lower usage and easier recycling of ionic liquids, as well as the reduced viscosity of the handling solution, pre-treatment with aqueous-IL mixture are potentially cost-effective. However, a more envisaged investigation is required, mainly about the acidic properties of water at high temperatures and its effect on biomass pre-treatment.

\section{IL recycling and reuse}

The reuse of recycled ILs for pre-treatment of biomass is a crucial factor for the economic efficiency of the pretreatments with ILs, since ILs are more expensive than conventional pre-treatment agents, such as ammonia and sulphuric acid. Nevertheless, the IL recovery process has been underexplored and for an effective operation must be highly efficient.

Generally, after the regeneration process, the liquid stream is composed of an antisolvent with dissolved IL and soluble biomass compounds (lignin, soluble carbohydrates with low molecular weight, degradation products, extractives and others) that were not precipitated in the regeneration step. Depending on the IL recovery process, these compounds can be recovered if further fractionation steps are applied. For instance, lignin could be precipitated by acidification of the liquid stream after the regeneration process $[25,78]$. Therefore, the IL recovery is largely dependent on the antisolvent used, as well as on the pre-treatment conditions applied that guides to certain extend carbohydrates dissolution, lignin removal and biomass degradation products present in the liquid stream. Focused on maximising IL recovery, several processes were developed and further reuse pre-treatments were performed to evaluate the pretreatment efficiency after recycle $[48,68,78,91,93]$. Figure 4 represents three processes of IL recovery that were developed up to present.

Generally, the easiest way to recover the IL is to evaporate the antisolvent after the regeneration process, although this process would finish with several impurities present in the IL, originated from the dissolved biomass $[29,34,51,55,56,63]$. For instance, [bmim] $[\mathrm{Cl}]$ was recycled by simple evaporation of water from the aqueous/IL solution obtained after separation of the regenerated legume straw. The yield of the recycled $[\mathrm{bmim}][\mathrm{Cl}]$ varied from $94 \%$ to $98 \%$. However, a large quantity of impurities were determined, which changed the colourless initial IL to an amber colour for the recovered IL [55]. To overcome this limitation, sophisticated recovery processes were developed. Li et al. studied the [emim][DEP] recovery using two different antisolvents, namely water and methanol [91]. The liquid stream after regeneration was washed several times with diethyl ether. During washings, salt was formed and then dissolved in chloroform/methanol mixture. Subsequently, the remaining liquid was passed through a column filled with neutral activated alumina and the mixture solvent was then evaporated to obtain the recovered [emim][DEP]. The yield of the recycled IL using methanol as antisolvent was higher (96\%) than that observed in the case of water (91\%), although the amount of the regenerated biomass was lower with methanol [91]. Tan et al. used [emim] [ABS] for pre-treatment and $\mathrm{NaOH}$ aqueous solution as the antisolvent, which resulted in a total mass of IL recovery between $96.1 \%$ and $99.4 \%$ demonstrating a good recovery potential and high final purity [78]. Here the IL solution was neutralised and water removed by evaporation resulting in collecting $\mathrm{IL}$ and $\mathrm{NaCl}$ as precipitated solids. Acetonitrile was added to dissolve selectively the IL, while $\mathrm{NaCl}$ remained as a solid to be filtrated in the next step. The IL was finally recovered by acetonitrile evaporation [78]. Lan et al. also performed a similar IL recovery process for $[\mathrm{bmim}][\mathrm{Cl}][93]$.

Alternative for recovering ILs is provided by their ability to form a biphasic liquid-liquid system with the addition of an aqueous solution containing a kosmotropic anion, such as phosphate, carbonate, or sulphate. Aqueous solutions of $\mathrm{K}_{3} \mathrm{PO}_{4}$ and $\mathrm{K}_{2} \mathrm{HPO}_{4}$ salts were employed resulting in a biphasic liquid-liquid system comprised by a salt-rich aqueous phase and an IL-rich phase containing most of the lignin. The salting-out effect leads to precipitation of a solid-phase rich in cellulose, simultaneously to the biphasic formation [48]. Shill et al. tested the IL recovery process with [emim] $\left[\mathrm{CH}_{3} \mathrm{COO}\right]$ after pre-treatment of Miscanthus [48]. The aqueous phosphate solution in the lower phase contained a high concentration of salt and trace amounts of IL and sugars. The IL-rich phase was recycled after removal of water by evaporation achieving only a $72 \%$ IL 

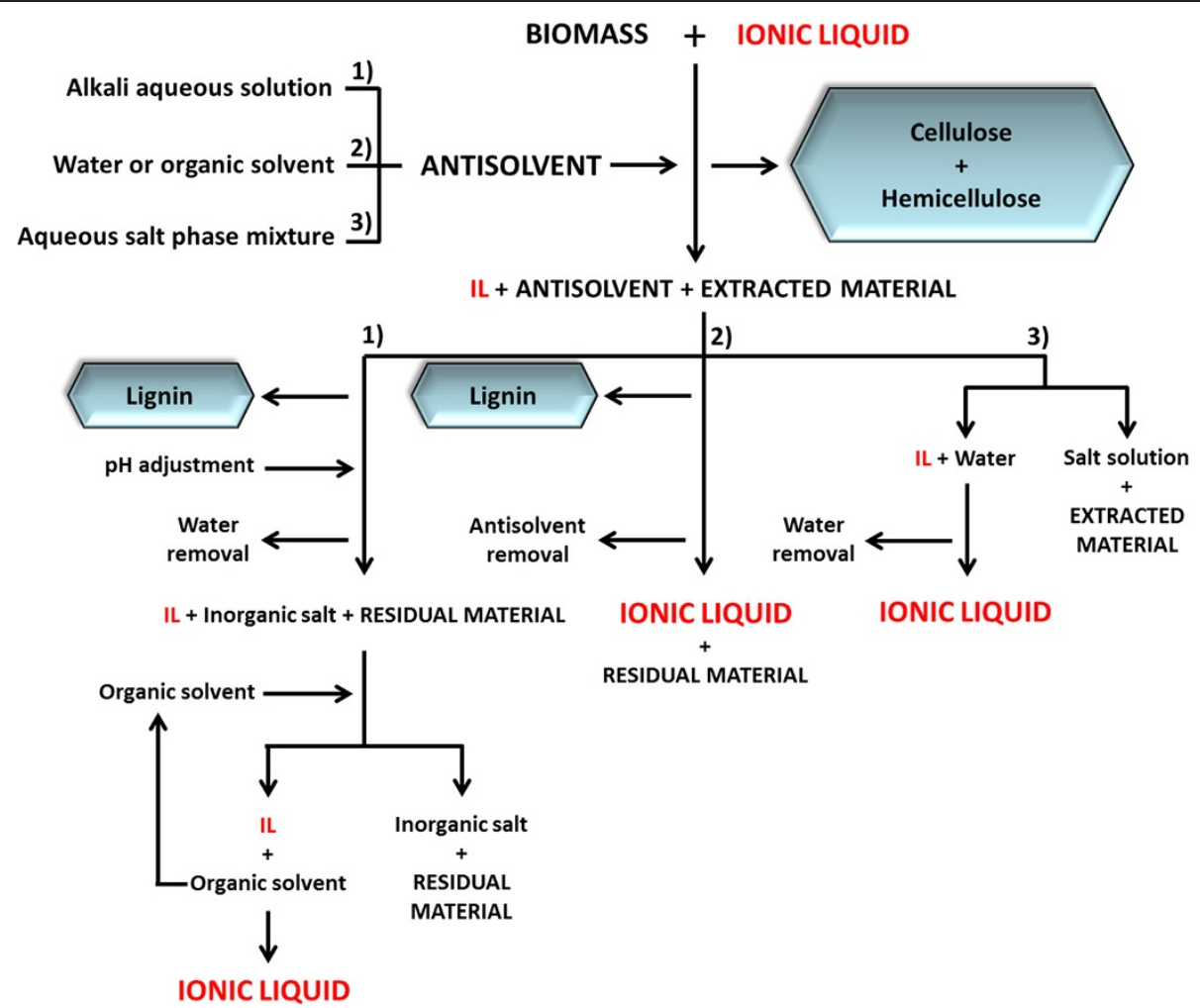

Figure 4 Schematic representation of the IL recovery technologies developed up to present. After pre-treatment the liquid stream is composed by $\mathrm{IL}$, antisolvent and extracted material that can be recovered. The extracted material contains lignin, residual hemicellulose, degradation products and other soluble compounds. Generally, only lignin is recovered from liquid stream leading to losses of biomass residual materials at the end of the process. Depending on the IL recovery technology lower or higher pure IL can be obtained.

recovery ready to be reused (without further solvent evaporation). The part of the IL loss occurred in the washing of the regenerated biomass [48]. Nevertheless, after the washing, water can be evaporated to recover the missing mass of the IL, although with noticeable impurities (mostly hemicellulose and lignin). It was referred that basicity of the $\mathrm{K}_{3} \mathrm{PO}_{4}$ solution presumably results in partial cleavage of lignin, allowing it to remain soluble in the IL. The main advantage of this process is the decreased amount of water present in the IL that must be evaporated and thus reduced energy costs.

In an innovative process, Dibble et al. promoted phase separation in the regeneration step by adding an antisolvent mixture constituted by ethanol and acetone in concentration that creates a quaternary solution containing IL-water-ketone-alcohol [68]. The [emim] $\left[\mathrm{CH}_{3} \mathrm{COO}\right]$ ionic liquid was selected as miscible with acetone by adjusting the quantities of water and ethanol in the solution. After regeneration, ethanol was maintained in the solution with IL. Next, ethanol and part of the added acetone were distilled and dry acetone was added to the remained solution (mainly water and [emim] $\left.\left[\mathrm{CH}_{3} \mathrm{COO}\right]\right)$ creating a phase separation. Aliphatic compounds were removed in the acetone phase (the upper phase). After this process, several biomass components remained dissolved in the IL solution comprising low molecular weight carbohydrates, a portion of the original lignin, residual non-polar biomass components, and other compounds. The precipitation and recovery of the majority of these residual solutes were performed by the addition of 2-propanol known as a low polarity solvent. This step reduced the accumulation of the very soluble biomass compounds in the IL. Therefore, after water distillation an efficient reuse of the IL for a new pre-treatment could be attained [68]. After the pre-treatment process, the separation of dissolved low molecular weight carbohydrates, non-polar substances, low molecular weight lignin fragments, and other biomass components in ILs is a challenging task. In fact, the recycling process should remove these compounds from the IL fraction as they are responsible for decreasing of the pre-treatment efficiency of the reused ILs. The IL recovery process proposed by Dibble et al. [68] requires a minimal addition of reagents and it is assumed that it would not result in significant IL degradation. The reported recovery process resulted in $89 \%$ of the initial IL without the addition of acid or other catalysts for the recovery of lignin and other solutes from the used IL [68]. 
In the IL recovery process, the antisolvent is evaporated from the IL, thus volatile solvents could be economically desirable as they can reduce the energy required for distillation process comparing to water distillation. However, in biomass processing the use of volatile organic solvents, such as methanol, should be avoided from an environmental prospect. Thus, water plays an important role as an antisolvent in the biomass regeneration. Therefore, an economical life-cycle assessment of the IL recovery should be evaluated.

Apart from existent processes for IL recovery, a given IL can be recycled if it is stable during the pre-treatment and fractionation steps. Therefore, different pre-treatment conditions should be considered for the optimal stability of the IL. In general, the studies that tested the IL recycle, made no mention of the degradation of the IL at the pretreatment conditions applied and fairly good IL recovery yields were obtained. One exception was observed in a work attempting to recycle $[\mathrm{bmim}]\left[\mathrm{MeSO}_{4}\right]$ [53]. As rated above the $\left[\mathrm{MeSO}_{4}\right]$ anion was partially hydrolysed to form $\left[\mathrm{HSO}_{4}\right]$, promoted by the hydrolytic instability of the ester bonds in $\left[\mathrm{MeSO}_{4}\right]$ anions under the conditions of the pretreatment $\left(120^{\circ} \mathrm{C}, 2-22\right.$ hours). In this case, mixtures of the ester and the hydrolysed form were produced [53].

After IL recovery process there can still be several impurities present in the recovered IL. One of the major impurities is lignin that comes from the original biomass during pre-treatment. Furthermore, lignin accumulation was observed after reusing IL in a new pre-treatment and this performance was continuously detected cycle after cycle, without further purification of the IL $[28,41,48,56,93]$. Lee et al. concluded that lignin accumulation in $[\mathrm{emim}]\left[\mathrm{CH}_{3} \mathrm{COO}\right]$ occurs due to the high solubility of lignin in this IL and that it does not affect the efficiency of the pre-treatment of wood flour. Moreover, they mentioned a similar pre-treatment efficiency as that observed for fresh [emim] $\left[\mathrm{CH}_{3} \mathrm{COO}\right]$ [28]. In fact, lignin accumulation and subsequently increased concentration in ILs can be advantageous for lignin recovery as the facilitated precipitation of lignin could be accomplished for further use in the generation of ligninderived chemical products [28,41]. Notwithstanding, a maximum lignin removal from ILs is advisable because it may be necessary to prolong the lifetime of the recycled IL [48]. However, not only lignin can be present in ILs after recycle, but also other contaminants, such as degraded biomass, organic acids formed during pretreatment or even introduced chemicals, water and other solvents [93]. Lan et al. observed a clear increase in colour saturation after several reuse trials of [bmim] [Cl] in the pre-treatment of sugarcane bagasse [93]. Nevertheless, ${ }^{1} \mathrm{H}$ NMR analysis showed no obvious difference between fresh and recycled IL. Change in colour intensity could indicate the existence of trace amounts of contaminants in the recycled IL that were not detected by ${ }^{1} \mathrm{H}$ NMR analysis [93]. Tan et al. reported the loss of hemicellulose in the recovered IL reducing the overall sugar recovery from the lignocellulosic biomass and making difficulties in the IL recovery process [71]. Hemicellulose and cellulose are described to be partially degraded during pre-treatment with ILs. After several pre-treatment cycles in which the IL is reused, some degraded products, such as acetic acid seem to accumulate in the recovered IL, and could catalyse the acidic fragmentation of carbohydrates in further reuse pre-treatments [56].

$\mathrm{Li}$ et al. observed that reuse of $[\mathrm{emim}]\left[\mathrm{CH}_{3} \mathrm{COO}\right]$ in wood pre-treatment did not affect the wood yield, although the composition of the wood was changed with the number of IL recycles [56]. Therefore, the efficiency of the recycled [emim] $\left[\mathrm{CH}_{3} \mathrm{COO}\right]$ could be questionable. Haykir et al. determined the lignin extraction from cotton stalks with [emim] $\left[\mathrm{CH}_{3} \mathrm{COO}\right]$ to be $47 \%$ via fresh IL and only a $27 \%$ for the first recycle of IL [63]. Wu et al., by using the same IL in corn stover pre-treatment, reported a decrease in the extracted lignin content from $44 \%$ in the first pre-treatment to a $20 \%$ in the tenth run, possibly due to lignin accumulation in the IL [41]. However, no effect on subsequent fermentable sugar yields was demonstrated, thus [emim] $\left[\mathrm{CH}_{3} \mathrm{COO}\right]$ could be reused up to 10 times, in spite of the lower extraction yield of lignin. The authors affirmed that $\beta$ parameter of [emim $]\left[\mathrm{CH}_{3} \mathrm{COO}\right]$ remains unaffected after each recycle beside the accumulation of lignin. Since the interaction between the IL and lignin occurs mainly through the cation, the anions are still available to disrupt hydrogen bonds from the semi-crystalline cellulose. Therefore, no significant loss in the sugar yields of corn stover pretreated with this recycled IL was observed [41]. Nguyen et al. tested a preceding treatment of rice straw with ammonia that provided an increase of the recycle number of $[\mathrm{emim}]\left[\mathrm{CH}_{3} \mathrm{COO}\right]$ [51]. An insignificant increase in the cellulose recovery from $82 \%$ to $83 \%$ was noticed for the twentieth run with the recycled IL. The pretreatment with the fifth time recycled [emim] $\left[\mathrm{CH}_{3} \mathrm{COO}\right]$ showed a $97 \%$ glucose conversion in comparison with the starting IL. Even for the tenth recycling cycle of IL, over $94 \%$ of the glucose conversion was attained [51]. Cotton stalk samples pre-treated with recycled and fresh [emim] $\left[\mathrm{CH}_{3} \mathrm{COO}\right]$ exhibited similar appearances presenting a lack of organised structure. In fact, according to a X-ray diffraction analysis, the crystallinity disruption of cellulose to an amorphous form was unaffected after reusing [emim] $\left[\mathrm{CH}_{3} \mathrm{COO}\right][41,63]$. The $[\mathrm{emim}]\left[\mathrm{CH}_{3} \mathrm{COO}\right]$ reuse was also feasible with respect to enzymatic digestibility, where the hydrolysis of pre-treated cotton stalk apparently showed no change after three times of IL recycling $[41,63]$. 
The IL reuse was also investigated for other ILs $[34,91,93]$. The dissolution and regeneration rates of pine wood obtained from both fresh and recycled [amim $][\mathrm{Cl}]$ were close to each other under comparable pre-treatment conditions. Moreover, the structure of the cellulose-rich regenerated material collected from the recycled IL was also similar to that obtained using fresh [amim] $[\mathrm{Cl}]$, as verified by the ${ }^{13} \mathrm{C} \mathrm{CP/MAS} \mathrm{NMR,} \mathrm{FTIR,}$ $\mathrm{XRD}$, and SEM techniques [34]. In the case of [bmim] $[\mathrm{Cl}]$, the yield of regenerated sugarcane bagasse for the recycled IL decreased in comparison with that for the fresh IL [93]. The [emim][DEP] was reused in wheat straw pre-treatment, for which it was noted that after the fifth run a $52.8 \%$ yield of reducing sugars was obtained in comparison with $54.8 \%$ at the first pretreatment. This result indicates that recycling and further reuse of [EMIM][DEP] did not rather affect the pre-treatment [91].

\section{Perspectives}

The lignocellulosic biomass is a cheap and plentiful source of energy, chemicals and materials present in the complex recalcitrant matrix. The current needs for nonfossil sources of energy and a strong development of biorefinery concept obligate to process biomass as an abundant feedstock. The classical methods of biomass pre-treatment are an interesting methodology to valorise biomass; however, drawbacks of these methods limit their wide application. That is why the emerging methodologies such as the application of ILs is a real alternative. The numerous literature reports on this subject prove these needs and demonstrate the enormous potential of ILs. However, the complexity of both the biomass matrix and ILs themselves makes the process very challenging. That is why a large number of issues must to be considered in the designing of this kind of process. Unfortunately, majority of literature reviews do not tackle main problems, instead focusing only on some aspects. The number of potentially available ILs allows assuming that "designer solvent - IL" can be found for each particular problem. However, following the literature reports someone may have an impression that only acetate and chloride-based ionic liquids exist. Of course some types of ILs might be preferential for some particular application; nevertheless, this should not limit the study to rediscover already existing ILs and their use in the biomass processing. It is especially weird as there are already successful examples of IL use in the biomass component processing with ILs characterised by favourable physico-chemical properties such as hydrophilicity/ hydrophobicity, viscosity, melting point and others [98]. Another important aspect related to the use of ILs in the fractionation of biomass is the stability of ILs. ILs are considered to be generally extremely stable [10].
Although it must be understood that the IL thermal stability measurements usually performed using differential scanning calorimeter are mainly done for pure ILs in the continuously increasing temperature mode. So, it is clear that these experiments do not represent the conditions of the process with biomass. Pre-treatment of biomass in ILs is always a time consuming process that takes from minutes to dozen of hours and it takes place in the presence of contaminants present in biomass, namely water, acids and degradation products released from hemicellulose hydrolysis upon pre-treatment. Definitively, under these much harsher conditions, the stability of ILs might be completely different, especially for ILs containing a relatively strong base, such as $\left[\mathrm{CH}_{3} \mathrm{COO}\right]$ $\left(\mathrm{pK}_{\mathrm{a}}=4.77\right)$ [99] that show the slow, but noticeable decomposition after prolonged time $[25,100]$.

Pre-treatment of biomass allow producing cellulose, hemicellulose and lignin and in some cases products of their hydrolysis. These fractions are the subject of further processing, very often with microorganisms (yeasts, bacterias, etc.), to produce ethanol or other high value added chemicals, e.g. xylitol. As it was aforementioned, ILs form an enormous class of compounds with widely tuneable properties including e.g. toxicity. Extensive studies of the toxicity of ILs towards various organisms, including some of those used for biomass fraction processing exist [101]; however, additional systematic work on this topic is strongly demanded.

Another factor that for now is rarely mentioned in the literature; however, has a fundamental importance in the relation to the practical use of ILs is the economic and energetic efficiency of the pre-treatment with ILs. As it was shown in this review, the pre-treatment with ILs is more effective and biomass fractions demonstrate higher purity conversely to the fractions obtained from classical pre-treatments. Therefore, in general, it can be stated that the technological problems are overcome. However, the economic feasibility still might be questionable. One of reasons for this is an investment cost related to the price of ILs. Nowadays, the availability and thus prices are much more affordable; however, ILs are still more expensive than classical solvents. Nevertheless, it is important to underline that IL prices at the industrial scale are similar to organic solvents [102] and together with the proven potential of IL reuse make processes more economically feasible. Furthermore, with respect to the energy consumption in the performance of the whole process, IL use is also advantageous, as was already shown by Yoon et al. [33] This pioneering work requires more efforts and needs to be continued to present the whole picture and to guarantee a fair comparison with the different methods available.

The literature reports show that ILs are efficient tools for biomass processing towards cellulose, hemicellulose 
and lignin fractions. The majority of the work dealing with this subject focuses on the further processing of cellulose that can be easily converted to cellulosic ethanol widely used as biofuel. However, the two other fractions, hemicellulose and lignin are more rarely considered as important. The probable reason for this is the great diversity of both fractions that, on one hand, makes the process more difficult, but on the other opens the room for a variety of commodities that can be obtained. The valorisation of these two diverse fractions constituted by different compounds depending on the raw material is especially important as it allows obtaining products (e.g. xylitol, oligosaccharides, polyphenols, etc.) [103-105] with high commercial value that can make the whole process more economically feasible.

The use of ILs in biomass pre-treatment is an important and interesting alternative; however, the aspects discussed above are rarely tackled in the literature and require a profound and extensive analysis and study. Only after this careful and detailed analysis can the rational assessment of biomass pre-treatment be performed. Unfortunately, the vast majority of papers presenting work about the pre-treatment of biomass with ILs do not challenge these issues, thereby resulting in the incomplete demonstration of the pros and cons of biomass processing with ILs.

\section{Conclusions}

Lignocellulosic biomass is a widely abundant renewable feedstock. The great diversity of lignocellulosic biomass opens a great opportunity for the production of various commodities using the wise valorisation processes. Ionic liquids have proven the inordinate potential in reactions and separation including biomass processing. This review shows that ILs have potential to be used in the biomass pre-treatment. As it was demonstrated, ILs can be successfully used to obtain cellulose, hemicellulose and lignin fractions with purity and efficiency equal or superior to the classical pre-treatment methods. The exploitation of ILs in the lignocellulosic biomass processing demonstrates the enormous potential in this research area, especially in the context of a biorefinery; however, an extensive research is still required to better understand and predict outcomes of these processes.

\section{Additional file}

Additional file 1: Table S1. Pre-treatment of grasses, agricultural and forest residues and other residues in ILs $[28,69,63,49,34,52,53,41,90$, $28,79,51,69,86,106,33,72,63,76,72,53,55,52,53,41,53,69,53,28$, $66,42,66,79,69,78,52,42,28,62,79,67,51,69,33,48,59,50,43,64,92$, $107,63,51,97,96,53,51,60,64,63,91,33,52,42,52,51,52,63,89,69,52]$.

\section{Competing interests}

The authors declare that they have no competing interests.

\section{Authors' contributions}

$A M C L$ and $A R C M$ wrote the principle part of the review. KJG did a literature data collection. EBL was responsible for the compilations of the literature data in the tables. RBL was responsible for the overall work with the particular attention to perspectives and conclusions. All authors read and approved the final manuscript.

\section{Acknowledgments}

This work was supported by the Fundação para a Ciência e a Tecnologia (FCT, Portugal) through grants SFRH/BPD/26356/2006, PEst-C/EQB/LA0006/ 2011 and Programme Ciência 2008, and by the European Commission for the financial support of the PROETHANOL2G Project (FP7-ENERGY-2009-BRAZIL; Grant agreement: 251151). Authors wish to acknowledge LNEG for the financing of the ERA-IB project (Products from lignocelluloses-EIB.10.013).

\section{Author details}

'Laboratório Nacional de Energia e Geologia, Unidade de Bioenergia, 1649-038 Lisbon, Portugal. ${ }^{2}$ Departamento de Química, Faculdade de Ciências e Tecnologia, REQUIMTE, Universidade Nova de Lisboa, 2829-516 Caparica, Portugal.

Received: 31 January 2013 Accepted: 19 April 2013

Published: 22 May 2013

\section{References}

1. Kamm B, Kamm M, Gruber PR, Kromus S: Biorefinery systems - an overview, Biorefineries-industrial processes and products. Wiley-VCH Verlag $\mathrm{GmbH}$; Weinheim, Germany. 2008:1-40

2. Harmsen P, Huijgen W, Bermudez L, Bakker R: Literature review of physical and chemical pretreatment processes for lignocellulosic biomass, Report/ Wageningen UR, Food \& Biobased Research;1 184. Wageningen UR, Food \& Biobased Research: Wageningen; 2010.

3. Lynd LR, Weimer PJ, Van ZyI WH, Pretorius IS: Microbial cellulose utilization: fundamentals and biotechnology. Microbiol Mol Biol Rev 2002, 66:506-577.

4. Carels N: The challenge of Bioenergies- an overview, Biofuel's Engineering process technology. InTech; Rijeka, Croatia. 2011:23-64.

5. Stöcker M: Biofuels and biomass-to-liquid fuels in the biorefinery: catalytic conversion of lignocellulosic biomass using porous materials. Angew Chem Int Ed 2008, 47:9200-9211.

6. Bernardo-Gil MG, Roque R, Roseiro LB, Duarte LC, Gírio F, Esteves P: Supercritical extraction of carob kibbles (Ceratonia siliqua L.). J Supercrit Fluids 2011, 59:36-42.

7. Chakar FS, Ragauskas AJ: Review of current and future softwood kraft lignin process chemistry. Ind Crop Prod 2004, 20:131-141.

8. Kabo GJ, Blokhin AV, Paulechka YU, Kabo AG, Shymanovich MP, Magee JW Thermodynamic properties of 1-butyl-3-methylimidazolium hexafluorophosphate in the condensed state. J Chem Eng Data 2004, 49:453-461.

9. Paulechka YU, Kabo GJ, Blokhin AV, Vydrov OA, Magee JW, Frenkel M: Thermodynamic properties of 1-butyl-3-methylimidazolium hexafluorophosphate in the ideal gas state. J Chem Eng Data 2003, 48:457-462.

10. Domanska U, Bogel-Lukasik R: Physicochemical properties and solubility of alkyl-(2-hydroxyethyl)-dimethylammonium bromide. J Phys Chem B 2005, 109:12124-12132.

11. Coleman D, Gathergood N: Biodegradation studies of ionic liquids. Chem Soc Rev 2010, 39:600-637.

12. Ranke J, Mölter K, Stock F, Bottin-Weber U, Poczobutt J, Hoffmann J, Ondruschka B, Filser J, Jastorff B: Biological effects of imidazolium ionic liquids with varying chain lengths in acute Vibrio fischeri and WST-1 cell viability assays. Ecotoxicol Environ Saf 2004, 58:396-404.

13. Swatloski RP, Holbrey JD, Memon SB, Caldwell GA, Caldwell KA, Rogers RD: Using Caenorhabditis elegans to probe toxicity of 1-alkyl-3methylimidazolium chloride based ionic liquids. Chem Commun 2004:668-669.

14. Huddleston JG, Visser AE, Reichert WM, Willauer HD, Broker GA, Rogers RD: Characterization and comparison of hydrophilic and hydrophobic room temperature ionic liquids incorporating the imidazolium cation. Green Chem 2001, 3:156-164.

15. Chiappe C, Pieraccini D: lonic liquids: solvent properties and organic reactivity. J Phys Org Chem 2005, 18:275-297. 
16. Vasiltsova TV, Verevkin SP, Bich E, Heintz A, Bogel-Lukasik R, Domanska U: Thermodynamic properties of mixtures containing ionic liquids. Activity coefficients of ethers and alcohols in 1-methyl-3-ethyl-imidazolium bis (trifluoromethyl-sulfonyl) imide using the transpiration method. J Chem Eng Data 2005, 50:142-148.

17. Fukaya Y, Sugimoto A, Ohno H: Superior solubility of polysaccharides in low viscosity, polar, and halogen-free 1,3-dialkylimidazolium formates. Biomacromolecules 2006, 7:3295-3297.

18. Kimizuka N, Nakashima T: Spontaneous self-assembly of glycolipid bilayer membranes in sugar-philic ionic liquids and formation of ionogels. Langmuir 2001, 17:6759-6761.

19. Swatloski RP, Spear SK, Holbrey JD, Rogers RD: Dissolution of cellulose with ionic liquids. J Am Chem Soc 2002, 124:4974-4975.

20. Wu Y, Sasaki T, Irie S, Sakurai K: A novel biomass-ionic liquid platform for the utilization of native chitin. Polymer 2008, 49:2321-2327.

21. Xie H, Zhang S, Li S: Chitin and chitosan dissolved in ionic liquids as reversible sorbents of $\mathrm{CO}_{2}$. Green Chem 2006, 8:630-633.

22. Zakrzewska ME, Bogel-Łukasik E, Bogel-Łukasik R: Solubility of carbohydrates in ionic liquids. Energy Fuel 2010, 24:737-745.

23. Fort DA, Remsing RC, Swatloski RP, Moyna P, Moyna G, Rogers RD: Can ionic liquids dissolve wood? Processing and analysis of lignocellulosic materials with 1-n-butyl-3-methylimidazolium chloride. Green Chem 2007, 9:63-69.

24. Kilpeläinen I, Xie H, King A, Granstrom M, Heikkinen S, Argyropoulos DS: Dissolution of wood in ionic liquids. J Agric Food Chem 2007, 55:9142-9148.

25. Sun N, Rahman M, Qin Y, Maxim ML, Rodríguez H, Rogers RD: Complete dissolution and partial delignification of wood in the ionic liquid 1-ethyl3-methylimidazolium acetate. Green Chemistry 2009, 11:646-655.

26. Zavrel M, Bross D, Funke M, Büchs J, Spiess AC: High-throughput screening for ionic liquids dissolving (ligno-) cellulose. Bioresour Technol 2009, 100:2580-2587.

27. Van Spronsen J, Cardoso MAT, Witkamp GJ, De Jong W, Kroon MC: Separation and recovery of the constituents from lignocellulosic biomass by using ionic liquids and acetic acid as co-solvents for mild hydrolysis. Chem Eng Proc Proc Intens 2010, 50:196-199.

28. Lee SH, Doherty TV, Linhardt RJ, Dordick JS: Ionic liquid-mediated selective extraction of lignin from wood leading to enhanced enzymatic cellulose hydrolysis. Biotechnol Bioeng 2009, 102:1368-1376.

29. Viell J, Marquardt W: Disintegration and dissolution kinetics of wood chips in ionic liquids. Holzforschung 2011, 65:519-525.

30. Torr KM, Love KT, Cetinkol ÖP, Donaldson LA, George A, Holmes BM, Simmons BA: The impact of ionic liquid pretreatment on the chemistry and enzymatic digestibility of Pinus radiata compression wood. Green Chemistry 2012, 14:778-787.

31. Singh S, Simmons BA, Vogel KP: Visualization of biomass solubilization and cellulose regeneration during ionic liquid pretreatment of switchgrass. Biotechnol Bioeng 2009, 104:68-75.

32. Vo HT, Kim CS, Ahn BS, Kim HS, Lee H: Study on dissolution and regeneration of poplar wood in imidazolium-based ionic liquids. $J$ Wood Chem Technol 2011, 31:89-102.

33. Yoon LW, Ngoh GC, Chua M, Seak A, Hashim M: Comparison of ionic liquid, acid and alkali pretreatments for sugarcane bagasse enzymatic saccharification. J Chem Technol Biotechnol 2011, 86:1342-1348.

34. Wang X, Li H, Cao Y, Tang Q: Cellulose extraction from wood chip in an ionic liquid 1-allyl-3-methylimidazolium chloride (AmimCl). Bioresour Technol 2011, 102:7959-7965.

35. Leskinen T, King AWT, Kilpelainen I, Argyropoulos DS: Fractionation of lignocellulosic materials with ionic liquids. 1. Effect of mechanical treatment. Ind Eng Chem Res 2011, 50:12349-12357.

36. King AWT, Zoia L, Filpponen I, Olszewska A, Xie H, Kilpelainen I, Argyropoulos DS: In situ determination of lignin phenolics and wood solubility in imidazolium chlorides using 31P NMR. J Agric Food Chem 2009, 57:8236-8243.

37. Kamlet MJ, Taft RW: Solvatochromic comparison method I. Beta-scale of solvent hydrogen-bond acceptor (Hba) basicities. J Am Chem Soc 1976, 98:377-383.

38. Taft RW, Kamlet MJ: Solvatochromic comparison method II. Alpha-scale of solvent hydrogen-bond donor (Hbd) acidities. J Am Chem Soc 1976, 98:2886-2894

39. Yokoyama T, Taft RW, Kamlet MJ: Solvatochromic comparison method III. Hydrogen-bonding by some 2-nitroaniline derivatives. J Am Chem Soc 1976, 98:3233-3237.
40. Brandt A, Hallett JP, Leak DJ, Murphy RJ, Welton T: The effect of the ionic liquid anion in the pretreatment of pine wood chips. Green Chem 2010, 12:672-679.

41. Wu H, Mora-Pale M, Miao J, Doherty TV, Linhardt RJ, Dordick JS: Facile pretreatment of lignocellulosic biomass at high loadings in room temperature ionic liquids. Biotechnol Bioeng 2011, 108:2865-2875.

42. Muhammad N, Man Z, Bustam MA, Mutalib MIA, Wilfred CD, Rafiq S: Dissolution and delignification of bamboo biomass using amino acid-based ionic liquid. Appl Biochem Biotechnol 2011, 165:1-12.

43. Yoon LW, Ang TN, Ngoh GC, Chua ASM: Regression analysis on ionic liquid pretreatment of sugarcane bagasse and assessment of structural changes. Biomass Bioenergy 2012, 36:160-169.

44. Moniruzzaman M, Ono T: lonic liquid assisted enzymatic delignification of wood biomass: a new 'green'and efficient approach for isolating of cellulose fibers. Biochem Eng J 2011, 60:156-160.

45. Mora-Pale M, Meli L, Doherty TV, Linhardt RJ, Dordick JS: Room temperature ionic liquids as emerging solvents for the pretreatment of lignocellulosic biomass. Biotechnol Bioeng 2011, 108:1229-1245.

46. Maki-Arvela P, Anugwom I, Virtanen P, Sjoholm R, Mikkola J: Dissolution of lignocellulosic materials and its constituents using ionic liquids-a review. Ind Crop Prod 2010, 32:175-201.

47. Remsing RC, Swatloski RP, Rogers RD, Moyna G: Mechanism of cellulose dissolution in the ionic liquid 1-n-butyl-3-methylimidazolium chloride: a ${ }^{13} \mathrm{C}$ and ${ }^{35 / 37} \mathrm{Cl}$ NMR relaxation study on model systems. Chem Commun 2006:1271-1273

48. Shill K, Padmanabhan S, Xin Q, Prausnitz JM, Clark DS, Blanch HW: Ionic liquid pretreatment of cellulosic biomass: enzymatic hydrolysis and ionic liquid recycle. Biotechnol Bioeng 2011, 108:511-520.

49. Jiang $M$, Zhao M, Zhou Z, Huang T, Chen X, Wang Y: Isolation of cellulose with ionic liquid from steam exploded rice straw. Ind Crop Prod 2011, 33:734-738.

50. Ninomiya K, Kamide K, Takahashi K, Shimizu N: Enhanced enzymatic saccharification of kenaf powder after ultrasonic pretreatment in ionic liquids at room temperature. Bioresour Technol 2012, 103:259-265.

51. Nguyen TAD, Kim KR, Han SJ, Cho HY, Kim JW, Park SM, Park JC, Sim SJ: Pretreatment of rice straw with ammonia and ionic liquid for lignocellulose conversion to fermentable sugars. Bioresour Technol 2010, 101:7432-7438.

52. Abe M, Fukaya $\mathrm{Y}$, Ohno H: Extraction of polysaccharides from bran with phosphonate or phosphinate-derived ionic liquids under short mixing time and low temperature. Green Chemistry 2010, 12:1274-1280.

53. Brandt A, Ray MJ, To TQ, Leak DJ, Murphy RJ, Welton T: Ionic liquid pretreatment of lignocellulosic biomass with ionic liquid-water mixtures. Green Chemistry 2011, 13:2489-2499.

54. Cammarata L, Kazarian S, Salter P, Welton T: Molecular states of water in room temperature ionic liquids. Phys Chem Chem Phys 2001, 3:5192-5200.

55. Wei L, Li K, Ma Y, Hou X: Dissolving lignocellulosic biomass in a 1-butyl-3methylimidazolium chloride-water mixture. Ind Crop Prod 2012, 37:227-234

56. Li B, Asikkala J, Filpponen I, Argyropoulos DS: Factors affecting wood dissolution and regeneration of ionic liquids. Ind Eng Chem Res 2010 49:2477-2484

57. Shafiei M, Zilouei H, Zamani A, Taherzadeh MJ, Karimi K: Enhancement of ethanol production from spruce wood chips by ionic liquid pretreatment. Applied Energy 2012, 102:163-169.

58. Doherty TV, Mora-Pale M, Foley SE, Linhardt RJ, Dordick JS: Ionic liquid solvent properties as predictors of lignocellulose pretreatment efficacy. Green Chemistry 2010, 12:1967-1975.

59. Samayam IP, Hanson BL, Langan P, Schall CA: lonic-liquid induced changes in cellulose structure associated with enhanced biomass hydrolysis. Biomacromolecules 2011, 12:3091-3098.

60. Pezoa R, Cortinez V, Hyvärinen S, Reunanen M, Hemming J, Lienqueo M, Salazar O, Carmona R, Garcia A, Murzin D: Use of ionic liquids in the pretreatment of forest and agricultural residues for the production of bioethanol. Cellul Chem Technol 2010, 44:165-172.

61. Shamsuri AA, Abdullah DK: Isolation and characterization of lignin from rubber wood in ionic liquid medium. Modern Applied Sci 2010, 4:19-27.

62. Li C, Knierim B, Manisseri C, Arora R, Scheller HV, Auer M, Vogel KP, Simmons BA, Singh S: Comparison of dilute acid and ionic liquid pretreatment of switchgrass: biomass recalcitrance, delignification and enzymatic saccharification. Bioresour Technol 2010, 101:4900-4906.

63. Haykir NI, Bahcegul E, Bicak N, Bakir U: Pretreatment of cotton stalk with ionic liquids including 2-hydroxy ethyl ammonium formate to enhance biomass digestibility. Ind Crop Prod 2013, 41:430-436. 
64. Bahcegul E, Apaydin S, Haykir NI, Tatli E, Bakir U: Different ionic liquids favor different lignocellulosic biomass particle sizes during pretreatment to function efficiently. Green Chemistry 2012, 14:1896-1903.

65. Shoda Y, Nakamoto A, Goto M, Tokuhara W, Noritake Y, Katahira S, Ishida N, Nakashima K, Ogino C, Kamiya N: Short time ionic liquids pretreatment on lignocellulosic biomass to enhance enzymatic saccharification. Bioresour Technol 2011, 103:446-452.

66. Hou XD, Smith TJ, Li N, Zong MH: Novel renewable ionic liquids as highly effective solvents for pretreatment of rice straw biomass by selective removal of lignin. Biotechnol Bioeng 2012, 109:2484-2493.

67. Arora R, Manisseri C, Li C, Ong MD, Scheller HV, Vogel K, Simmons BA, Singh S: Monitoring and analyzing process streams towards understanding ionic liquid pretreatment of switchgrass (Panicum virgatum L.). BioEnergy Research 2010, 3:134-145.

68. Dibble DC, Li C, Sun L, George A, Cheng A, Çetinkol ÖP, Benke P, Holmes BM, Singh S, Simmons BA: A facile method for the recovery of ionic liquid and lignin from biomass pretreatment. Green Chemistry 2011, 13:3255-3264.

69. Sant'Ana Da Silva A, Lee SH, Endo T, Bon E: Major improvement in the rate and yield of enzymatic saccharification of sugarcane bagasse via pretreatment with the ionic liquid 1-ethyl-3-methylimidazolium acetate ([Emim][Ac]). Bioresour Technol 2011, 102:10505-10509.

70. Crosthwaite JM, Aki SNVK, Maginn EJ, Brennecke JF: Liquid phase behavior of imidazolium-based ionic liquids with alcohols: effect of hydrogen bonding and non-polar interactions. Fluid Phase Equilibria 2005, 228:303-309.

71. Tan HT, Lee KT: Understanding the impact of ionic liquid pretreatment on biomass and enzymatic hydrolysis. Chem Eng J 2012, 183:448-458.

72. Geng X, Henderson WA: Pretreatment of corn stover by combining ionic liquid dissolution with alkali extraction. Biotechnol Bioeng 2011, 109:84-91.

73. Wyman CE, Dale BE, Elander RT, Holtzapple M, Ladisch MR, Lee Y: Coordinated development of leading biomass pretreatment technologies. Bioresour Technol 2005, 96:1959-1966.

74. Mosier N, Wyman C, Dale B, Elander R, Lee Y, Holtzapple M, Ladisch M: Features of promising technologies for pretreatment of lignocellulosic biomass. Bioresour Technol 2005, 96:673-686.

75. Xie H, Shi T: Liquefaction of wood (Metasequoia glyptostroboides) in allyl alkyl imidazolium ionic liquids. Wood Sci Technol 2010, 44:119-128.

76. Kimon KS, Leslie Alan E, William Orlando Sinclair D: Enhanced saccharification kinetics of sugarcane bagasse pretreated in 1-butyl-3methylimidazolium chloride at high temperature and without complete dissolution. Bioresour Technol 2011, 102:9325-9329.

77. Labbé N, Kline LM, Moens L, Kim K, Kim PC, Hayes DG: Activation of lignocellulosic biomass by ionic liquid for biorefinery fractionation. Bioresour Technol 2012, 104:701-707.

78. Tan SSY, MacFarlane DR, Upfal J, Edye LA, Doherty WOS, Patti AF, Pringle JM, Scott JL: Extraction of lignin from lignocellulose at atmospheric pressure using alkylbenzenesulfonate ionic liquid. Green Chem 2009, 11:339-345.

79. Fu D, Mazza G, Tamaki Y: Lignin extraction from straw by ionic liquids and enzymatic hydrolysis of the cellulosic residues. J Agric Food Chem 2010, 58:2915-2922

80. Shigematsu M, Morita M, Sakata I, Tanahashi M: Enhancement of miscibility between hemicellulose and lignin by addition of their copolymer, the lignin-carbohydrate complex. Macromol Chem Phys 1994, 195:2827-2837.

81. Baptista C, Robert D, Duarte AP: Effect of pulping conditions on lignin structure from maritime pine kraft pulps. Chem Eng J 2006, 121:153-158.

82. El Hage R, Chrusciel L, Desharnais L, Brosse N: Effect of autohydrolysis of Miscanthus giganteus on lignin structure and organosolv delignification. Bioresour Technol 2010, 101:9321-9329.

83. Hoareau W, Trindade WG, Siegmund B, Castellan A, Frollini E: Sugar cane bagasse and curaua lignins oxidized by chlorine dioxide and reacted with furfuryl alcohol: characterization and stability. Polym Degrad Stab 2004, 86:567-576.

84. Miyafuji H, Miyata K, Saka S, Ueda F, Mori M: Reaction behavior of wood in an ionic liquid, 1-ethyl-3-methylimidazolium chloride. J Wood Sci 2009, 55:215-219.

85. Zhao H, Jones CL, Baker GA, Xia S, Olubajo O, Person VN: Regenerating cellulose from ionic liquids for an accelerated enzymatic hydrolysis. J Biotechnol 2009, 139:47-54.
86. Tan HT, Lee KT, Mohamed AR: Pretreatment of lignocellulosic palm biomass using a solvent-ionic liquid [BMIM] $\mathrm{Cl}$ for glucose recovery: an optimisation study using response surface methodology. Carbohydr Polym 2011, 83:1862-1868.

87. Brennan TCR, Datta S, Blanch HW, Simmons BA, Holmes BM: Recovery of sugars from ionic liquid biomass liquor by solvent extraction. BioEnergy Res 2010, 3:123-133.

88. Ungurean M, Fitigau F, Paul C, Ursoiu A, Peter F: Ionic liquid pretreatment and enzymatic hydrolysis of wood biomass. WASET 2011, 76:387-391.

89. Zhao H, Baker GA, Cowins JV: Fast enzymatic saccharification of switchgrass after pretreatment with ionic liquids. Biotechnol Prog 2009, 26:127-133.

90. Poornejad N, Karimi K, Behzad T: Improvement of saccharification and ethanol production from rice straw by NMMO and [BMIM][OAC] pretreatments. Ind Crop Prod 2013, 41:408-413.

91. Li Q, He YC, Xian M, Jun G, Xu X, Yang JM, Li LZ: Improving enzymatic hydrolysis of wheat straw using ionic liquid 1-ethyl-3-methyl imidazolium diethyl phosphate pretreatment. Bioresour Technol 2009, 100:3570-3575.

92. Qiu Z, Aita GM, Walker MS: Effect of ionic liquid pretreatment on the chemical composition, structure and enzymatic hydrolysis of energy cane bagasse. Bioresour Technol 2012, 117:251-256.

93. Lan W, Liu CF, Sun RC: Fractionation of bagasse into cellulose, hemicelluloses, and lignin with ionic liquid treatment followed by alkaline extraction. J Agric Food Chem 2011, 59:8691-8701.

94. Yang D, Zhong L-X, Yuan T-Q, Peng X-W, Sun R-C: Studies on the structural characterization of lignin, hemicelluloses and cellulose fractionated by ionic liquid followed by alkaline extraction from bamboo. Ind Crop Prod 2013, 43:141-149.

95. Lynam JG, Toufiq Reza M, Vasquez VR, Coronella CJ: Pretreatment of rice hulls by ionic liquid dissolution. Bioresour Technol 2012, 114:629-636.

96. Fu D, Mazza G: Aqueous ionic liquid pretreatment of straw. Bioresour Technol 2011, 102:7008-7011.

97. Fu D, Mazza G: Optimization of processing conditions for the pretreatment of wheat straw using aqueous ionic liquid. Bioresour Technol 2011, 102:8003-8010.

98. Conceicao LJA, Bogel-Lukasik E, Bogel-Lukasik R: A new outlook on solubility of carbohydrates and sugar alcohols in ionic liquids. RsC Advances 2012, 2:1846-1855.

99. Paquette LA: Encyclopedia of reagents for organic synthesis. In Encyclopedia of reagents for organic synthesis. Edited by Paquette LA. New York: John Wiley \& Sons; 1995:11. 11.

100. Wendler F, Todi LN, Meister F: Thermostability of imidazolium ionic liquids as direct solvents for cellulose. Thermochim Acta 2012, 528:76-84.

101. The UFT/Merck ionic liquids biological effects database. http://www.il-eco.uft uni-bremen.de/.

102. Wasserscheid P: New ionic liquid structures for green chemistry applications. Tallinn, Estonia: Chemistry TICoMaTfG ed; 2011

103. Girio FM, Fonseca C, Carvalheiro F, Duarte LC, Marques S, Bogel-Lukasik R: Hemicelluloses for fuel ethanol: a review. Bioresour Technol 2010, 101:4775-4800

104. Zakrzewska ME, Bogel-Lukasik E, Bogel-Lukasik R: lonic liquid-mediated formation of 5-hydroxymethylfurfural-a promising biomass-derived building block. Chem Rev 2011, 111:397-417.

105. Bozell JJ, Petersen GR: Technology development for the production of biobased products from biorefinery carbohydrates-the US department of energy's "Top 10" revisited. Green Chemistry 2010, 12:539-554.

106. Zhang J, Ma X, Yu J, Zhang X, Tan T: The effects of four different pretreatments on enzymatic hydrolysis of sweet sorghum bagasse. Bioresour Technol 2011, 102:4585-4589.

107. Perez-Pimienta JA, Lopez-Ortega MG, Varanasi P, Stavila V, Cheng G, Singh S, Simmons BA: Comparison of the impact of ionic liquid pretreatment on recalcitrance of agave bagasse and switchgrass. Bioresour Technol 2013, 127:18-24.

doi:10.1186/2043-7129-1-3

Cite this article as: da Costa Lopes et al: Ionic liquids as a tool for lignocellulosic biomass fractionation. Sustainable Chemical Processes 2013 $1: 3$. 